
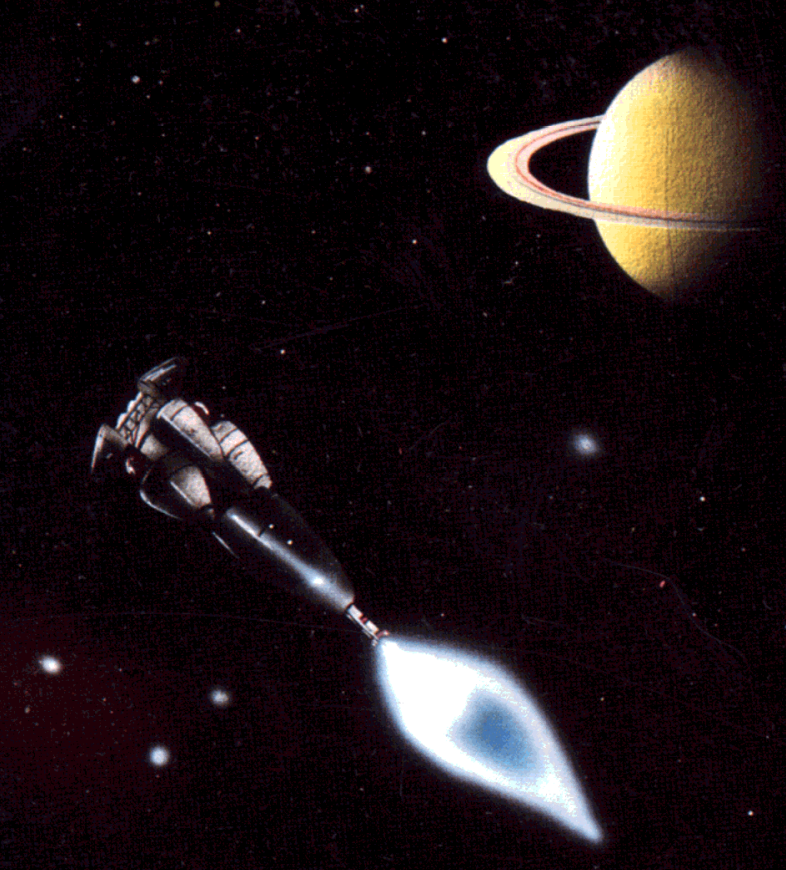

$$
\begin{gathered}
\text { SPACE NUCLEAR POWER, } \\
\text { PROPULSION, } \\
\text { AND RELATED } \\
\text { TECHNOLOGIES }
\end{gathered}
$$


Issued by Sandia National Laboratories, operated for the United States Department of Energy by Sandia Corporation.

NOTICE: This report was prepared as an account of work sponsored by an agency of the United States Government. Neither the United States Government nor any agency thereof, nor any of their employees, nor any of their contractors, subcontractors, or their employees, makes any warranty, expressed or implied, or assumes any legal liability or responsibility for the accuracy, completeness, or usefulness of any information, apparatus, product, or process disclosed, or represents that its use would not infringe privately owned rights. Reference herein to any specific commercial product, process, or service by trade name, trademark, manufacturer, or otherwise, does not necessarily constitute or imply its endorsement, recommendation, or favoring by the United States Government, any agency thereof, or any of their contractors or subcontractors. The views and opinions expressed herein do not necessarily state or reflect those of the United States Government, any agency thereof, or any of their contractors.

Printed in the United States of America.

Available from

National Technical Information Service

US Department of Commerce

5285 Port Royal Rd

Springfield, VA 22161

NTIS price codes

Printed copy: A04

Microfiche copy: A01

January 1992 
Sandia National Laboratories

\title{
SPACE NUCLEAR POWER, PROPULSION, AND RELATED TECHNOLOGIES
}

Scientific/Technical Editor: Marshall Berman Sandia National Laboratories

\author{
Publications Editor: John A. Stikar \\ Tech Reps., Inc. \\ Graphic Design: Renee Sparkia \\ Tech Reps., Inc. \\ Space Paintings: Shannon Whitehead \\ Tech Reps., Inc.
}




\section{Contents}

Introduction

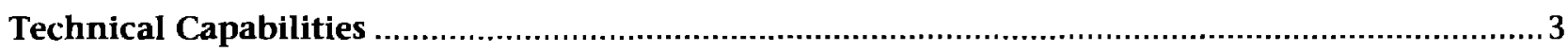

Nuclear Reactor Research, Development, and Testing .......................................................

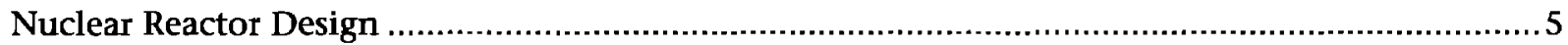

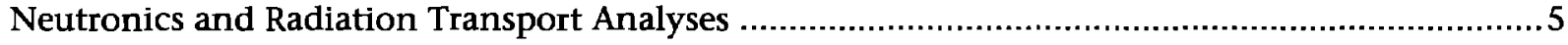

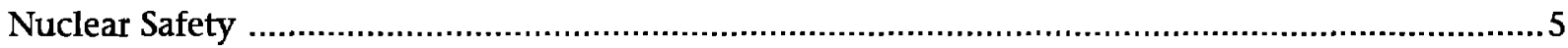

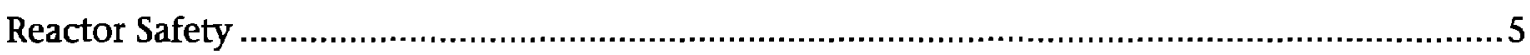

Phenomenological Analysis and Experimentation ............................................... 5

International Fuels Testing Program ................................................................... 6

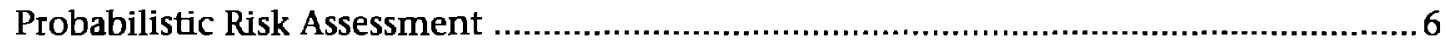

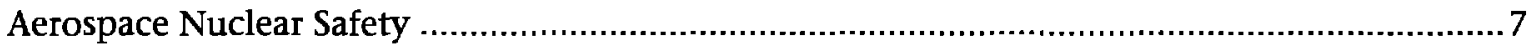

Safety and Security of Nuclear Weapons …......................................................................

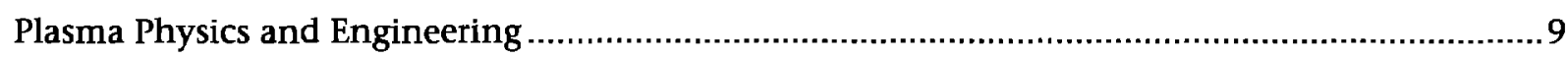

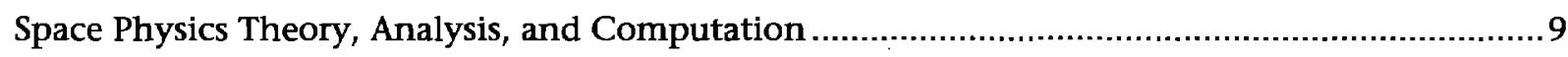

Fluid Mechanics and Heat Transfer ........................................................................................ 10

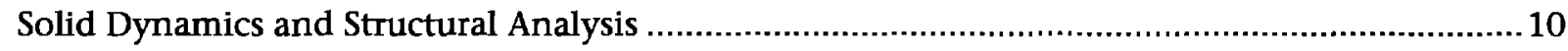

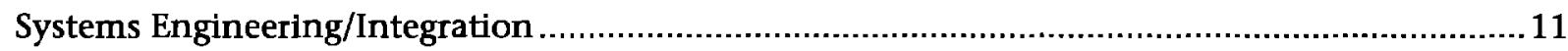

Verification Technology and Satellite Programs .............................................................. 11

Rocket Systems and Launch Capabilities ..................................................................... 11

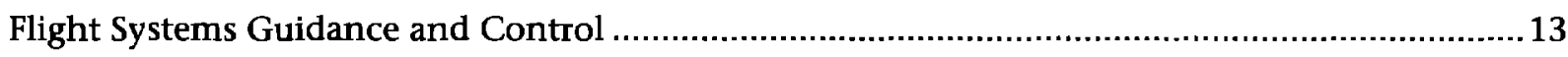

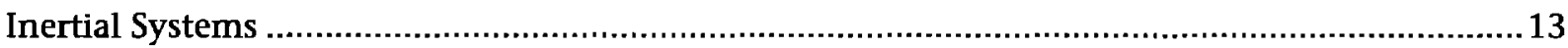

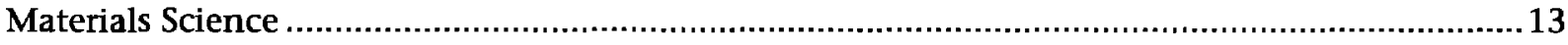

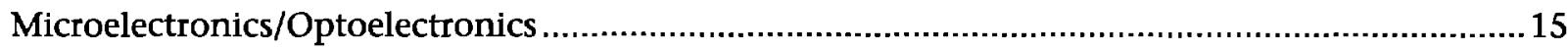

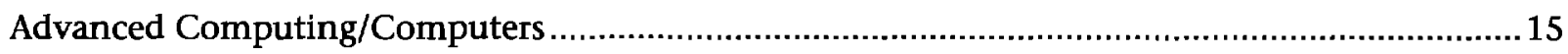

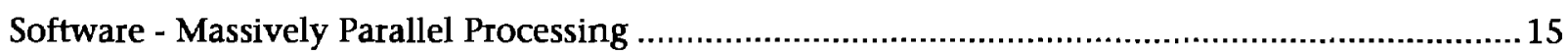

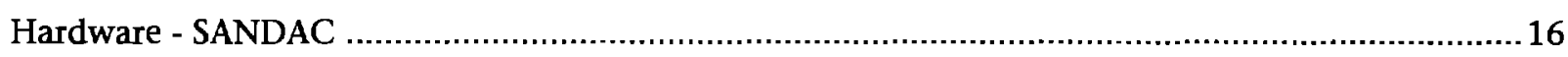

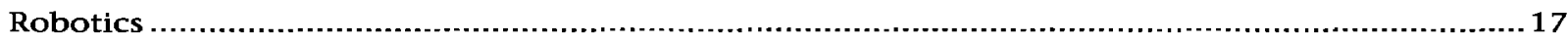

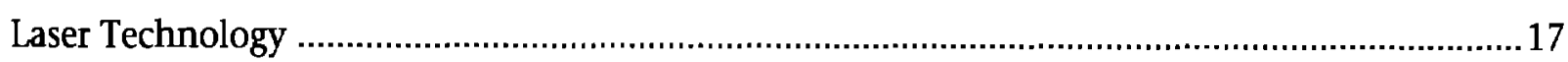

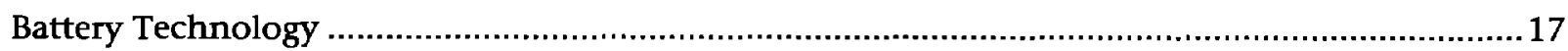

Statistical Analysis and Human Factors Engineering ............................................................ 19

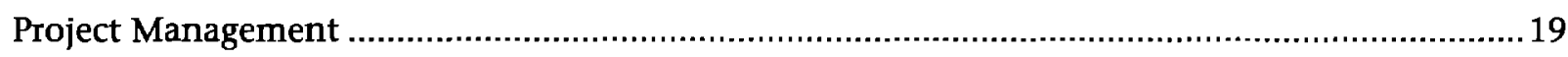

Developmental and Environmental Test Facilities .........................................................21

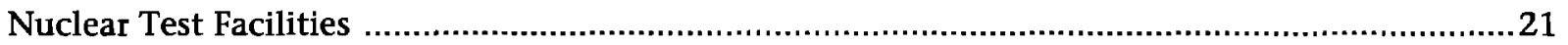




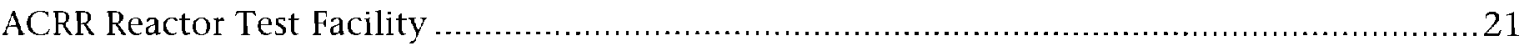

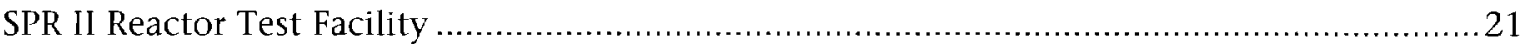

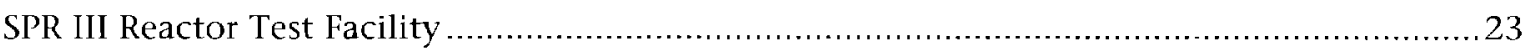

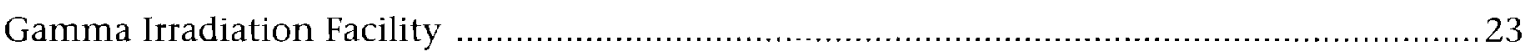

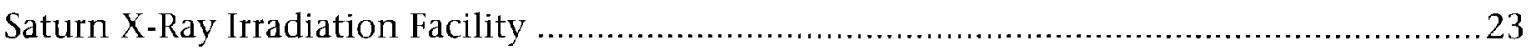

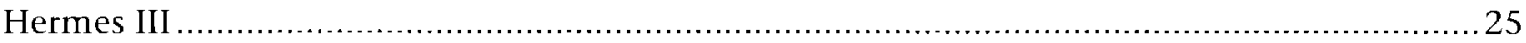

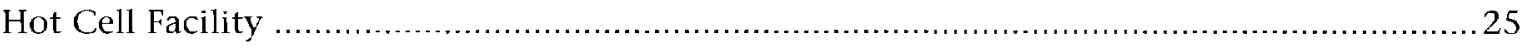

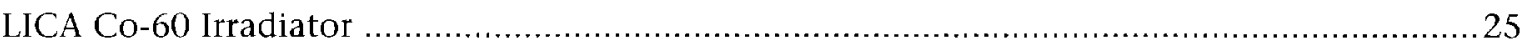

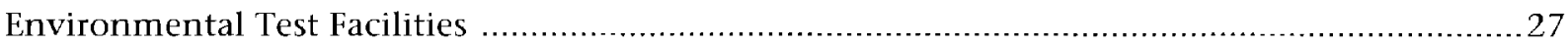

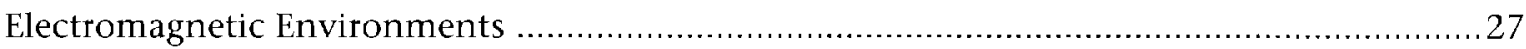

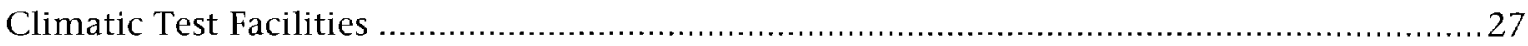

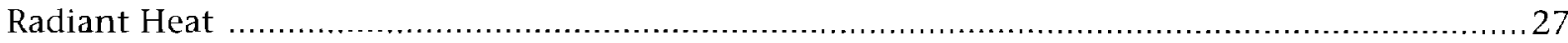

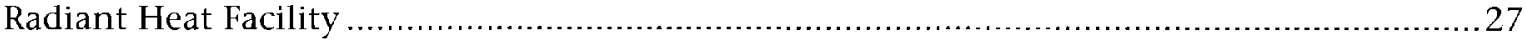

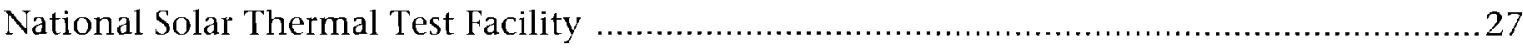

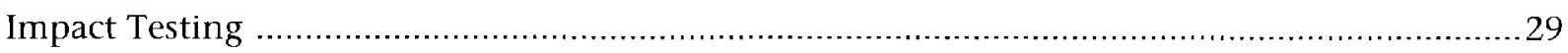

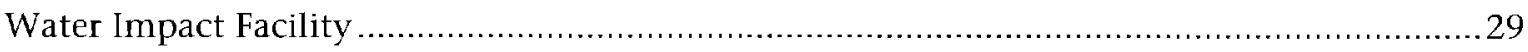

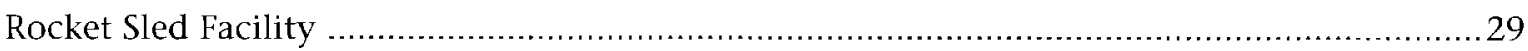

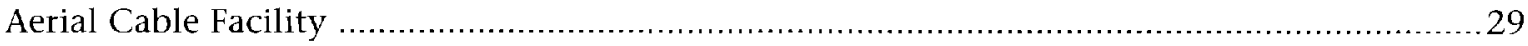

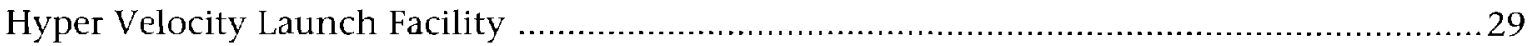

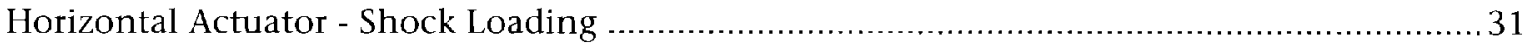

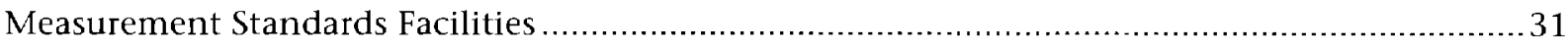

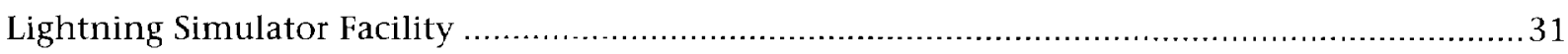

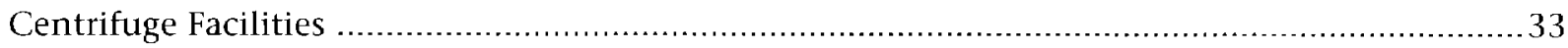

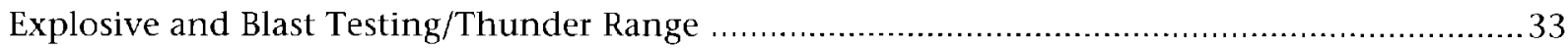

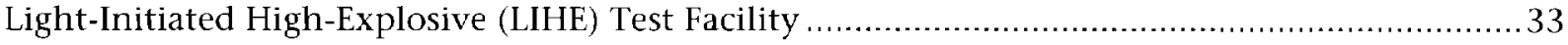

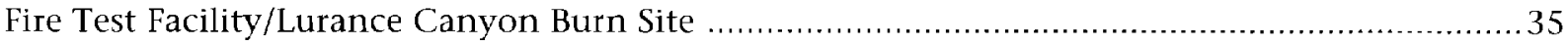

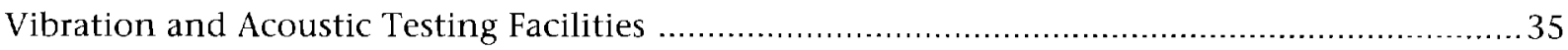

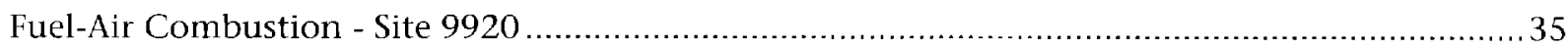

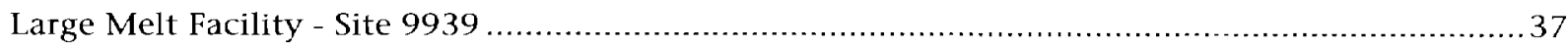

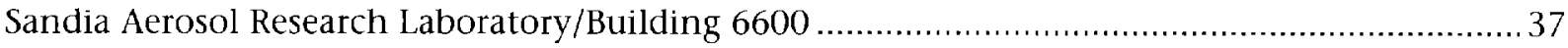

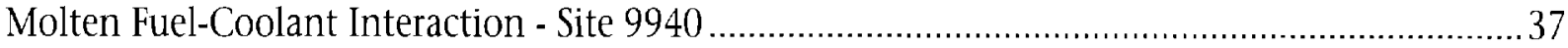

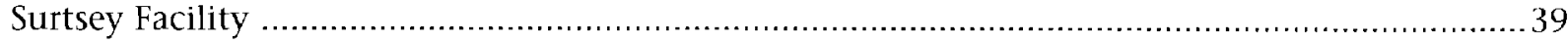

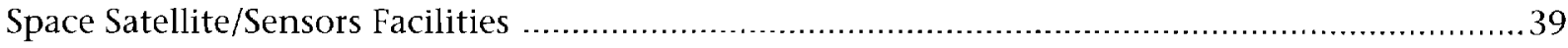

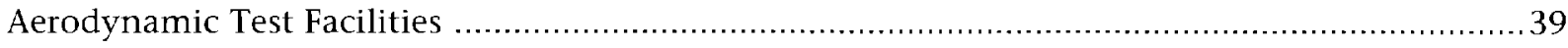

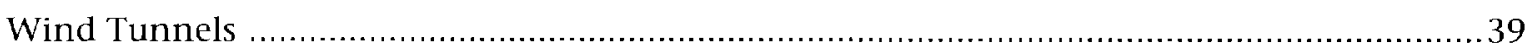

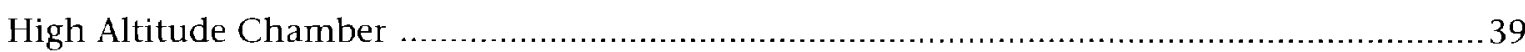




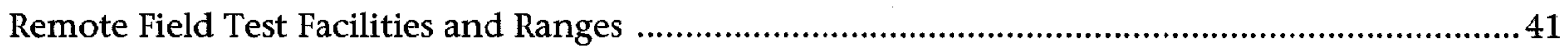

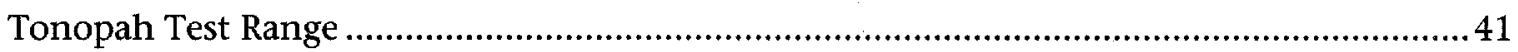

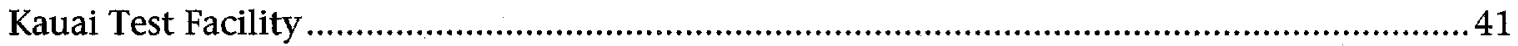

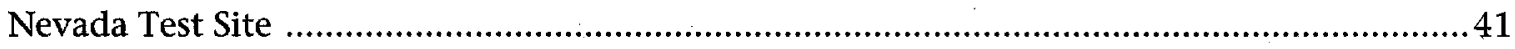

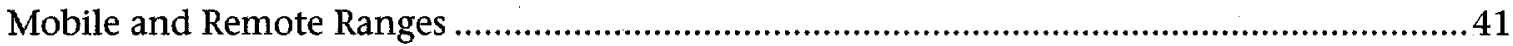

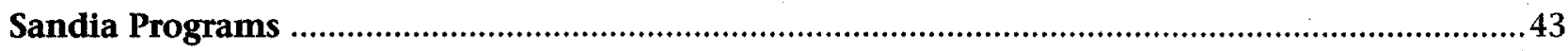

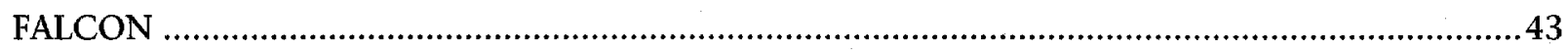

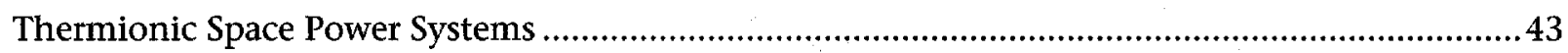

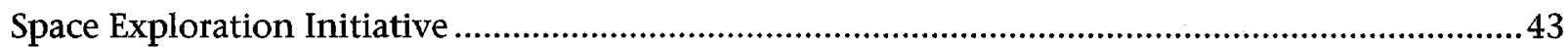

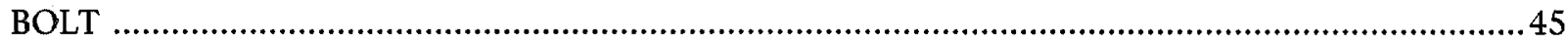

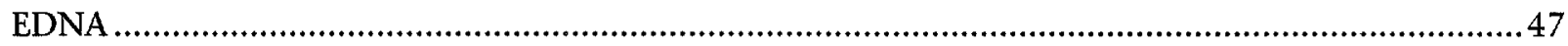

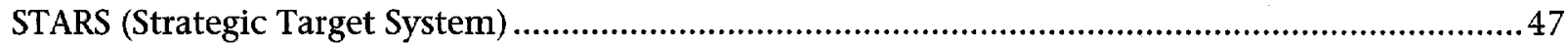

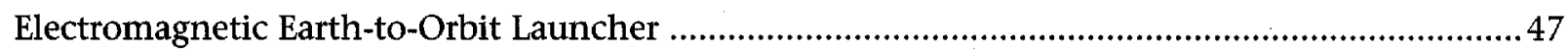

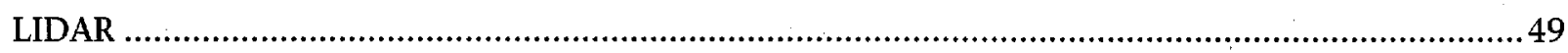

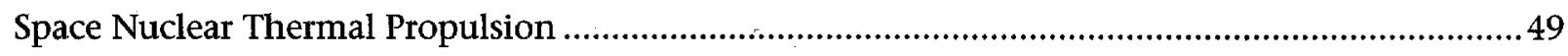

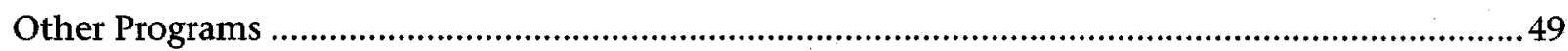

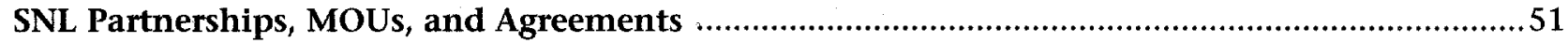

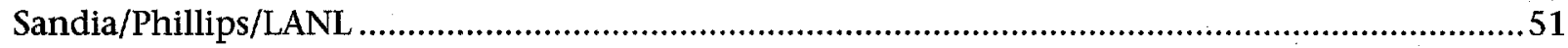

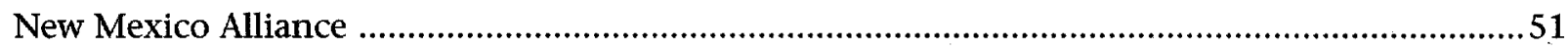

Specialty Metals Processing Consortium, Inc. ......................................................................5

UNM/Sandia Materials Research and Development Laboratory ..............................................53

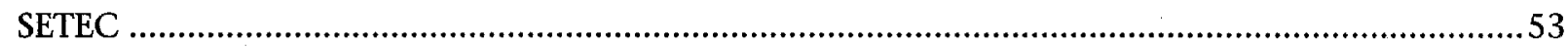

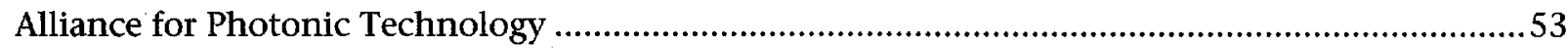

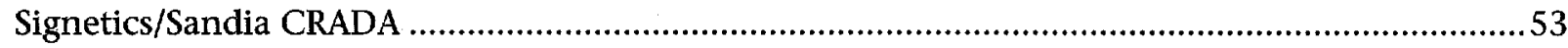

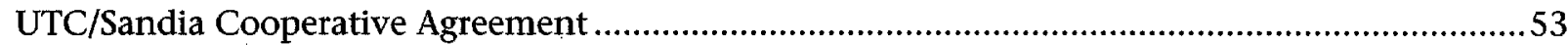

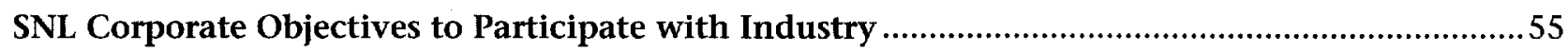

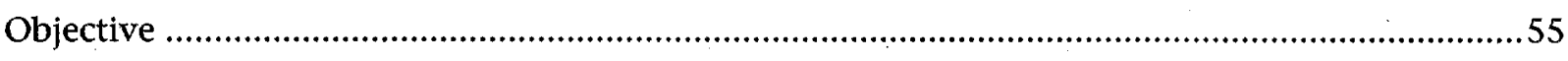

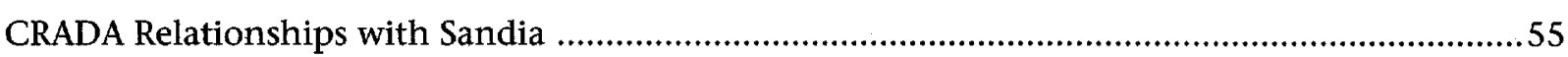

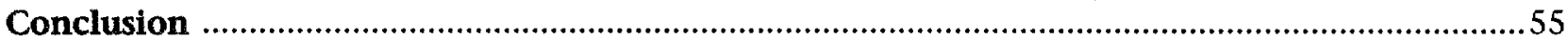




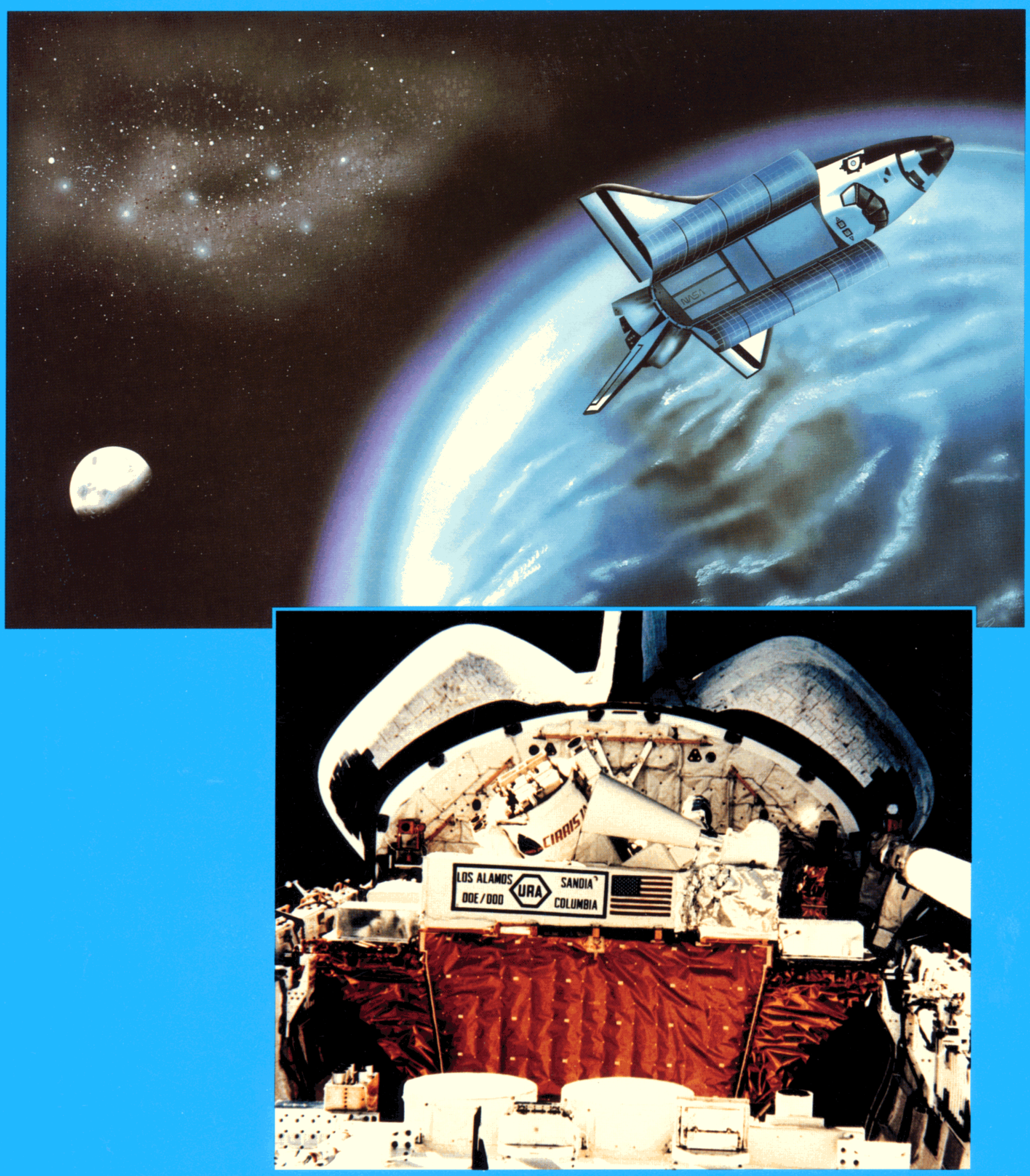

The Universally Redundant Array (URA) in the payload bay of the space shuttle Discovery during a military mission in May of 1991. 


\section{Introduction}

Sandia National Laboratories (Sandia) is one of the nation's largest research and development (R\&D) facilities, with headquarters at Albuquerque, New Mexico; a laboratory at Livermore, California; and a test range near Tonopah, Nevada. Smaller testing facilities are also operated at other locations.

Established in 1945, Sandia was operated by the University of California until 1949, when, at the request of President Truman, Sandia Corporation was formed as a subsidiary of Bell Lab's Western Electric Company to operate Sandia as a service to the U.S. Government without profit or fee. Sandia is currently operated for the U.S. Department of Energy (DOE) by AT\&T Technologies, Inc., a whollyowned subsidiary of AT\&T.

Sandia's responsibility is national security programs in defense and energy with primary emphasis on nuclear weapon research and development (R\&D). However, Sandia also supports a wide variety of projects ranging from basic materials research to the design of specialized parachutes. Assets, owned by
DOE and valued at more than $\$ 1.2$ billion, include about 600 major buildings containing about 372,000 square meters $\left(\mathrm{m}^{2}\right)$ ( 4 million square feet $\left[\mathrm{ft}^{2}\right]$ ) of floor space, located on land totalling approximately 1460 square kilometers $\left(\mathrm{km}^{2}\right)$ (562 square miles $\left[\mathrm{mi}^{2}\right]$ ).

Sandia employs about 8500 people, the majority in Albuquerque, with about 1000 in Livermore. Approximately $60 \%$ of Sandia's employees are in technical and scientific positions, and the remainder are in crafts, skilled labor, and administrative positions.

As a multiprogram national laboratory, Sandia has much to offer both industrial and government customers in pursuing space nuclear technologies. The purpose of this brochure is to provide the reader with a brief summary of Sandia's technical capabilities, test facilities, and example programs that relate to military and civilian objectives in space. Sandia is interested in forming partnerships with industry and government organizations, and has already formed several cooperative alliances and agreements.

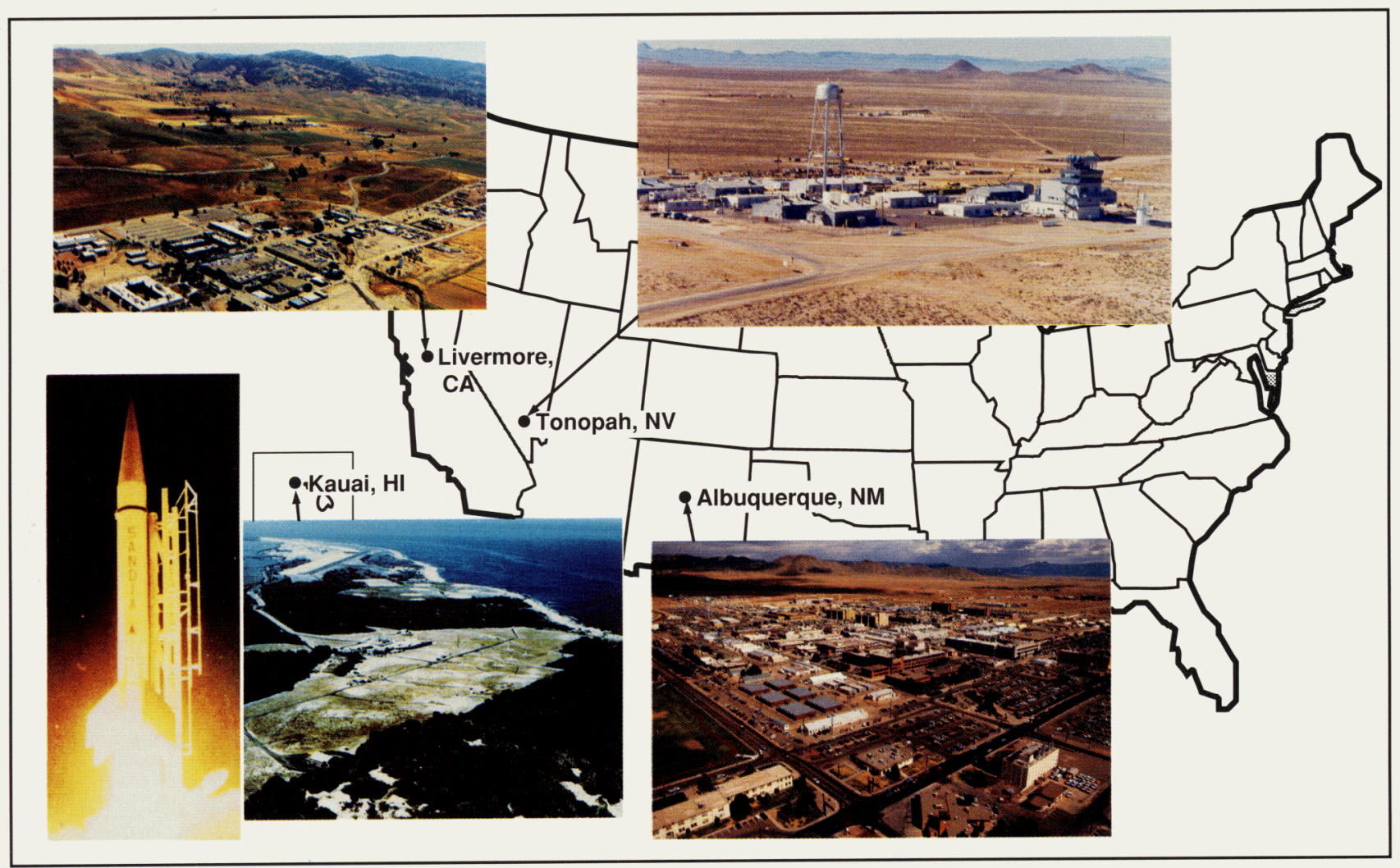

Sandia National Laboratories is headquartered in Albuquerque, NM; but has additional facilities at Livermore, CA; Tonopah, NV; and Kauai, HI. 


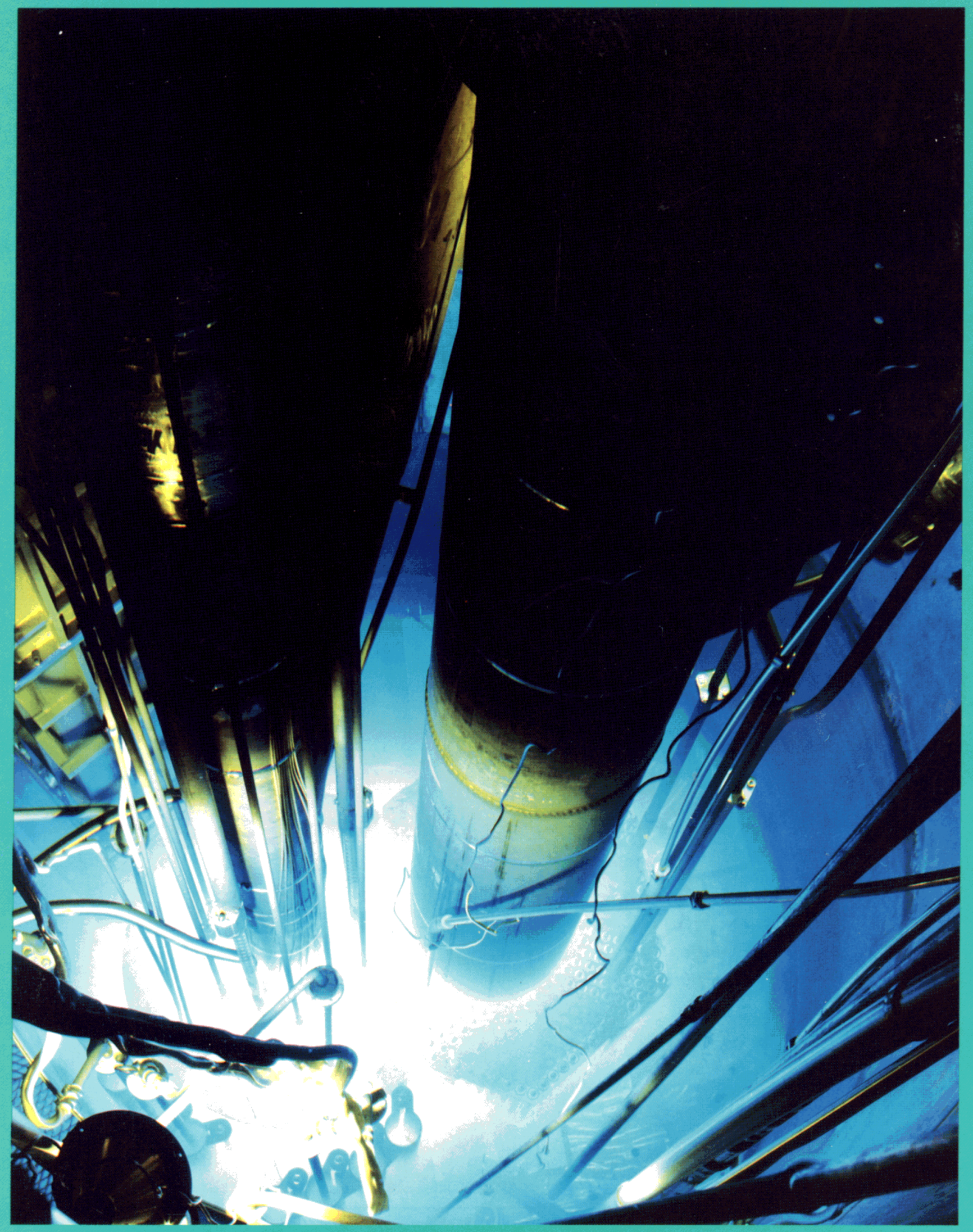

Cerenkov radiation observed in the Annular Core Research Reactor (ACRR). 


\section{Technical Capabilities}

\section{Nuclear Reactor Research, Development, and Testing}

In support of its primary nuclear weapons engineering and related energy missions for DOE, Sandia has developed a broad capability in designing, building, and using various nuclear reactors to conduct research, and to develop and test components and systems in nuclear environments. For 30 years, Sandia has supported nuclear weapons, aerospace nuclear, and commercial reactor development and safety programs. Sandia operates a radiation testing complex for DOE's nuclear weapons program. The complex provides a broad range of nuclear radiation environments to support the development and certification of radiation-hardened weapon systems developed by the nuclear weapons laboratories (Los Alamos (LANL), Lawrence Livermore (LLNL), and Sandia), as well as major defense contractors, and other industrial, government, and university users. Fifteen major radiation-producing facilities provide sources of neutrons, electrons, gamma-rays and $\mathrm{x}$ rays to support research, development, and testing (RD\&T) for nuclear and nonnuclear weapons systems, advanced and conventional (i.e., light water reactor [LWR]) nuclear reactors, effects simulation, radiation hardening, survivability, inertial confinement fusion, nuclear-excited laser development, space and terrestrial reactor safety, and other basic and applied research areas. This capability is supported by a state-of-the-art radiation diagnostics and dosimetry laboratory, a hot cell facility with complete metallographic capability, dedicated computers, modelling and analysis, and data acquisition systems.

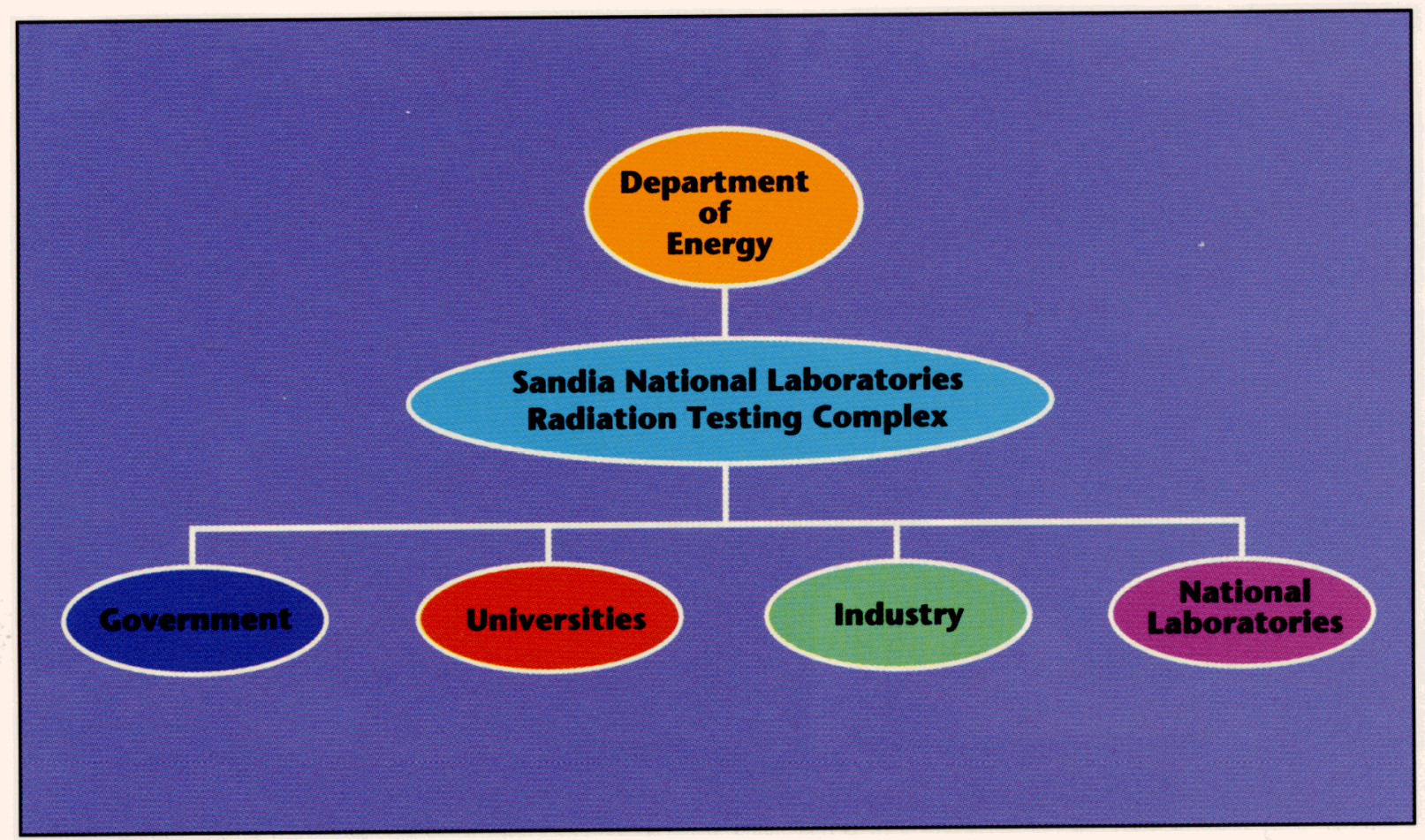

Participants in DOE's nuclear weapons program utilize Sandia's radiation testing complex. 

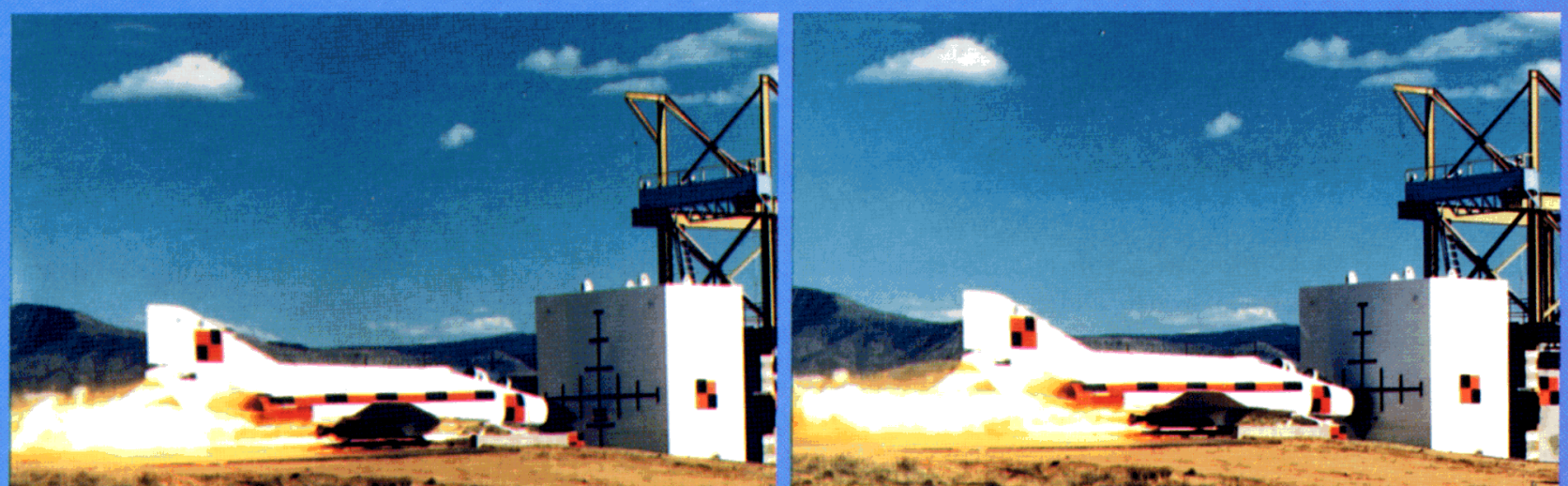

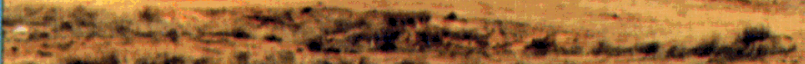

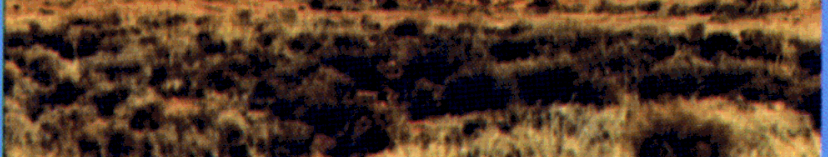

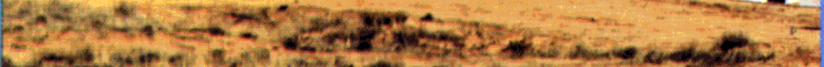

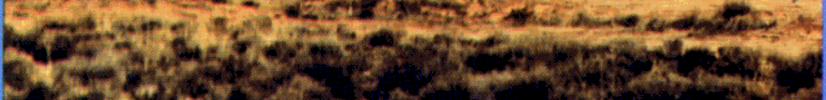

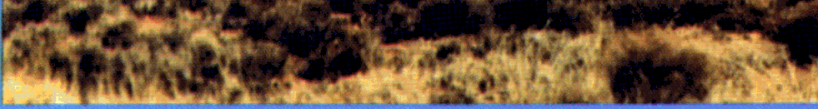

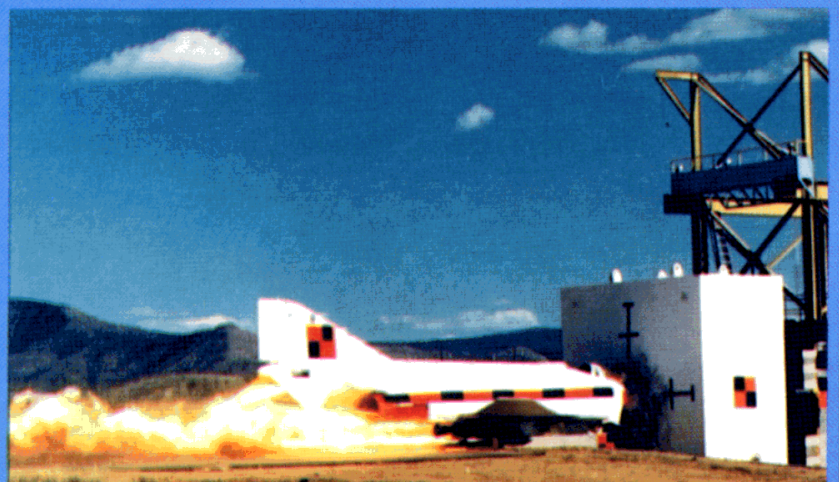

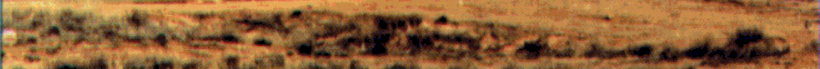

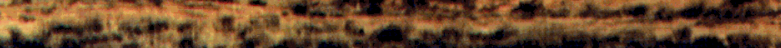

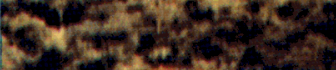

ist

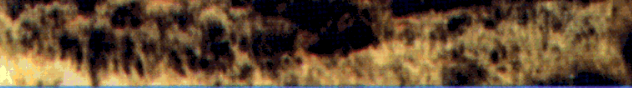
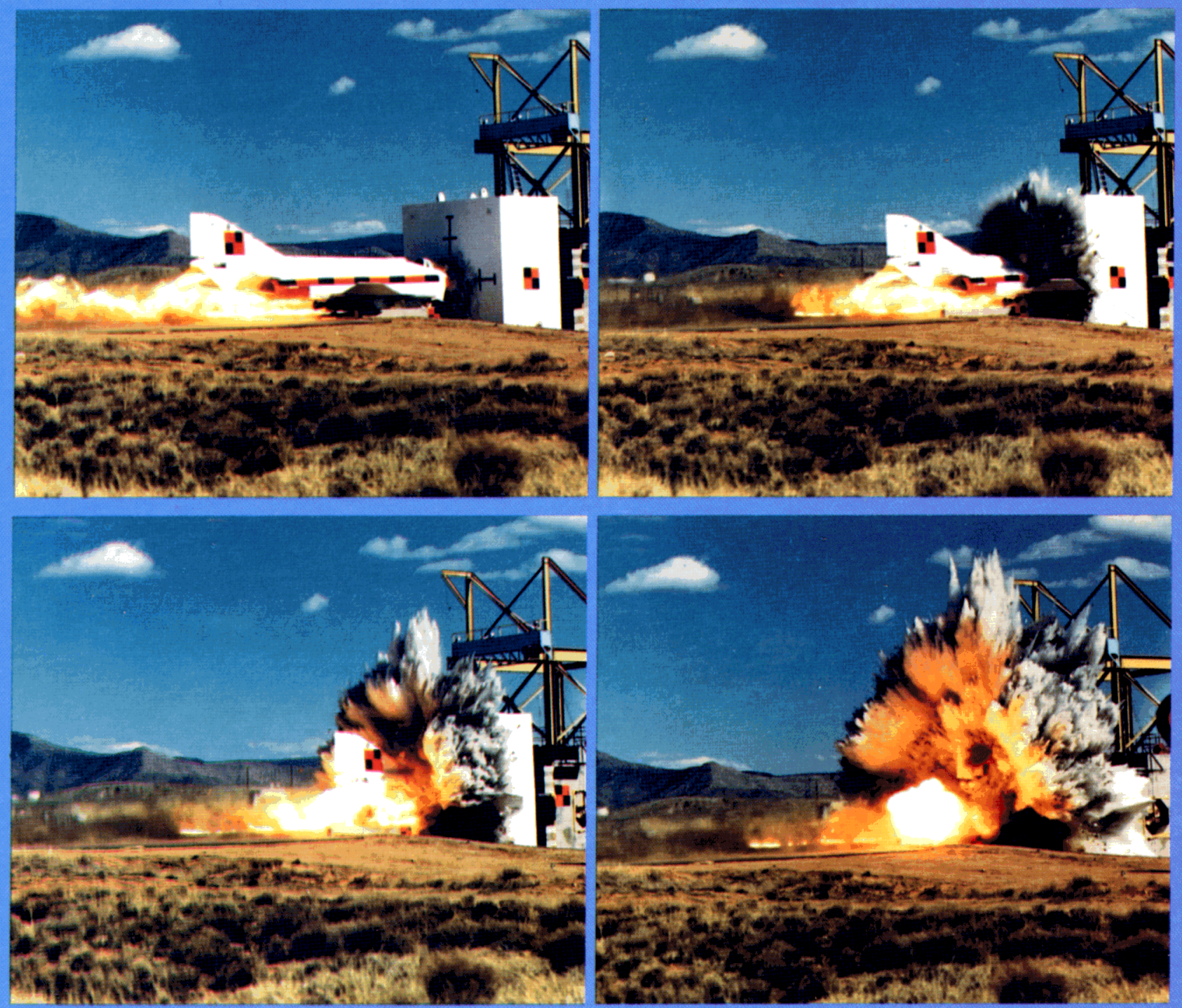

An F-4 Phantom slams head-on into concrete barrier at 480 miles per hour in test at Sandia's rocket-sled facility south of Albuquerque. The work is expected to advance the state of the art in designing large structures for nuclearpowerplants. 


\section{Nuclear Reactor Design}

The Sandia Annular Core Research Reactor (ACRR) (see ACRR Reactor Test Facility) and Sandia Pulse Reactor (SPR) (see SPR II Reactor Test Facility and SPR III Reactor Test Facility) facilities were designed and constructed by Sandia to address specific neutron and/or gamma radiation requirements. These pulsed reactor facilities serve as the primary national test bed for weapons simulation research as well as performing a broad range of reactor safety and advanced nuclear systems research for both defense and space applications. Neutronics, thermal hydraulics design, control system designs, and the development and testing of advanced fuels are performed at Sandia to develop facilities capable of meeting new requirements. The SPR III provides fission spectrum neutron irradiation in bursts as short as $70 \mu \mathrm{s}$ in either a large central or external exposure cavity. The ACRR employs a unique Sandia/
LLNL-developed $\mathrm{UO}_{2} / \mathrm{BeO}$ fuel providing significantly increased neutron and gamma fluences in millisecond (ms) bursts, programmed transients, or steady-state operations. The ACRR FREC (Fueled Ring External Cavity) facility is a unique fueled external cavity, 50.8 centimeters $(\mathrm{cm})$ in diameter, to provide large volume irradiations. Fuels testing for carbide-, beryllia- and zirconium-hydride-based fuels were performed in these facilities to develop suitable fuel materials for the stressing pulse reactor environment. The integrated reactor design approach employed on Sandia test facilities has been recognized by the international community and utilized by the Japanese PNC in a joint-reactor design study to examine test facility options for advanced reactor safety tests beyond currently existing test capabilities.

\section{Neutronics and Radiation Transport Analyses}

Sandia has designed, built, and currently operates several unique nuclear reactor and accelerator facilities to meet a wide variety of research and testing needs. Because these facilities were taken from concept to operating systems in-house, we have developed a significant theoretical and practical nuclear design capability. We routinely model the transport of neutral and charged particles in multiple dimensions using deterministic and Monte Carlo methods with problem-specific nuclear data.

Recent efforts include design work on several nuclear reactor concepts, from large, diffuse nuclear-pumped laser systems to compact, high-power-density test reactors. We provide nuclear analysis in the design process of large, complex nuclear experiments (both for internal and external customers) and to assure the safe conduct of these experiments in our reactors. We are a leader in the area of radiation simulation fidelity. Our expertise includes developing ASTM and Department of Defense (DoD) reactor testing standards, the development of new techniques of tailoring and characterizing our reactor spectra to meet customer needs, and the use of the latest ENDF/B-VI cross sections to interpret a customer's dosimetry and to translate the irradiation conditions into a measure consistent with the radiation damage mechanism of concern.

\section{Nuclear Safety}

Sandia has more than 40 years experience in nuclear safety. We share with our sister laboratories and the DoD the responsibility for the safety and security of the nuclear weapons stockpile, and have made significant contributions to both commercial and space nuclear safety.

\section{Reactor Safety}

\section{Phenomenological Analysis and}

Experimentation-Phenomenological research is directed toward identification, quantification and modelling of those physical processes that determine containment loads (pressure, thermal, etc.) and threats, as well as radionuclide release and transport in the event of a severe accident. This research addresses fuel melt progression and fission product release, transport, and chemistry; severe accident code development and assessment; exvessel core debris/basemat interactions; fuel/coolant interactions; hydrogen transport, mixing and combustion; high-pressure melt ejection and direct containment heating; and containment structural integrity and failure modes. 
International Fuels Testing Program-Reactor safety research included a unique series of internationally sponsored in-pile experiments to investigate core disruptive accidents in advanced reactors. These Sandia tests were jointly sponsored by the U.S. Nuclear Regulatory Commission (NRC), the German KfK, Japanese PNC, British AEA, and the French CEA. High-speed photography of the mechanics of fuel failure under severe accident scenarios provided first-of-a-kind high resolution data on the initial phases of a nuclear core disruptive accident. Molten fuel motion experiments investigated later stages of the accident. These experimental results were used to develop phenomenological models which could be used to estimate the severity of whole core events. Other tests examined the coolability of up to 30 kilograms $(\mathrm{kg})(66 \mathrm{lb})$ of core debris following a severe accident using fission heating to simulate a volumetric decay heat source. A variety of fuels have been tested including $\mathrm{UO}_{2}$, mixed oxides, and carbides. This approach enabled researchers to develop a much more complete understanding of the key processing controlling the progression of advanced- reactor accidents.
Probabilistic Risk Assessment-Sandia has been in the forefront of probabilistic risk assessment (PRA) research since the 1970s. Beginning with our contributions to the landmark Reactor Safety Study (WASH-1400), Sandia has led the development of improved PRA and uncertainty analysis methodology for the NRC. Recently, the Sandia PRA methodology has been adapted for use in the analysis of nuclear weapon reliability, and similar methodology has been used by industry to model diverse systems such as the space shuttle. Current emphasis is on the use of PRA techniques in the design process for new facilities and systems (e.g., the DOE New Production Reactor) to assure the highest possible levels of safety and reliability.

A related research area at Sandia is that of reliability, availability, and maintainability (RAM). Sandia has ongoing research in this area for the SEMATECH consortium that is aimed at assessing and improving the reliability of semiconductor manufacturing equipment for American industry. Both the PRA and RAM techniques are easily adapted to examine a wide variety of types of systems, and Sandia has

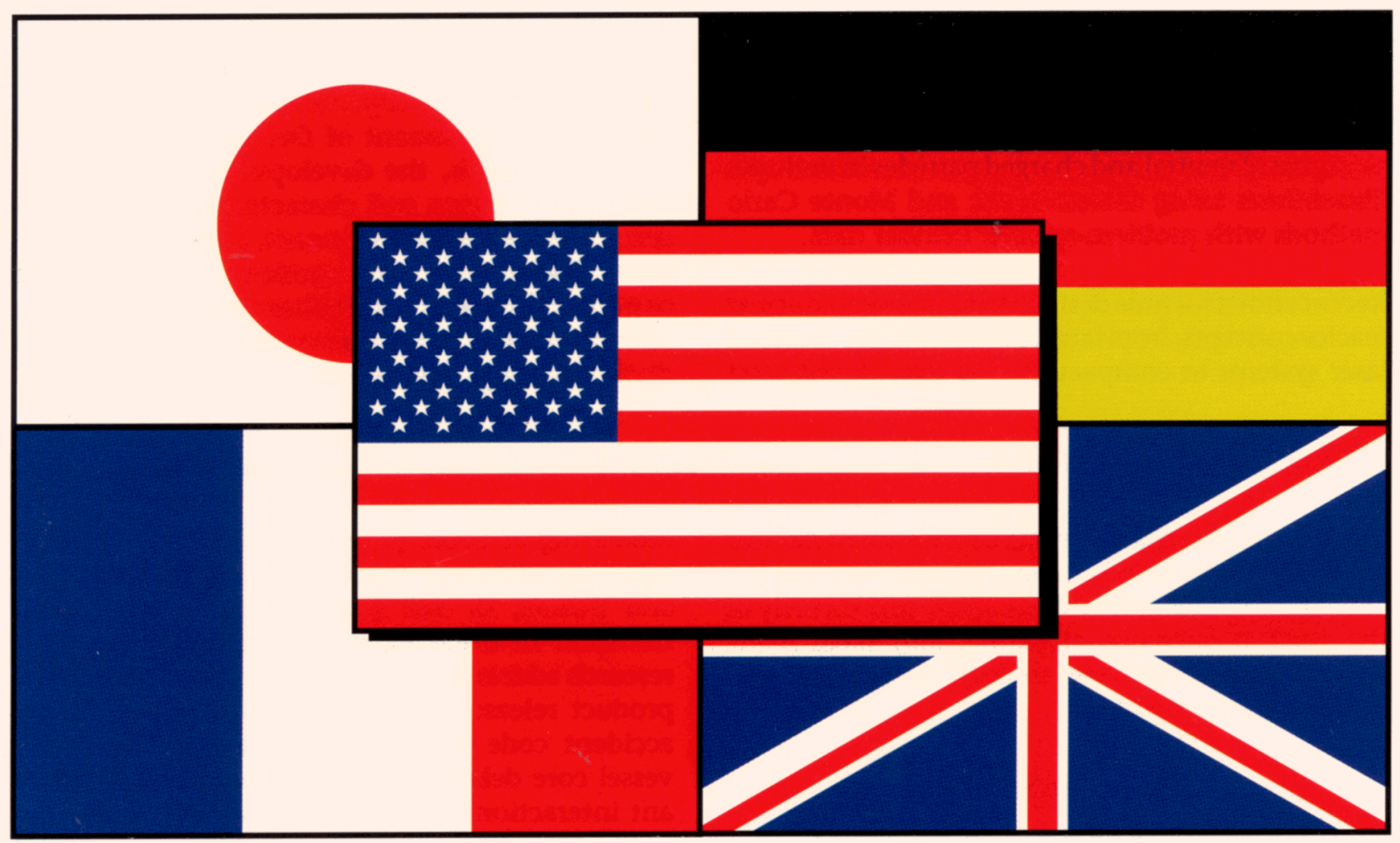

Multinational sponsors of unique in-pile experiments hosted by Sandia include agencies from the United States, Japan, The Federal Republic of Germany, Britain, and France. 
developed advanced computer software to support these types of analyses.

\section{Aerospace Nuclear Safety}

Sandia's multidisciplinary capabilities have enabled us to play a major role in much of this country's aerospace nuclear safety activity. These capabilities include mission analysis to define the consequences of critical launch aborts and other mission failures, range safety analysis to permit the determination of the fate of the fuel and the dispersion of radioactive and nonradioactive debris on the earth's surface for these mission failures, and a reentry analysis capability to determine the consequences of nuclear power sources entering the earth's atmosphere from space. These analysis capabilities are available through the variety of expertise that exists at Sandia in the areas of orbital decay analysis, aerodynamic predictions, trajectory simulations, reentry heating predictions, material response analyses, and vehicle disassembly simulation.

These capabilities enabled Sandia to assume a major role for aerospace nuclear safety during the early Radioisotope Thermal Generator (RTG) program including the SNAP-9, SNAP-19, SNAP-27, Cobalt60 and Isotec power sources. Sandia also had significant aerospace nuclear safety responsibility for SNAP-10A, the only nuclear reactor the U.S. has ever put into space. The Sandia reentry analysis capability was tested when the Apollo 13 mission was aborted on the way to the moon, and it became necessary to return to earth with the Lunar Module that contained a SNAP-27 power source. The orbital decay and reentry analysis was difficult as the Lunar Module was not designed for atmospheric entry and would quickly begin to break up. The Sandia reentry predictions facilitated National Aeronautics Space Administration (NASA) decisions to deorbit the Lunar Module and place the power source in deep water in the southern Pacific ocean.

Sandia's capabilities have been exercised in recent years to predict the fate of reentering Soviet satellites with nuclear power sources (Cosmos 954 and Cosmos 1402). Sandia was the only source of detailed reentry calculations (trajectory, aerodynamics, aeroheating, and material response) for the Cosmos 954 reentry and these efforts contributed to the recovery of the large fraction of reactor debris that was scattered across the Northwest Territory by that spacecraft.

\section{Safety and Security of Nuclear Weapons}

Sandia has furnished total concept-to-retirement engineering for the weaponization of bombs and warheads in the nuclear weapons stockpile since the 1940s. Sandia's special mission is to ensure that nuclear warheads meet the highest standards of safety, operational capability, reliability, and command and control. The potential consequences of an accidental or unauthorized nuclear weapon detonation or nuclear material dispersal are high. Thus, nuclear surety (i.e., safety, use control, and physical security) is the paramount concern in weapon design.

Product quality and reliability are major initiatives for Sandia. As part of meeting these requirements, we have streamlined both our designs and the manufacturing processes used in the nuclear weapons complex. Reliability is assessed through periodic laboratory and flight testing of samples of every weapon type in the stockpile. 


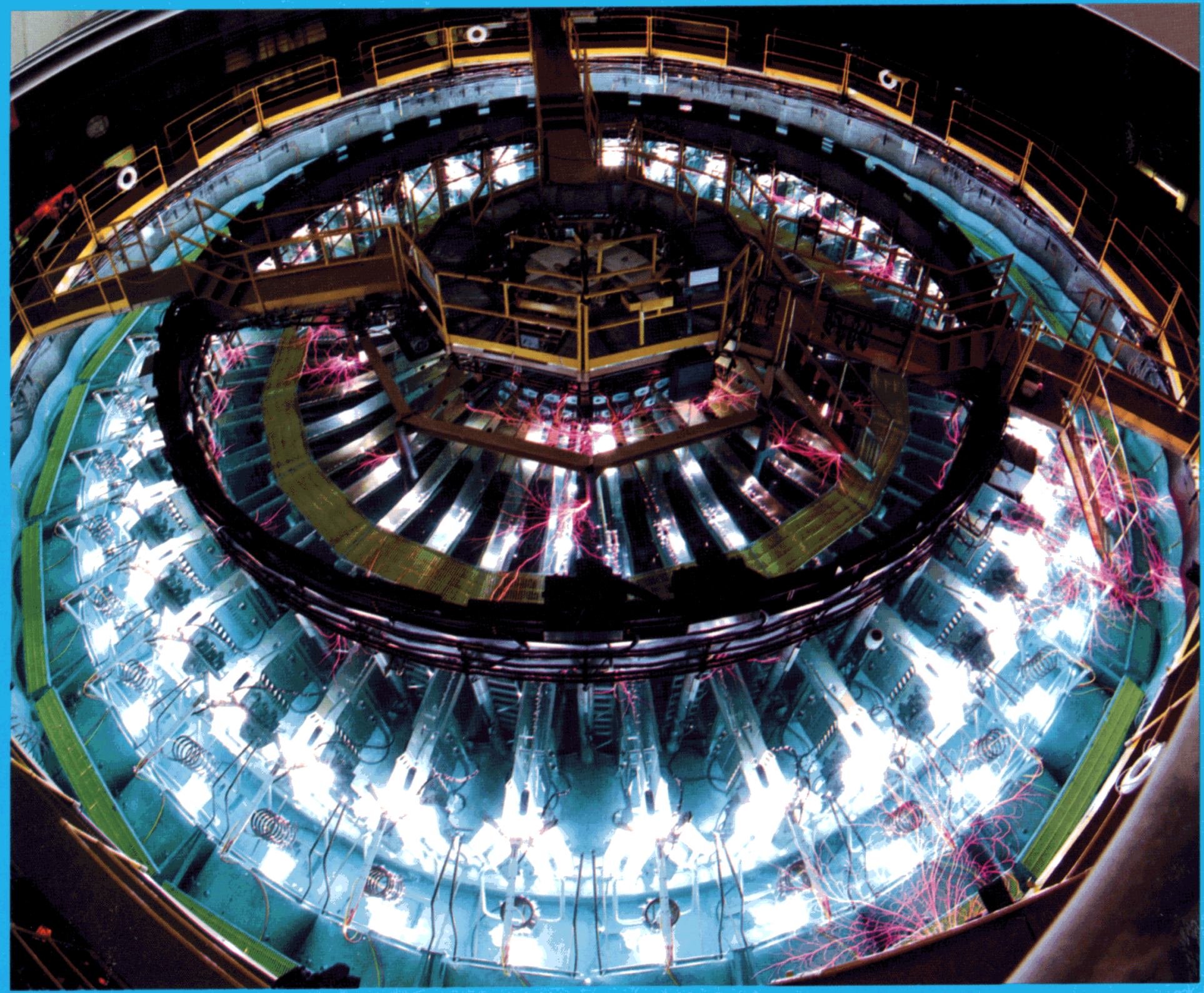

Pulsed power operation of the Saturn X-Ray accelerator. 


\section{Plasma Physics and Engineering}

Sandia is the DOE center for pulsed-power research. This technology produces intense pulses of energy for feasibility studies of controlled thermonuclear fusion, for nuclear-weapon-effects simulation, and for directed-energy weaponry research for the Defense Advanced Research Projects Agency (DARPA). The Saturn and Hermes III accelerators simulate nuclear-weapon effects as part of the Simulation Technology Laboratory. Sandia also has advanced facilities and expertise for the design, testing, and analysis of plasma-facing components in magnetic confinement plasmas, with extensive collaborations in the major controlled magnetic fusion facilities in the U.S. and abroad.

Sandia's Particle Beam Fusion Accelerator II (PBFA II) is the world's most powerful particle accelerator and is considered to be the first machine with the potential for igniting a controlled fusion reaction in the laboratory via the implosion approach. PBFA II consists of 36 pulsed-power modules, arranged around a central hub, which deliver power from all directions. Built at a cost of $\$ 48$ million, PBFA II can deliver up to 100 trillion watts $(\mathrm{W})$ of power. Sandia is DOE's lead laboratory for inertial confinement fusion experimentation with light ions.

Closely coupled with the experimental research on pulsed power and controlled fusion, Sandia is also developing complex three-dimensional plasma dynamics codes to enhance its capabilities in these areas. Sandia has also developed advanced plasma diagnostics and plasma-surface interaction facilities for experimentation in this unique and challenging environment.

\section{Space Physics Theory, Analysis, and Computation}

Sandia has developed expertise in several computational space physics areas. Researchers at Sandia are currently developing a new global model of the magnetosphere. The model is based on three new magnetic limiting currents that have been shown to control the magnitudes of the plasma sheet current, the Birkeland region I current, and the ring currents. This model builds on research conducted in Sandia's fusion and charged particle beam programs. This model is the first to describe the quiet-time magnetosphere and quantitatively predict many features, including the thickness of the low altitude boundary layer. In addition, perturbations to the quiet-time magnetosphere model are being used to study magnetic storms and substorms. This model gives Sandia a unique capability to study magnetosphere-related phenomena.

Other examples of Sandia's expertise in computational space physics include (1) Auroral Arc Accelerator: Sandia pioneered the study of the auroral double layer with the first large scale simulation of the interaction of a magnetized current sheet with the earth's conducting ionosphere. This was the first self-consistent simulation to explain how auroral electrons are accelerated to keV energies above the polar ionosphere; (2) Auroral Kilometric Radia- tion: Sandia performed the first simulation of one of the most powerful radio sources in the solar system and have shown that the cyclotron maser instability is responsible; (3) Solar Flares: Sandia has studied the physics of current flow through a density depression in a solar flare to help understand energetic electron and $\mathrm{x}$-ray events during solar flares; and (4) Spacecraft Charging: Sandia is currently simulating the spacecraft charging process (and its cure) that occurs when a high current relativistic electron beam is launched from Sandia's BOLT/Delphi rocket platform (see BOLT).

State-of-the-art computer codes are available now, and many have already been used for space-related research. Examples are (1) Buckshot: a 3-D gridless magnetostatic particle code to study the propagation of charged particle beams in space; (2) PIC Codes: 1-D, 2-D, and 3-D particle-in-cell codes can be used to study space plasma physics. There are electrostatic, magnetostatic, electromagnetic, guiding center and MHD-particle versions; and (3) Neutral Gas: This code is used to study neutral gas dynamics in space, particularly in the vicinity of spacecraft, and in the interior of accelerators flying on board spacecraft. 


\section{Fluid Mechanics and Heat Transfer}

As part of its primary mission, Sandia has developed an extensive capability in modelling heat transfer and fluid mechanics phenomena and structural response to static and dynamic loads. State-of-theart computer codes have been developed to model heat conduction and convection, radiation heat transfer, Newtonian and non-Newtonian fluid mechanics, multiphase and chemically reacting flows, fluid flow and heat transfer in porous media, transport phenomena, and thermodynamics. In addition, advanced diagnostics have been developed for experimental investigations of fluid flow and heat transfer. Current programs address weapons, space, and transportation systems; nuclear waste disposal; materials processing; nuclear reactor safety; microelectronics manufacturing; suspension rheostats; energetic materials; ignition and combustion phenomena; aerosols; solar, geothermal and magma energy; naval hydrodynamics; and cooling of microelectronic components.

The CTH computer code, developed by Sandia, can analyze the interaction of high-velocity space debris and meteors with space vehicles. CTH was originally developed to model the strong shocks and large deformations associated with hypervelocity impacts and explosion phenomena. It is a finitedifference code that solves the conservation of mass, momentum and energy on a two- or three-dimensional Eulerian grid. It has been well validated against a broad base of experimental data including the only 10 kilometers per second $(\mathrm{km} / \mathrm{s})$ impact data available, and is an excellent tool to extrapolate into the regime encountered in space which is beyond the capabilities of current experimentation. We are currently working with both Johnson and Marshall Space Flight Centers to analyze the effectiveness of their current family of debris shields.

Sandia also has a broad capability in developing and applying computer codes to model thermal-hydraulic phenomena for particular reactor systems and accident-induced phenomena. For over a decade, we have developed and applied multidimensional thermal-hydraulic codes to analyze the behavior of design-basis and severe accidents in light water and liquid metal reactors. Computational tools have been developed to analyze the transport and mixing of gases, liquids, and aerosols; combustion phenomena; molten-fuel coolant and molten-fuel concrete interactions; fission product chemistry and transport; fuel melt progression; debris bed formation and characteristics; containment loads and responses; and other phenomena of concern for reactor safety analyses.

\section{Solid Dynamics and Structural Analysis}

Sandia has developed a broad range of computational structural mechanics tools in support of weapons and energy projects. They include finite element codes for large-scale static and transient-dynamic analyses of structures with complicated nonlinear material behavior. These codes use current finite element technology and handle large strains associated with severe loadings. We have coupled closely with material scientists at Sandia to ensure that the material models are appropriate and to develop new models as needed. A Center for Advanced Mechanics and Materials has been formed to address problems whose solutions involve a close synergism between computational mechanics and materials expertise. In support of our finite element codes, we have also developed state-ofthe-art mesh generation and visualization tools for generating input and interpreting the results of our calculations.
We have used our PRONTO2D and PRONTO3D dynamic codes to analyze the response of containment structures to transient loadings associated with severe accidents. These loads can be computed with the hydrodynamics codes (e.g., CTH) discussed in Fluid Mechanics and Heat Transfer above. Our static codes, JAC2D, JAC3D, and SANTOS, along with commercially available software, can be used to design experiments on scale-models of containments and to predict the response of the containments during the tests. Tearing of liners of containment buildings near penetrations has also been investigated as has ductile failure (tearing) of cases designed to protect components of nuclear weapons. 


\section{Systems Engineering/Integration}

A program as complex and multidisciplinary as the design, development, and testing of space nuclear reactors will require high-quality systems engineering. Sandia considers one of its major competencies to be the integration of many disciplines into the development of a total solution. "Total" means timely, cost-effective, comprehensive, prototypical, tested, and rapid conversion of concept into marketable product. An example of a past success in systems integration would be the development pro- gram for the W88 warhead for the Strategic Navy's Trident II sub-launched missile. We undertook tasks in the fuzing system, programmer, radar, timers, materials, testing, effects simulation, etc. Throughout the labs, Sandians, together with outside organizations (Draper Labs, Allied-Signal, LANL, Lockheed, etc.) helped solve Trident-related problems contributing everything from reliability assessments and hydrogen combustion concerns to the detailed testing programs.

\section{Verification Technology and Satellite Programs}

Sandia has the largest arms-control verification technology program in the country and has contributed significantly to the development of major satellite and ground-based verification systems. In the early 1960s Sandia and Los Alamos National Laboratory began designing special-purpose instrumentation for VELA satellites. These spacecraft were devoted to developing the capability to detect nuclear detonations, first in space and later in the atmosphere. The VELA experience provided the early technology for treaty verification, and the satellites collected data from numerous detonations in the atmosphere by nations that had not signed the 1963 Limited Test Ban Treaty. Since then, Sandia has maintained a leading role in reliable miniature electronics and sensor technology. A new generation of Global Positioning System (GPS) satellites has been developed. Los Alamos is providing the x-ray sensors and dosimeters, and Rockwell International is providing the spacecraft and electromagnetic pulse sensors. Our optical sensors, data processors, and power supplies support all the sensors used for monitoring nuclear detonations. The GPS is a critical part of the US defense system for the 1990s and the next century.

\section{Rocket Systems and Launch Capabilities}

Sandia uses a broad spectrum of rocket systems in meeting its prime mission for the DOE. Sandia has launched more than 1400 rockets from 17 worldwide locations during the past 33 years.

Single and multistage rail-launched rocket systems are employed to provide cost effective launch capability to carry small to medium payloads (up to 500 $\mathrm{kg}$ [1100 lb]) to apogee altitudes of over $1000 \mathrm{~km}$ $(620 \mathrm{mi})$. These rocket systems can also be used for reentry testing by reorienting the upper stage and firing the last stage back towards the earth to provide the required reentry conditions.
An extensive and integrated capability to support rocket systems development and testing exists at Sandia, including telemetry systems, radio command and control; safing, arming, and sequencing; payload attitude control; mission planning; instrumentation; documentation; control and data systems; trajectory formulation and simulation; environment test and qualification; motion simulation; mass properties measurement; dynamic balancing; and wind tunnel testing. 


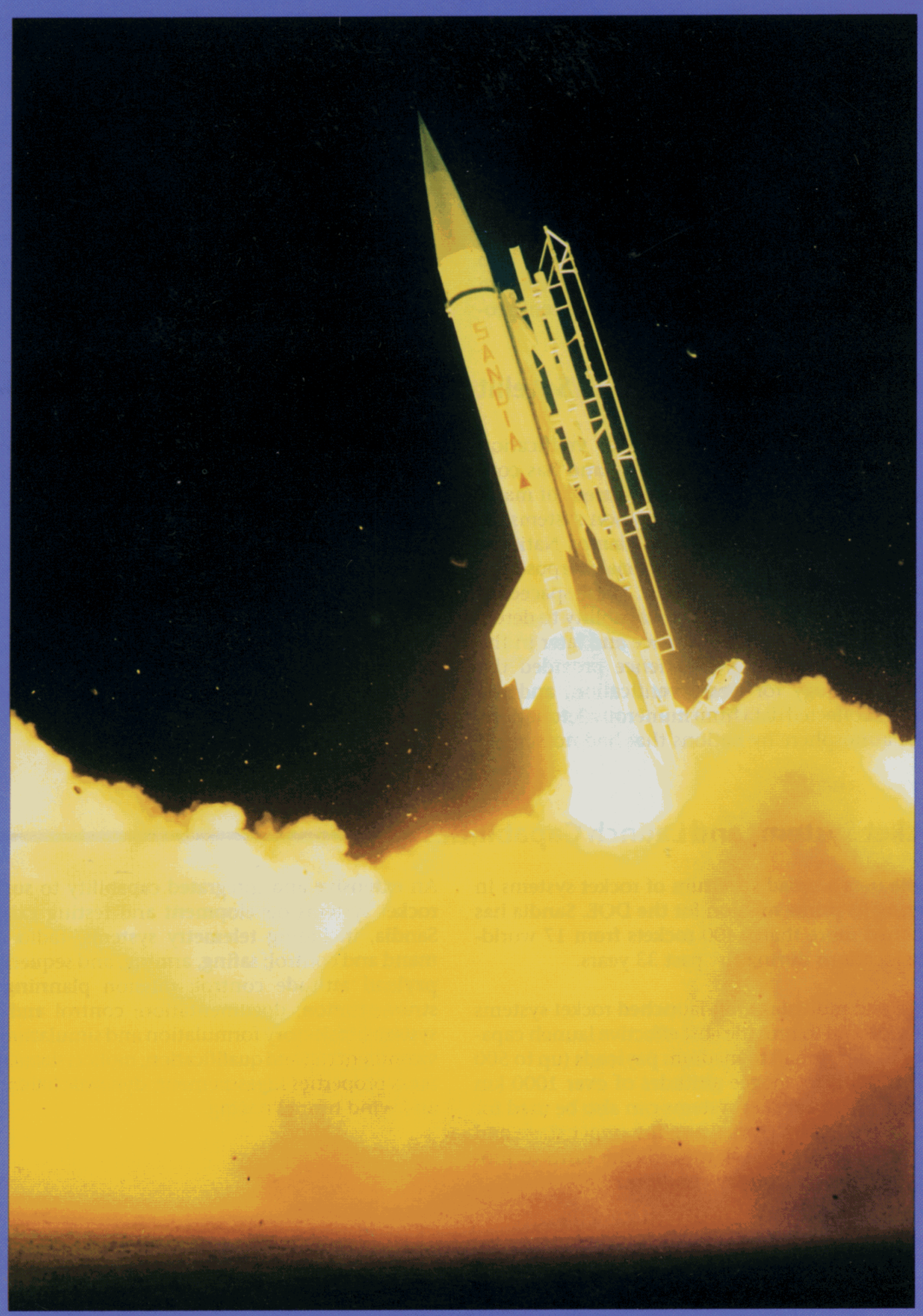

Strypi booster being launched from Sandia's Kauai Test Facility. 


\section{Flight Systems Guidance and Control}

Sandia has supported numerous flight test programs during the past 30 years which incorporated instrumentation and control of ballistic and maneuvering reentry vehicles, and booster/payload guidance for space experiments. Sandia has developed a well tested family of inertial systems, flight computers, and flight control systems. These systems are designed to perform in an extremely adverse flight environment of high steady-state acceleration, high vehicle spin rates, and severe vibration. Space applications also typically constrain the system with low volume and weight budgets. A unique shared-memory simulation facility at Sandia allows interactive operation of guidance and navigation systems and validation of all software and systems before flight. Sandia development of custom guidance hardware for unique requirements is performed in close cooperation with industrial suppliers of inertial instruments and guidance systems. Our comprehensive experience in guidance and control systems development, systems integration, and flight testing assures high efficiency and rapidresponse capability in support of ambitious flighttest schedules.

\section{Inertial Systems}

Sandia has developed inertial measurement hardware for use in spinning vehicles, such as sounding rockets, to provide vehicle control systems with data necessary to determine the attitude of the vehicle. The MINI-RIMS (Miniature Roll-Stabilized Inertial Measurement System) is an inertial measurement system weighing $5.5 \mathrm{~kg}(12 \mathrm{lb})$ with a volume of $4100 \mathrm{~cm}^{3}$ ( 250 cubic inches [in ${ }^{3}$ )). MINIRIMS provides the user with information on vehicle angular velocity and acceleration for three axes. Gyroscope performance is 0.3 degrees/hour. A successor design to MINI-RIMS, which is presently in the latter stages of development, is the RLGA (Ring Laser Gyro Assembly). The RLGA improves performance capability by an order of magnitude by utilizing ring laser gyroscopes. Physical attributes are comparable: $5.5 \mathrm{~kg}(12 \mathrm{lb})$ and $4100 \mathrm{~cm}^{3}\left(250 \mathrm{in}^{3}\right)$; power consumption is $14 \mathrm{~W}$, but the RLGA drift performance is 0.01 degrees/hour.

Sandia has designed gimbal assemblies and control systems for pointing and stabilization of radar antennas in space and aircraft applications. The most recent designs utilize digital control which permits rapid modification of controller characteristics by software. Pointing errors of less than 0.01 degrees have been achieved with a gimballed pointing system used for motion compensation of a radar imaging system aboard an aircraft.

\section{Materials Science}

Space nuclear systems will require advanced refractory, light weight, composite, and radiation-resistant materials for fuels (form, manufacturing, hightemperature properties, etc.), shielding, reactor components, propellants, etc. Sandia has a broad range of analytical tools and facilities to analyze and characterize materials (using spectroscopic, microscopic, chemical, physical and thermophysical analysis, and other tools), to synthesize them (using state-of-the-art theory, computer-aided molecular design, MBE, CVD, etc.), and to process, test, and evaluate (using special purpose radiation, environmental, and mechanical test facilities) existing or new materials (ceramics, catalysts, metallic alloys, plastics, semiconductor devices, organics, and surface coatings). These capabilities encompass a wide range of facilities, capital equipment, trained and experienced staff, and a strong underpinning of basic research. 


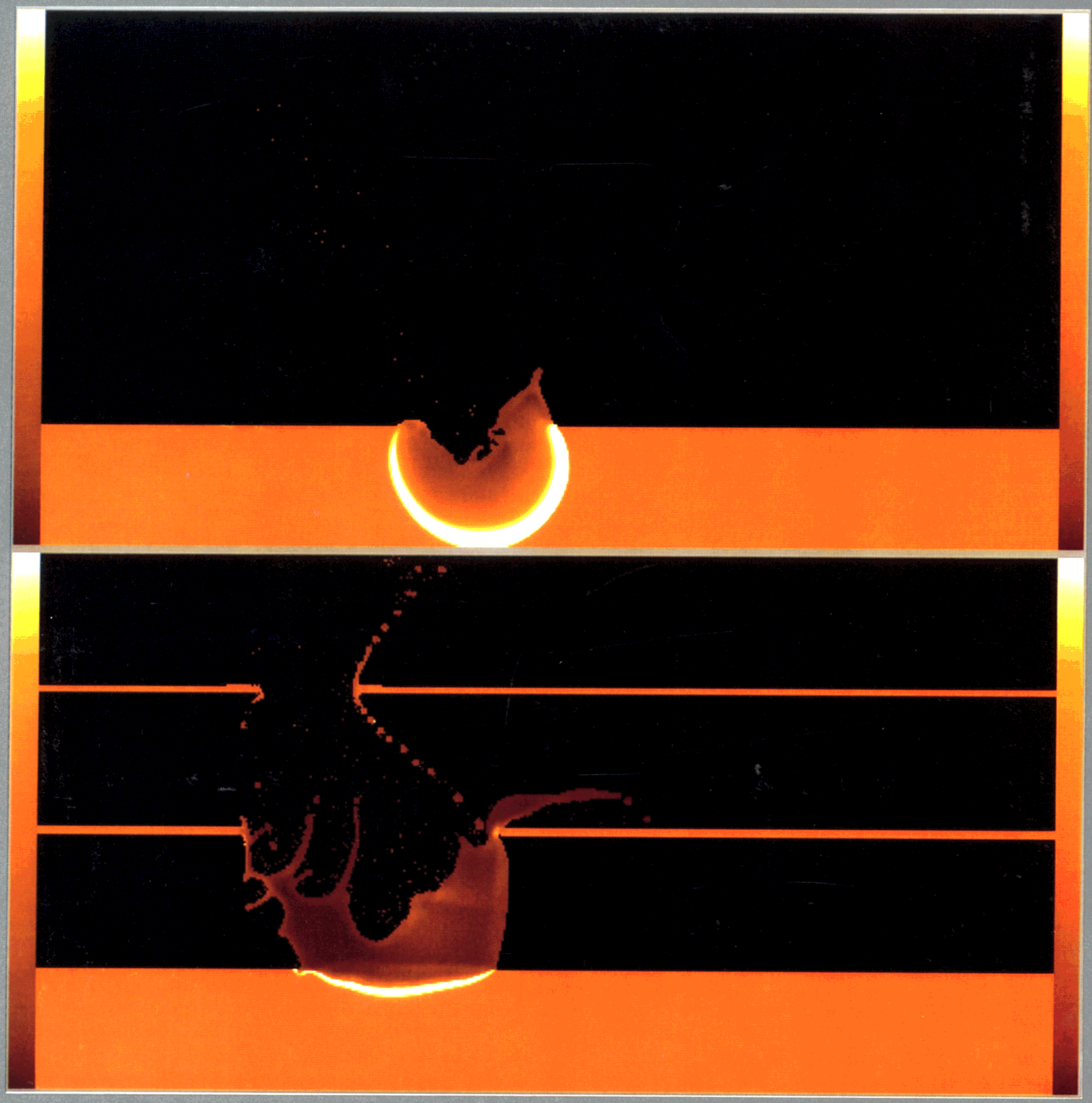

Representation of high-velocity collision of space debris with an orbiting space vehicle. Top image is the damage done to the vehicle's outer wall with no shields. Bottom image shows the lesser damage done with two shields in place. The calculation was done using a massively parallel code. 
Sandia has a distinguished microelectronics history that includes its invention of the laminar-flow clean room in the 1960s, major contributions to the development of radiation-hardened integrated circuits in the 1970s, and establishment of a worldclass Microelectronics Development Laboratory (MDL) in the 1980s. The MDL incorporates a 1210$\mathrm{m}^{2}\left(13,000-\mathrm{ft}^{2}\right)$ Class 1 clean room, which limits airborne particles to no more than one 0.1 -micron particle per cubic foot ( 35 particles per $\mathrm{m}^{3}$ ).

The $345-\mathrm{m}^{2}\left(3700-\mathrm{ft}^{2}\right)$ Center for Compound Semiconductor Technology (CCST) supports molecular beam epitaxy, metal-organic chemical vapor deposition, and the development of a variety of new strained layer superlattice devices with tailored electrical and optoelectronic characteristics. Devices include infrared sensors, diode lasers, optical modulators, and high-speed field effect transistors.
The microelectronics and semiconductor development stems from Sandia's critical need for extremely reliable microelectronic circuitry for military and space applications. To support this continuing need, the DOE established an extensive microelectronics reliability research, development, and characterization capability at Sandia.

These facilities are available to private industry through the Microelectronics Quality/Reliability Center (MQRC). To help achieve defect-free products, Sandia has state-of-the-art capabilities for testbed characterization, single-event upset evaluation for space environments, and failure-analysis. These include wafer level tests, packaged part tests, physical models, statistical models, in-line process monitors, and test structures. No similar facilities exist at other government laboratories and universities, and few exist in private industry.

\section{Advanced Computing/Computers}

\section{Software - Massively Parallel Processing}

Sandia has the largest massively parallel computing operation in the United States. We are rapidly converting from serial to parallel the computer codes used to solve a wide range of complex scientific and engineering problems. Some 20 key codes that account for $95 \%$ of the computing time on Sandia's computers have been, or are being converted for use on massively parallel computers. These applications range from simulations of the arrangements of atoms on a surface to complicated three-dimensional problems in fluid dynamics, molecular dynamics, global ocean-atmosphere modelling, and the design of everything from meteoroid-resistant space structures to new semiconductor materials and catalysts.

In 1987, Sandia made massive parallelism work on real problems and showed for the first time that improvements could be made in problem-solving speeds almost in direct proportion to the number of processors working in parallel. Since then, the conversion to massively parallel processing has gone far beyond the bounds of computer science research and has begun to have practical consequences in the solution of important scientific and engineering problems, some of which were considered impossible only two years ago. 


\section{Hardware - SANDAC}

Sandia is among the world's leaders in the development of rugged, miniaturized computers. Originally developed for flight test vehicles in the weapons programs, the SANDAC (Sandia Airborne Computer) puts the computational power of a desk-sized general purpose computer into a very small package. The latest model, SANDAC V, is a full 32-bit multiprocessor design. A three-parallel-processor unit in a navigational configuration uses only $30 \mathrm{~W}$ of power, weighs just $2.3 \mathrm{~kg}(5 \mathrm{lb})$ and occupies about $3440 \mathrm{~cm}^{3}\left(210 \mathrm{in}^{3}\right.$ - smaller than a shoe box). The most recent design uses the million-transistor Motorola MC68040 microprocessor with a throughput of 15 million instructions per second, more than five times faster than the previous version. SANDACs are used to control reentry vehicles, to help pilots manage numerous control and weapon functions under battle conditions, and to control spaceborne payload deployment and functionality for several "pop-up" experiments. The miniature computers are being considered for ground-based and space-station robotic systems.

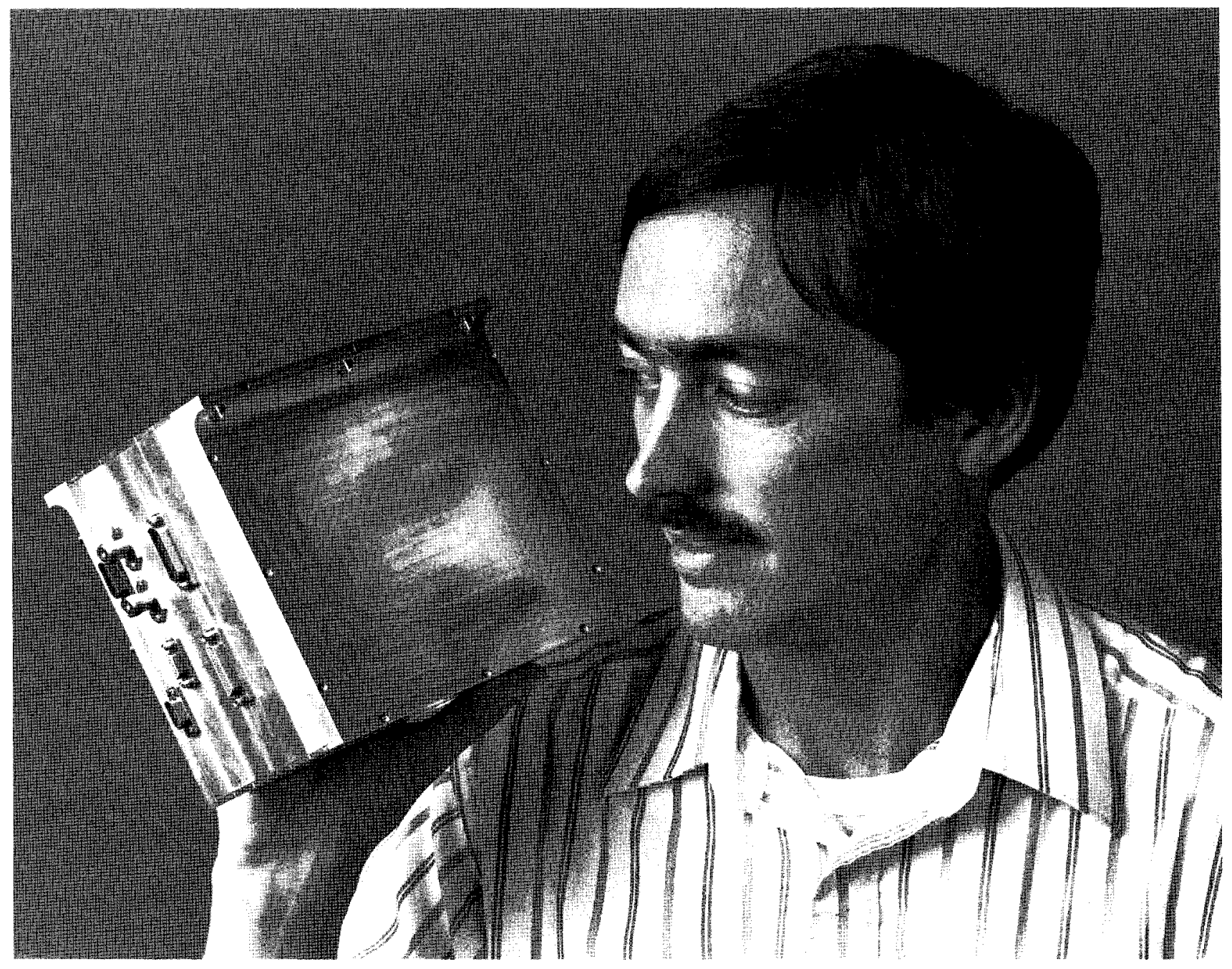

Sandia electrical engineer Glenn Russell displays the latest version of the SANDACV computer. 


\section{Robotics}

The handling of reactor materials, post-test inspection, and accident cleanup are two possible applications that would require automation to eliminate the exposure of personnel to hazardous environments or to improve the quality and productivity of manufacturing processes. Sandia is carrying out research in the areas of intelligent machine principles and systems. The work is multifaceted, but focuses on two key elements necessary to advance robotics systems. First is the automatic generation of robot programs using computer models of the robot, the workpiece, and the operation. These models may be geometric, physical, or heuristic. Second is the sensing which will allow future robots to work without requiring precise presentation of workpieces. The interdisciplinary staff is comprised of researchers from several disciplines-computer science, electrical engineering, mechanical engineering, physics, and mathematics. The specialties of this staff include automated planning and learn- ing, quantitative and qualitative physical modelling, computer-aided engineering, dynamics, kinematics, and sensing and instrumentation.

Sandia has had an extensive mobile robotics program since 1984. The multisponsor program develops state-of-the-art robotic systems for a wide range of applications from the battlefield to security to accident response. Applied research within the multidisciplinary group has produced unique capabilities within a number of areas including autonomous navigation, man-machine interface, highstrength dexterous mobile manipulation, and robotic telemanagement. To support these activities, the Robotic Vehicle Range (RVR) has established an extensive fleet of robotic vehicles with varying capabilities. The RVR covers approximately $0.8 \mathrm{~km}^{2}$ (200 acres) of various test ranges and includes a central compound of offices, support shops, and control stations.

\section{Laser Technology}

Sandia maintains broad capabilities in laser and related technologies. These range from low-power semiconductor lasers for optical communication and signal processing to potentially several tens of megawatt (MW) power levels that may be possible using direct nuclear reactor excitation of gas lasers. In many areas, an emphasis is placed on laser system miniaturization and enhanced robustness. Laser- related technologies potentially include LIDAR (Light Detection and Ranging) for environmental monitoring (including from space to earth), treaty verification, and drug interdiction; imaging of space objects from earth; optical computing; optical ignition and detonation of explosives and pyrotechnics; power transmission; and optically-based sensors.

\section{Battery Technology}

Although technologies for generating electrical power are well developed, scientific understanding of energy storage for later use is incomplete. Sandia has a leading role in the nationwide attempt to improve this knowledge. We are actively engaged in developing and evaluating primary, secondary (i.e., rechargeable), and reserve batteries for DOE, military, aerospace, and commercial energy applications. In 1982 we became the lead laboratory for DOE's Exploratory Battery Technology Development and Testing (ETD) project.

A number of battery systems are under study at Sandia. Primary batteries include lithium/sulfur dioxide and lithium/thionyl chloride, used in applications requiring high energy density, wide operating temperature range, and a high degree of reliability. Secondary chemistries include zinc/bromine, zinc/air, sodium/sulfur, lithium/polymer, hydrogen/nickel-oxide, and sealed lead/acid. These batteries are being evaluated for electric vehicle, standby power, and other DOE applications. Reserve batteries include lithium alloy thermal batteries, zinc/ silver oxide, and lithium/thionyl chloride chemistries for DOE and military use, both terrestrial and in space. We are also studying double-layer capacitors and radioluminescent light power sources. 


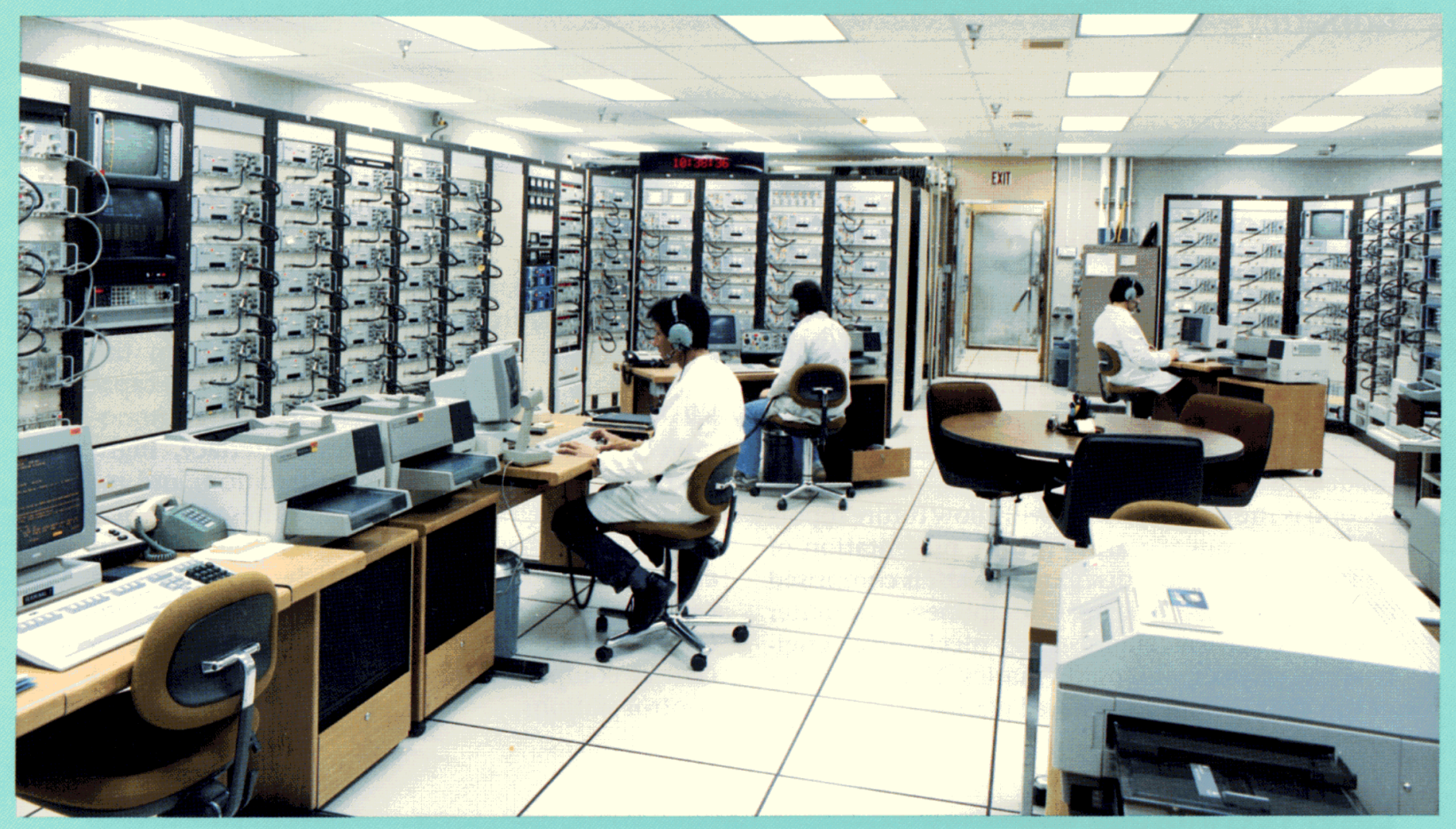

Data acquisition equipment in the main screen room of the Simulation Technology Laboratory.

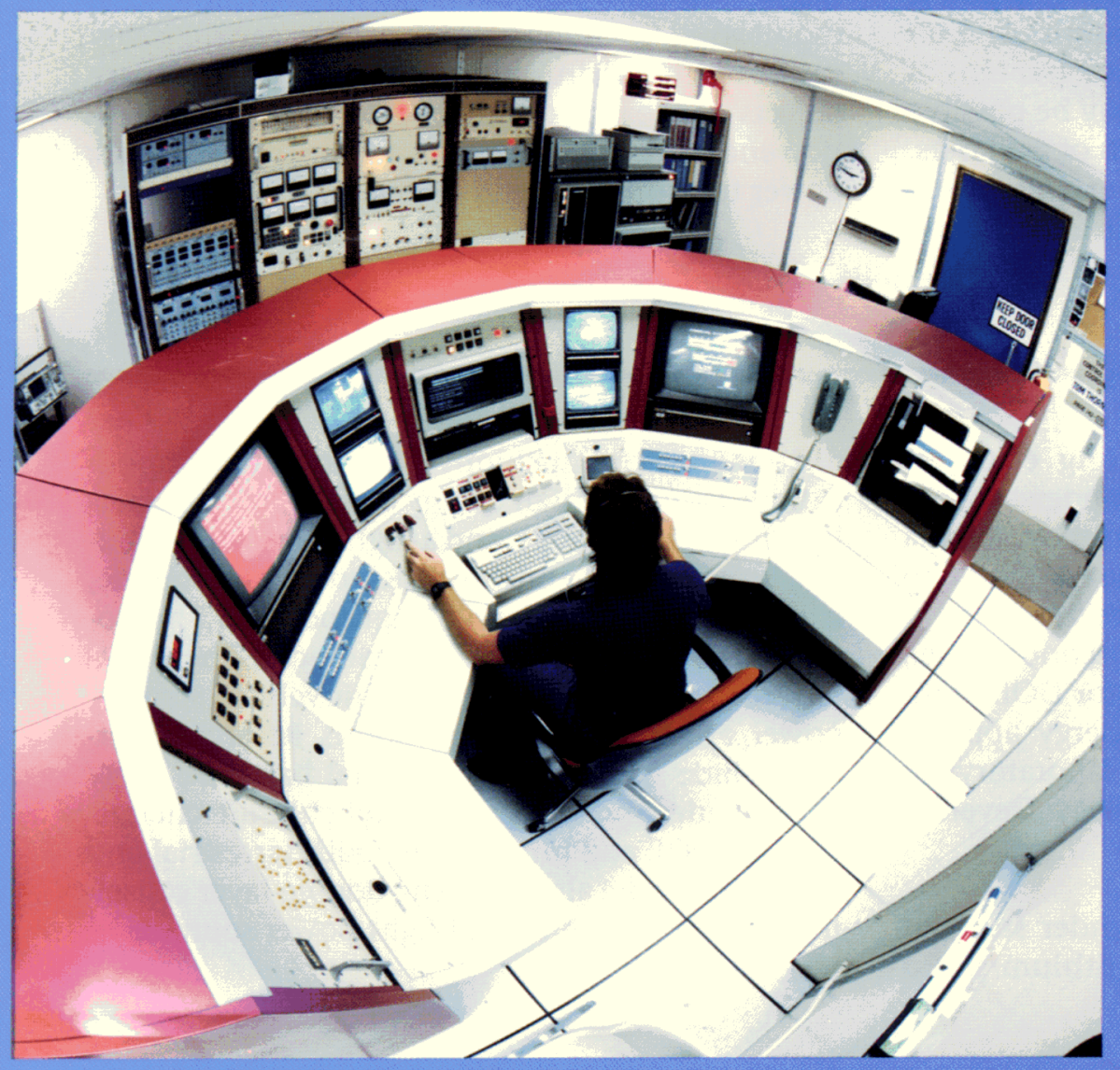

The Saturn control console. 


\section{Statistical Analysis and Human Factors Engineering}

Sandia's continuing emphasis on high quality and high reliability requires that statisticians are team members in projects pertaining to component feasibility, development, and production. In the concept phase, statisticians may provide services in probabilistic modelling to assess feasibility. In development, statisticians design and analyze experiments to characterize potential component designs and manufacturing processes. This front-end work assures the customer that manufacturability and reliability are designed into components. In production, statisticians develop and propose tools for continuous monitoring of product quality and assessment of reliability. An on-going research interest is the efficient use of component test data in reliability assessment. More recent research con- cerns the development of efficient component test plans based on system requirements.

Human Factors Engineering (HFE) is one of several technical areas required for a full systems approach to the design, development, and production of human-machine systems. This discipline focuses on capabilities and limitations of humans and machines to ensure adequate producibility, maintainability, operability, performance, reliability, and safety at an acceptable cost. At Sandia, HFE is an integral part of hardware and software design, development, and evaluation activities. Human factors personnel, in conjunction with systems, hardware, and software engineers, assure that HFE principles are addressed during the project cycle.

\section{Project Management}

Sandia, as part of its Strategic Plan, has identified project management (PM) as a preferred business practice for managing projects. Sandia has established project offices in several technical directorates to facilitate this function. A specific project office has been established to support our Space Nuclear Technology programs. Utilizing state-ofthe-art project management technology, the project office works with management and staff to establish project teams, develop policies and procedures, and provide basic management functions. In addition, the project offices establish project data bases, develop and control budgets and schedules, authorize project related procurement activities, and provide a procurement interface. They also provide for continuous planning and communication among project participants. Examples of successful large $R \& D$ construction projects that have been managed using formal project management methods include the Particle Beam Fusion Accelerators I and II, the Saturn and Hermes III radiation simulators (which are part of the Simulation Technology Laboratory), and the Strategic Defense Facility.

Other areas of project support are quality assurance, ES\&H coordination, writing environmental documents, coordinating facility construction, security, technical writing, and graphics capabilities. 


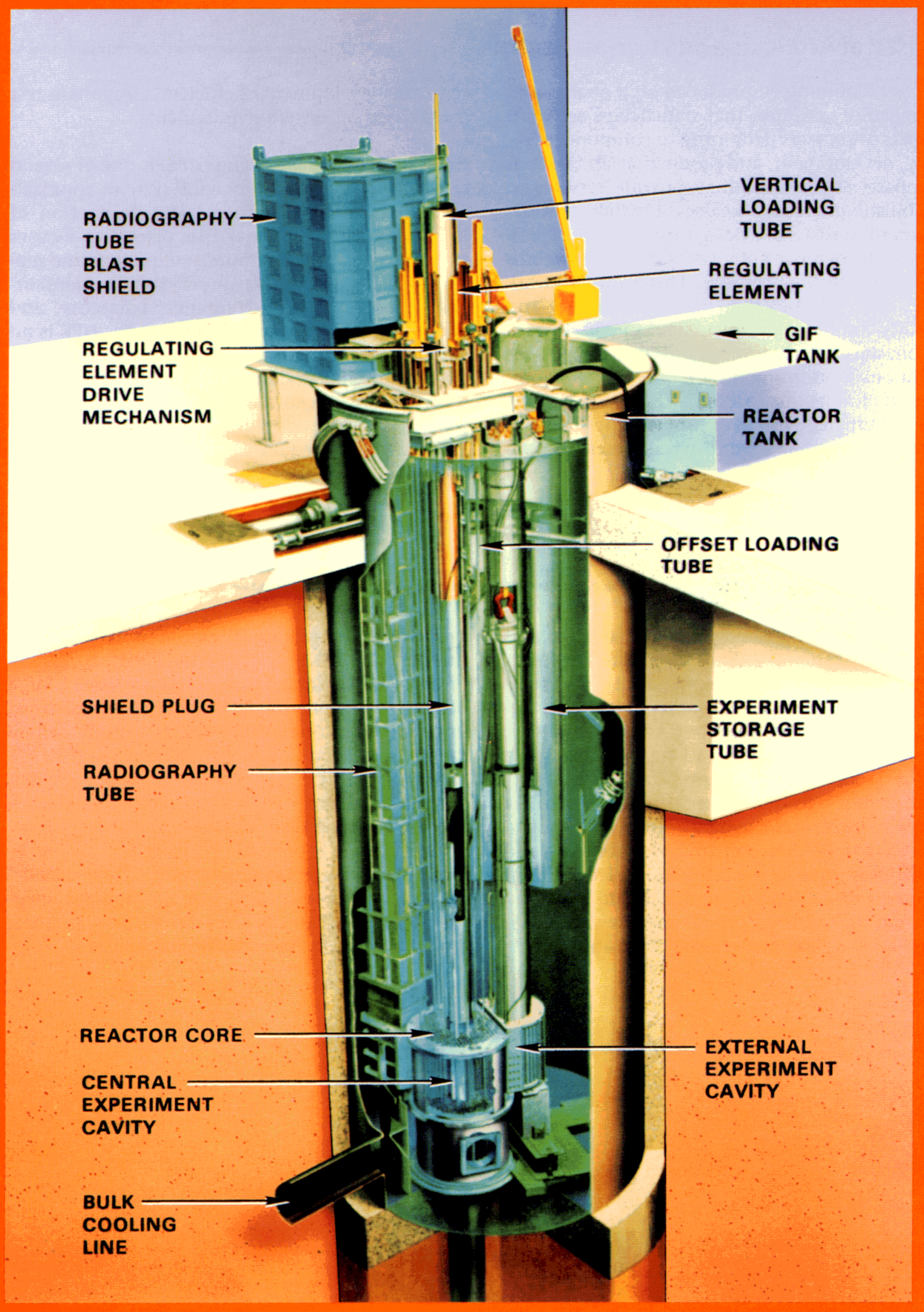

The Annular Core Research Reactor (ACRR) is capable of both pulsed and steady-state operation. 


\section{Developmental and Environmental Test Facilities}

Sandia has an extensive set of facilities, laboratories, and field-test sites located in five major sites at Albuquerque, New Mexico; Livermore, California; Kauai, Hawaii; Tonopah, Nevada; and at various locations at the Nevada Test Site, Nevada. Sandia's assets, owned by DOE, are valued at more than $\$ 1.2$ billion and include about 600 major buildings containing about $372,000 \mathrm{~m}^{2}\left(4\right.$ million $\left.\mathrm{ft}^{2}\right)$ of floor space. They are located on land totalling approximately $1455 \mathrm{~km}^{2}\left(562 \mathrm{mi}^{2}\right)$, most of which $\left(1360 \mathrm{~km}^{2}\right.$ [525 $\left.\mathrm{mi}^{2}\right]$ ) is at the Tonopah Test Range. In Albuquerque, the test facilities are located in five technical areas, and in a $150-\mathrm{km}^{2}\left(60-\mathrm{mi}^{2}\right)$ hazardous-test area 9.7 $\mathrm{km}(6 \mathrm{mi})$ south of the main Tech Area I.

These extensive facilities, used to support the development and maintenance of the nation's nuclear weapons stockpile and to support a multitude of DOE, DoD, NRC, and commercial programs, can also be used to help design and develop space nuclear systems, and to subject them to a broad spectrum of operational and accident environments.

\section{Nuclear Test Facilities}

Sandia has designed and built many research nuclear reactors and accelerator facilities which it operates for the DOE Office of Military Application. At each facility, research, development, and testing activities are conducted relating to nuclear weapon systems, nonnuclear weapons systems, commercial and advanced nuclear reactors, simulation source development, and other basic and applied research areas. Programs are conducted in support of DOE, DoD, NRC, multinational reactor safety, and university (public service) sponsors.

In addition to the existing reactors, our facilities have the flexibility to build, start-up and test new special purpose reactors and critical assemblies at existing sites.

\section{ACRR Reactor Test Facility}

The Annular Core Research Reactor (ACRR) is a pool-type research reactor capable of both pulsed (30,000 MW and 6.5 ms FWHM) and steady-state (2 MW) operation. It has a $23-\mathrm{cm}$ (9-in.) central irradiation cavity, two large (38- and 51-cm [15- and 20 in.]-diameter) interchangeable fuel ringed external cavities, a large (130- x 20-cm [51- x 8-in.]) rectangular unfueled external cavity, and a neutron radiography facility. The fuel height is $50.8 \mathrm{~cm}$ (20 in.). Two thermal neutron columns are available for neutron radiography. A microprocessor controller permits user-defined high-power transients ideally suited for real-time radiography of transient phenomena. The ACRR has a neutron spectrum with a significant epithermal component because of its undermoderated $\mathrm{UO}_{2} / \mathrm{BeO}$ fuel and core configuration. The ACRR is used primarily for the radiation hardness testing of nuclear weapon components and systems; including electronics, materials, and fissile components; and for reactor safety research.

The ACRR can be used for testing fuels proposed for use in nuclear thermal and nuclear electric propulsion engines and for space electric power systems. The testing could include initial screening of fuel pellets, etc., and then fuel bundles for both normal and accident conditions. It can also be used for testing the survivability and performance of reactor I\&C (instrumentation and control) electronics parts and full systems in hostile environments.

\section{SPR II Reactor Test Facility}

The Sandia Pulse Reactor II (SPR II) is a GODIVAtype, bare, fast-burst reactor capable of both pulsed and steady-state $(5-\mathrm{kW})$ operation. The primary use of the reactor is for experiments mounted around the periphery. However, a central irradiation cavity (3.8-cm diameter) may also be used for small experiments.

SPR II is used primarily to meet narrow-pulse, highdose-rate, and hard-neutron spectrum requirements in the testing of electronic and fissile devices. 


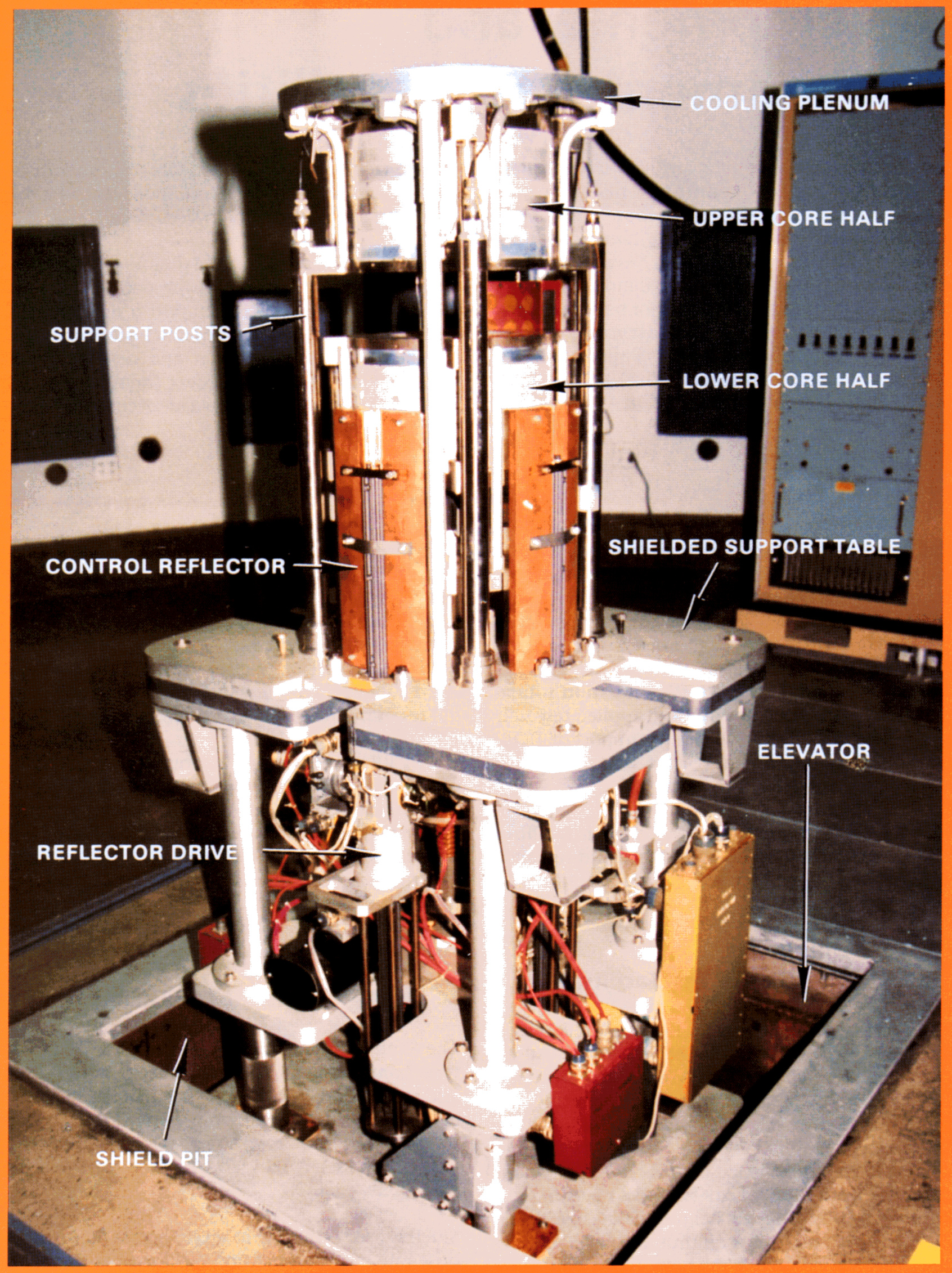

The Sandia Pulse Reactor III (SPR III) was designed and constructed by Sandia. 


\section{SPR III Reactor Test Facility}

The Sandia Pulse Reactor III (SPR III) is a fast-burst reactor that is bare-metal and reflector controlled. It has a 17-cm- (7-in.-) diameter central irradiation cavity, about $35 \mathrm{~cm}$ (14-in.) long. It is used primarily to meet high-neutron-fluence or pulsed highdose requirements in the testing of electronic subsystems and components. Operating conditions include steady-state power up to $10 \mathrm{~kW}$ (neutron flux of $5 \times 10^{11} \mathrm{n} /\left(\mathrm{cm}^{2} \bullet \mathrm{s}\right)$, and pulses to about 100,000 MW, FWHM of $76 \mu \mathrm{s}$.

The reactor can be used for testing fuels and electronic parts, in particular for survivability under normal and accident conditions.

\section{Gamma Irradiation Facility}

The Gamma Irradiation Facility (GIF) consists of two adjoining radiation cells situated over a 6-m (19-ft) deep pool of demineralized water. The north cell contains a cobalt- 60 source array with a strength of about 95 kilocuries and a cesium-137 source with a strength of approximately 142 kilocuries. The south cell contains a High-Intensity Adjustable Cobalt Array (HIACA) and the steam test facility.
The HIACA contains about 119 kilocuries of cobalt60 and the steam facility (designed for simultaneous reactor accidents tests in conjunction with the HIACA) has a working pressure of $1.5 \mathrm{MPa}(200$ psig).

The GIF can be used for testing critical reactor mechanisms (control drives, electronic sensors, etc.) in a large gamma flux representative of that generated by a space nuclear reactor.

\section{Saturn X-Ray Irradiation Facility}

Saturn uses pulsed power technology to produce a large-area X-ray source. Saturn can be used for subsystem and system testing. It can produce an x-ray environment of 150 krads peak dose (30-ms pulsewidth), $5.0 \times 10^{12} \mathrm{krads} / \mathrm{s}$ peak dose rate (30nanosecond [ns] pulsewidth), 500- $\mathrm{cm}^{2}\left(77-\mathrm{in}^{2}\right)$ exposure area (50\% falloff) (at lower fluence levels, an area up to $10,000 \mathrm{~cm}^{2}\left[1550-\mathrm{in}^{2}\right]$ is available), and a 15 - to $30-n s$ radiation pulsewidth (FWHM).

Saturn can be used to test electronic components to determine their sensitivity to $\mathrm{x}$-rays representative of solar exposure.

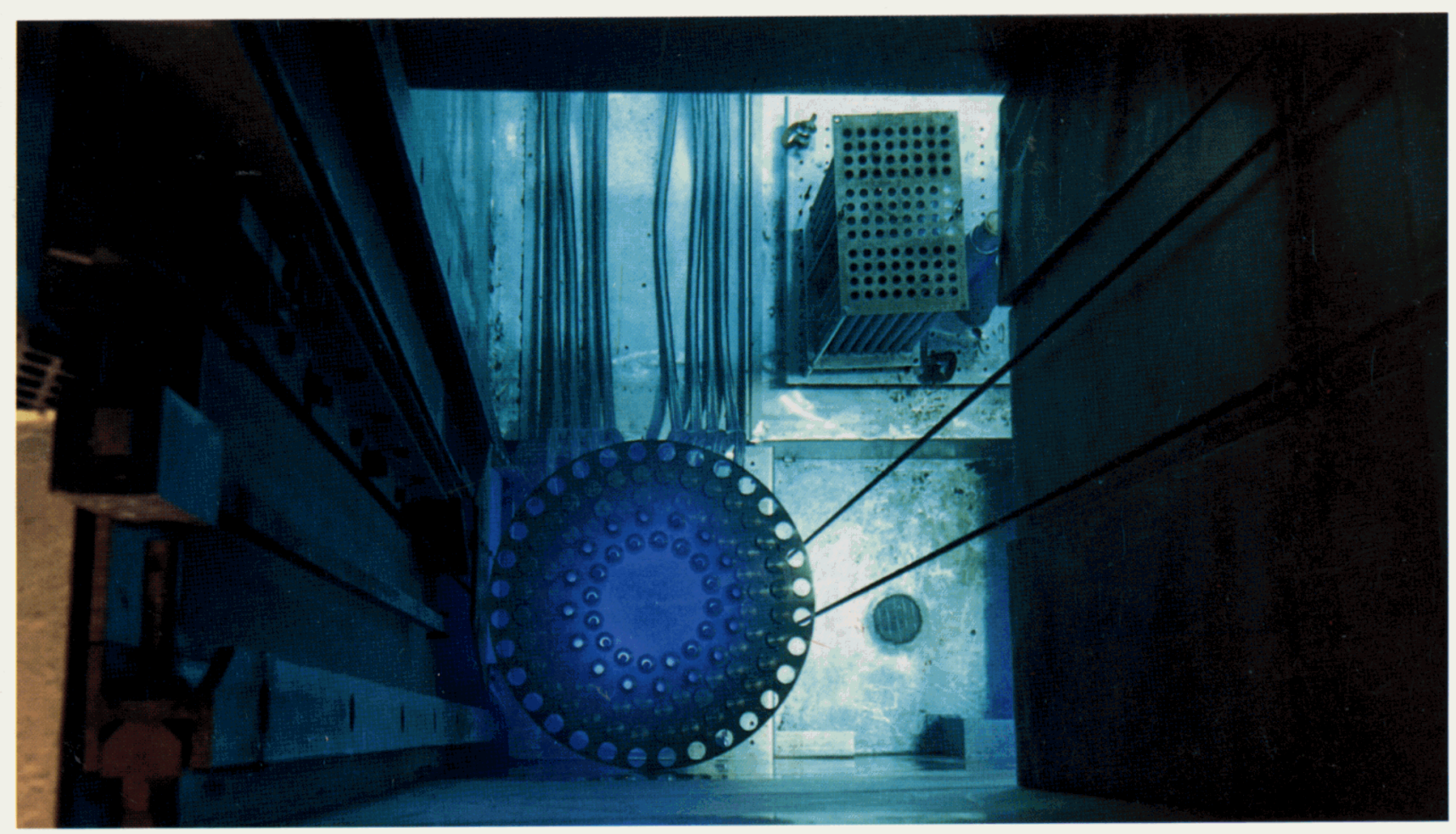

Stored cobalt sources in the north cell of the Gamma Irradiation Facility. 


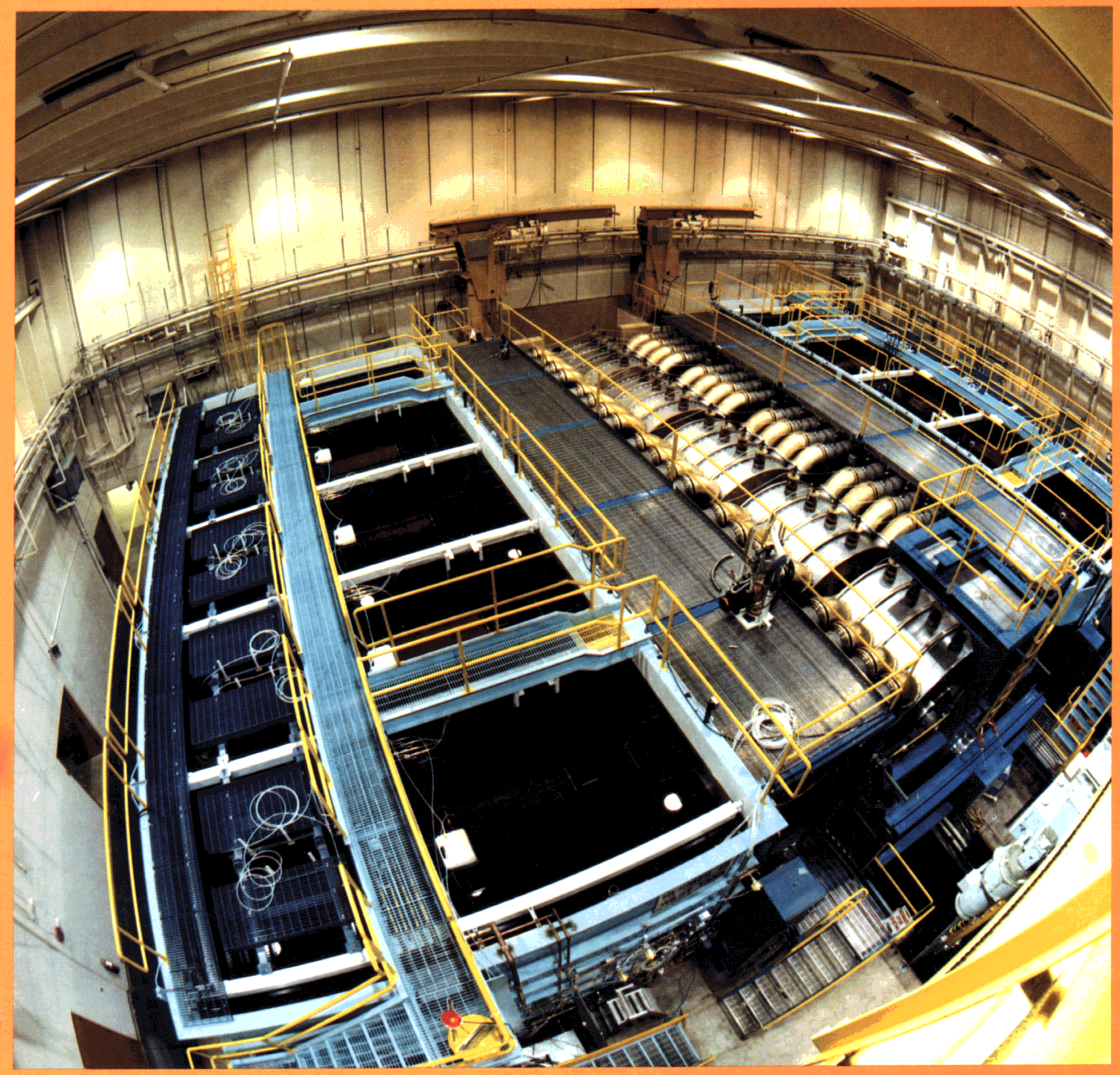

The Hermes III gamma-ray simulator was designed by Sandia. 


\section{Hermes III}

Hermes III is a state-of-the-art, high-energy linear induction accelerator with a bremsstrahlung gammaray converter.

It is the nation's most powerful gamma-ray machine designed to produce ultra-short pulses of intense high-energy radiation from $2.2 \times 10^{7}-\mathrm{V}$ bursts of electrical energy. It takes advantage of short-pulse, low-inductance, pulsed power technology to provide dose-rate area products that have not been previously available. Projected gamma-ray peak dose of 100 krads, peak dose rate of $5.0 \times 10^{12}$ rads $/ \mathrm{s}$, exposure area (50\% falloff) of $500 \mathrm{~cm}^{2}\left[77 \mathrm{in}^{2}\right]$, and radiation pulsewidth (FWHM) of 20 ns are available.

Hermes can be used to test electronic components to determine their sensitivity to high-energy gammas.

\section{Hot Cell Facility}

The Hot Cell Facility (HCF) provides means of handling and examining radioactive materials from the Sandia reactors and reactor experiments. The facility is comprised of three laboratories: the hot cell laboratory, the glove-box laboratory, and the analytical laboratory. The hot cell laboratory is a concrete shielded area containing three steel containment boxes and a staging area. The glove-box laboratory contains ten glove-boxes with high purity environments. The analytical laboratory provides for analysis and determination of elemental composition of metallurgical and radioactive material samples. It includes metallurgical sample preparation capability for metallic and ceramic materials that incorporates ion milling and etching, metal and carbon coating, and a Leitz remote metallographic microscope; optical microscopy and photomicroscopy by means of a free standing Wild M400 stereo microscope and a Zeiss Ultraphot II microscope; scanning electron microscope with both computer automated wavelength and energy-dispersive analytical capabilities; gas analysis using quadrupole mass spectrometry; x-ray diffractometry; limited wet chemical analysis; and leak detection equipment for detecting seal integrity in experiment packages.

\section{LICA Co-60 Irradiator}

The Low Intensity Cobalt Array (LICA) facility can simultaneously irradiate and heat (to $400^{\circ} \mathrm{C}\left[750^{\circ} \mathrm{F}\right]$ ) parts or materials. Dose rates range from about 5 $\mathrm{krad} /$ hour to about $1 \mathrm{Mrad} /$ hour. Unheated canisters are $12.7-\mathrm{cm}$ (5-in.) ID by $30.5 \mathrm{~cm}$ (12 in.) long; heated canisters are $7.6-\mathrm{cm}$ (3-in.) ID by $25.4 \mathrm{~cm}(10$ in.) long. There is also a 61-cm- (24-in.-) ID by 61cm- (24-in.-) long irradiator.

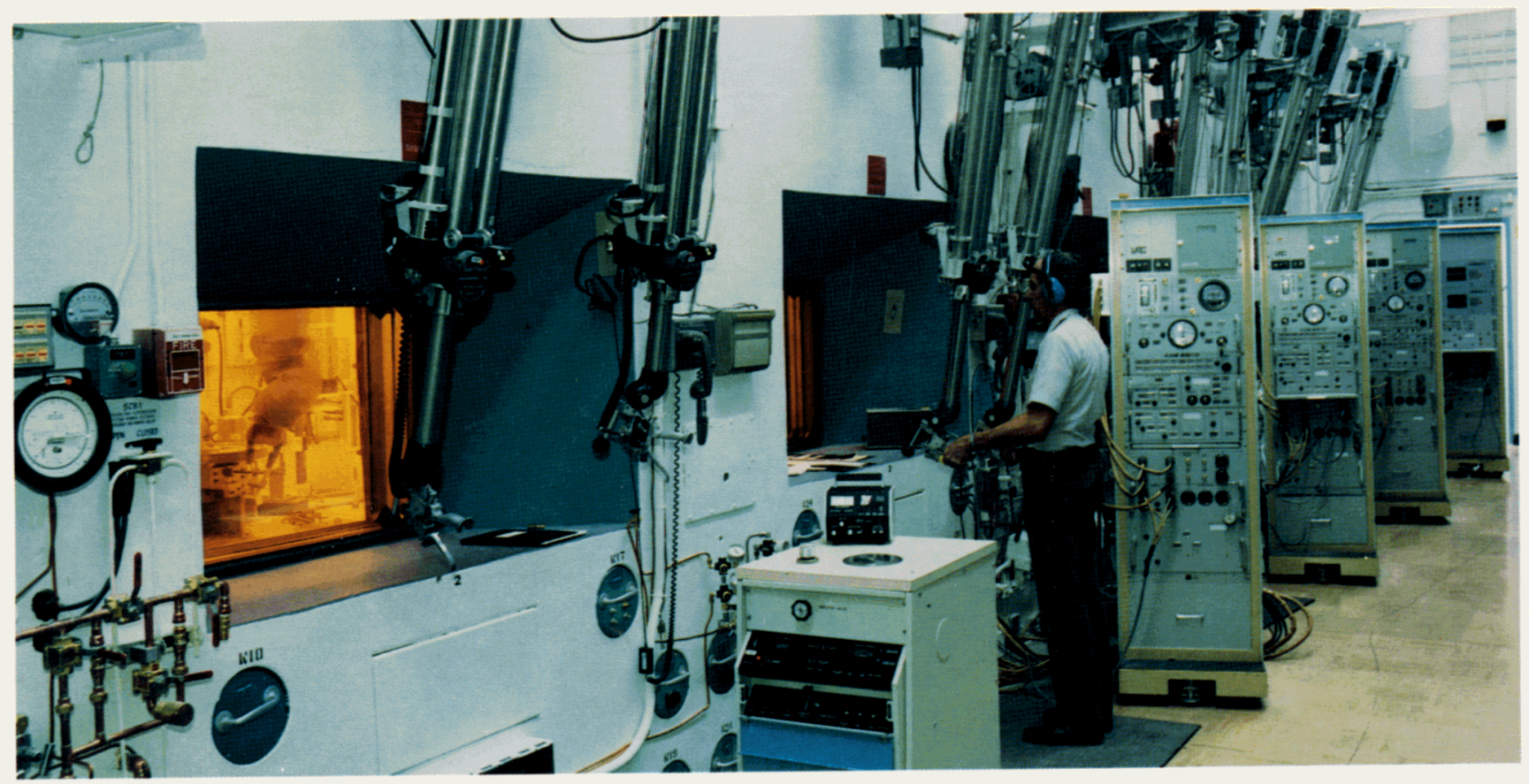

Remote manipulation of experiments in containment box at Sandia's Hot Cell Facility. 


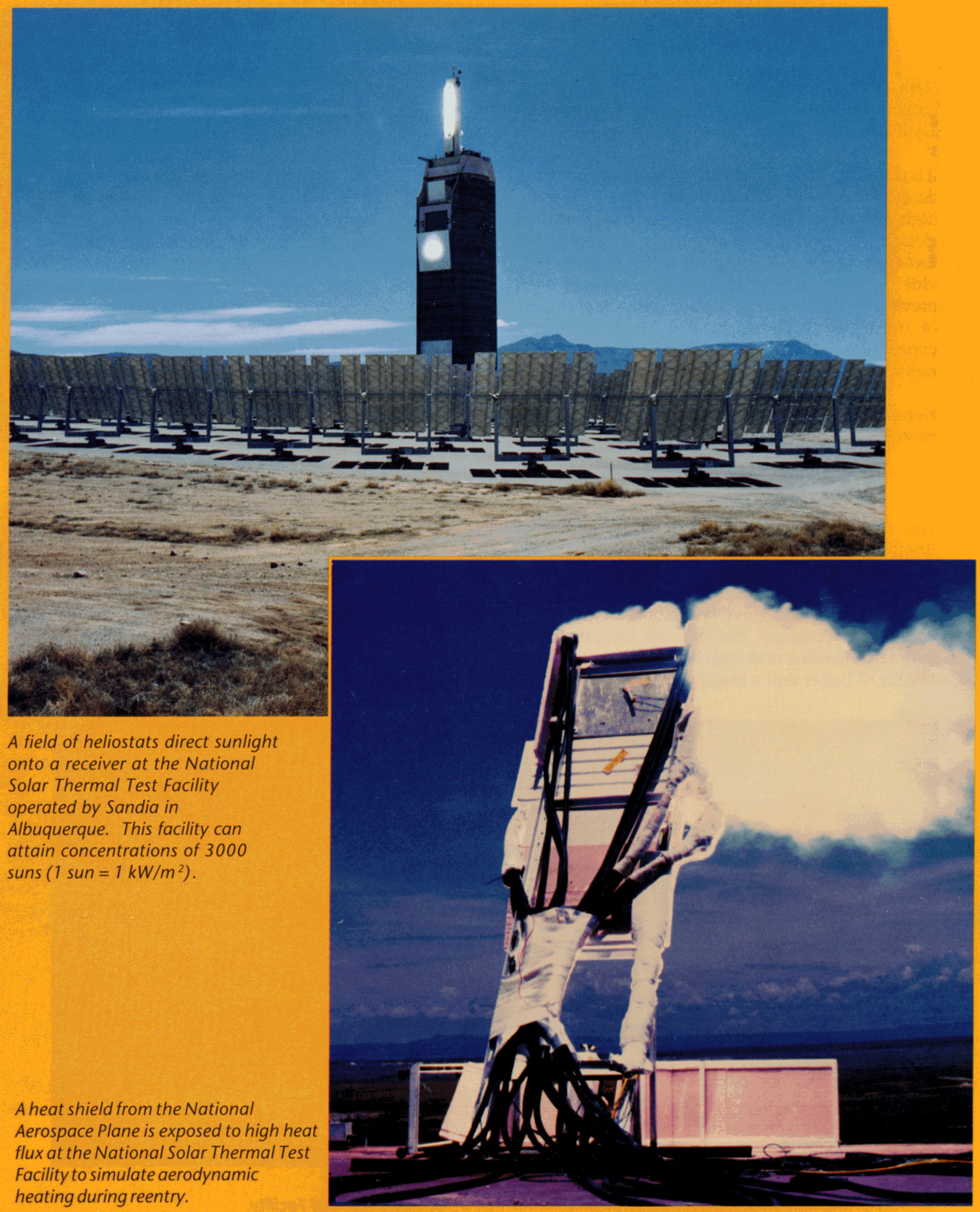




\section{Environmental Test Facilities}

\section{Electromagnetic Environments}

The Electromagnetic Environments Simulator (EMES) test facility is used to investigate the effects of electromagnetic environments on electrical systems and components. It is capable of subjecting

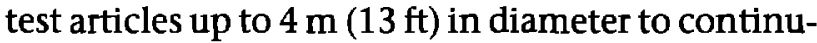
ous-wave electric fields over the frequency range of $4 \mathrm{MHz}$ to $10 \mathrm{GHz}$ and electromagnetic pulse fields of $100,000 \mathrm{~V} / \mathrm{m}$.

The EMES can be used to simulate the effects of the Van Allen radiation belts on actual reactor control components.

\section{Climatic Test Facilities}

The climatic test facilities consist of a large number of test chambers and ovens located in Areas I and III in Albuquerque and also in Livermore. Exposures are made to combinations of temperature, relative humidity, and altitude (i.e., barometric pressure), as well as salt-fog and rain. A $0.82-\mathrm{m}^{3}\left(29-\mathrm{ft}^{3}\right)$ chamber allows exposures of large components to a temperature range of $-73^{\circ} \mathrm{C}$ to $177^{\circ} \mathrm{C}\left(-100^{\circ} \mathrm{F}\right.$ to $\left.350^{\circ} \mathrm{F}\right)$. A smaller chamber $\left(0.04 \mathrm{~m}^{3}\left[1.5 \mathrm{ft}^{3}\right]\right)$ can be heated from ambient temperature to $1316^{\circ} \mathrm{C}\left(2400^{\circ} \mathrm{F}\right)$. Relative humidity ranges from 5 to $98 \%$, depending on temperature. Barometric pressures can simulate

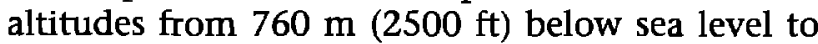
$76,000 \mathrm{~m}(250,000 \mathrm{ft})$ above sea level. It is also possible to test large objects in a 3- x 3- x 11-m (10x 10- x 33-ft) chamber.

The climatic test facilities can be used for testing of critical instrumentation and control components and reactor systems.

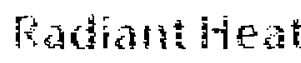

\section{Radiant Heat Facility}

Sandia's radiant heat facility can simulate a wide range of high-temperature environments and/or heat fluxes (e.g., reentry heating, accidental fires, concentrated solar energy, and nuclear environments) and record the responses of the test items to these environments. Test objects up to $23 \mathrm{~m}^{2}(250$ $\mathrm{ft}^{2}$ ) can be subjected to feedback-controlled temperatures greater than $2200^{\circ} \mathrm{C}\left(3992^{\circ} \mathrm{F}\right)$. Arrays of quartz lamps are used to supply heat fluxes up to 1.5 $\mathrm{MW} / \mathrm{m}^{2}$ peak and $0.8 \mathrm{MW} / \mathrm{m}^{2}$ sustained. Up to 4 $\mathrm{MW} / \mathrm{m}^{2}$ can be obtained with graphite bars. The facility has a 6-MW AC and a 5-MW DC power control system. The AC system can provide up to 18 independent heating zones. A bunker is available for testing explosive hardware or components up to the equivalent of $18 \mathrm{~kg}$ of TNT. Instrumentation includes thermocouples, heat flux sensors and optical pyrometers; infrared video; flash or real time radiography; and high-speed film. Special instrumentation systems such as high-temperature strain gages or special heat flux transducers can be developed.

The radiant heat facilities can subject critical Space Exploration Initiative (SEI) reactor control mecha- nisms to reentry heat environments. Radiant heat facilities can provide simulated launch pad abort fire environments.

\section{National Solar Thermal Test Facility}

The 5-MW National Solar Thermal Test Facility (NSTTF) employs a field of 222 individually guided heliostats to redirect sunlight onto a receiver at concentrations up to 3000 suns $\left(1\right.$ sun $\left.=1 \mathrm{~kW} / \mathrm{m}^{2}\right)$. Although constructed to support development of advanced solar power technology, the NSTTF has exposed a wide variety of other targets to intense heat fluxes. These targets have ranged in size from small material samples to a full-scale cockpit/canopy system from a fighter/bomber. Smaller targets can be exposed to fluxes greater than $15 \mathrm{MW} / \mathrm{m}^{2}$ on one of the NSTTF's $11-\mathrm{m}$ - (33-ft-) diameter parabolic dishes or one of two solar furnaces. The NSTTF can focus intense heat fluxes on targets of interest to SEI systems developers to study the effects of highintensity radiation and aerodynamic heating of new SEI materials and components, photovoltaics, and power conversion systems. 


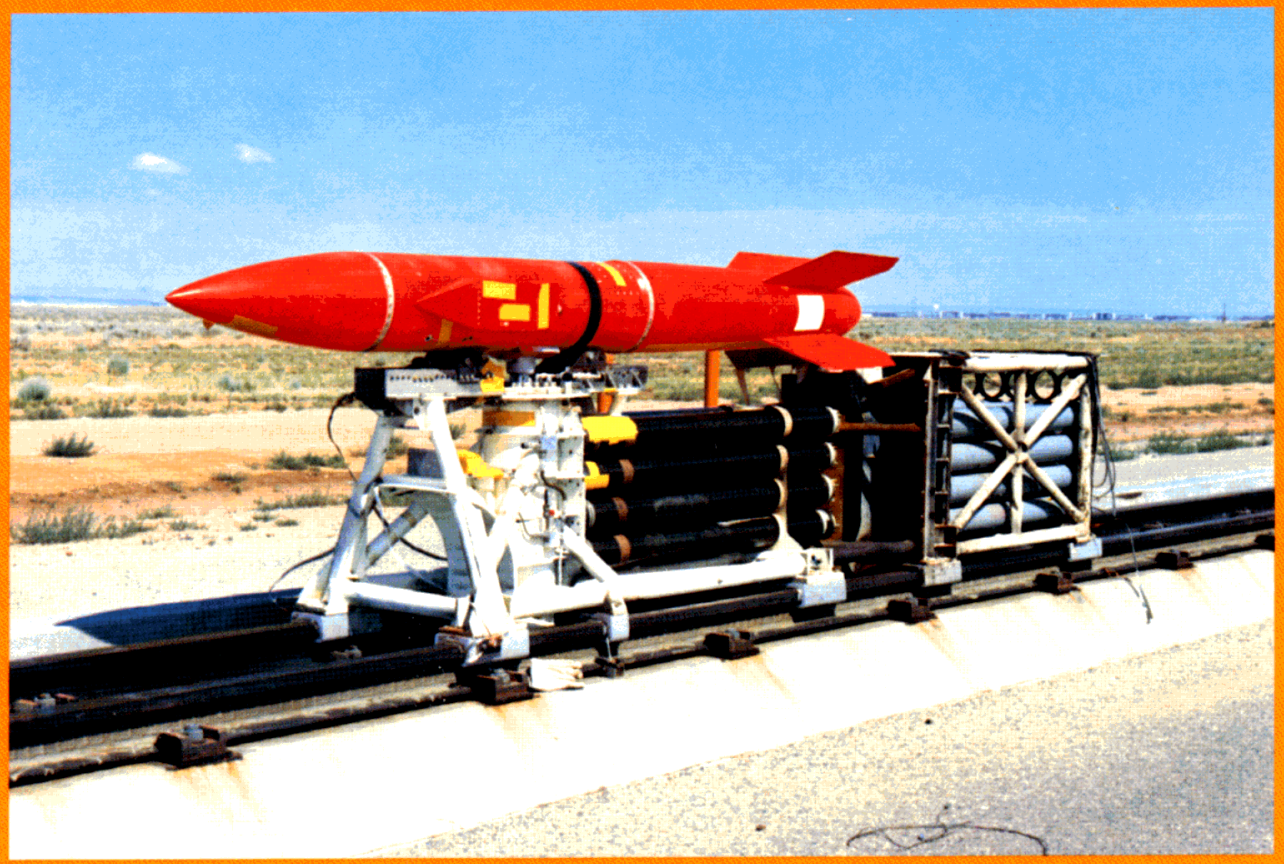

MK/B 61 shape on rocket sled for parachute system test. The rocket sled facility can also be used to study severe transportation accidents of nuclear material shipping containers.

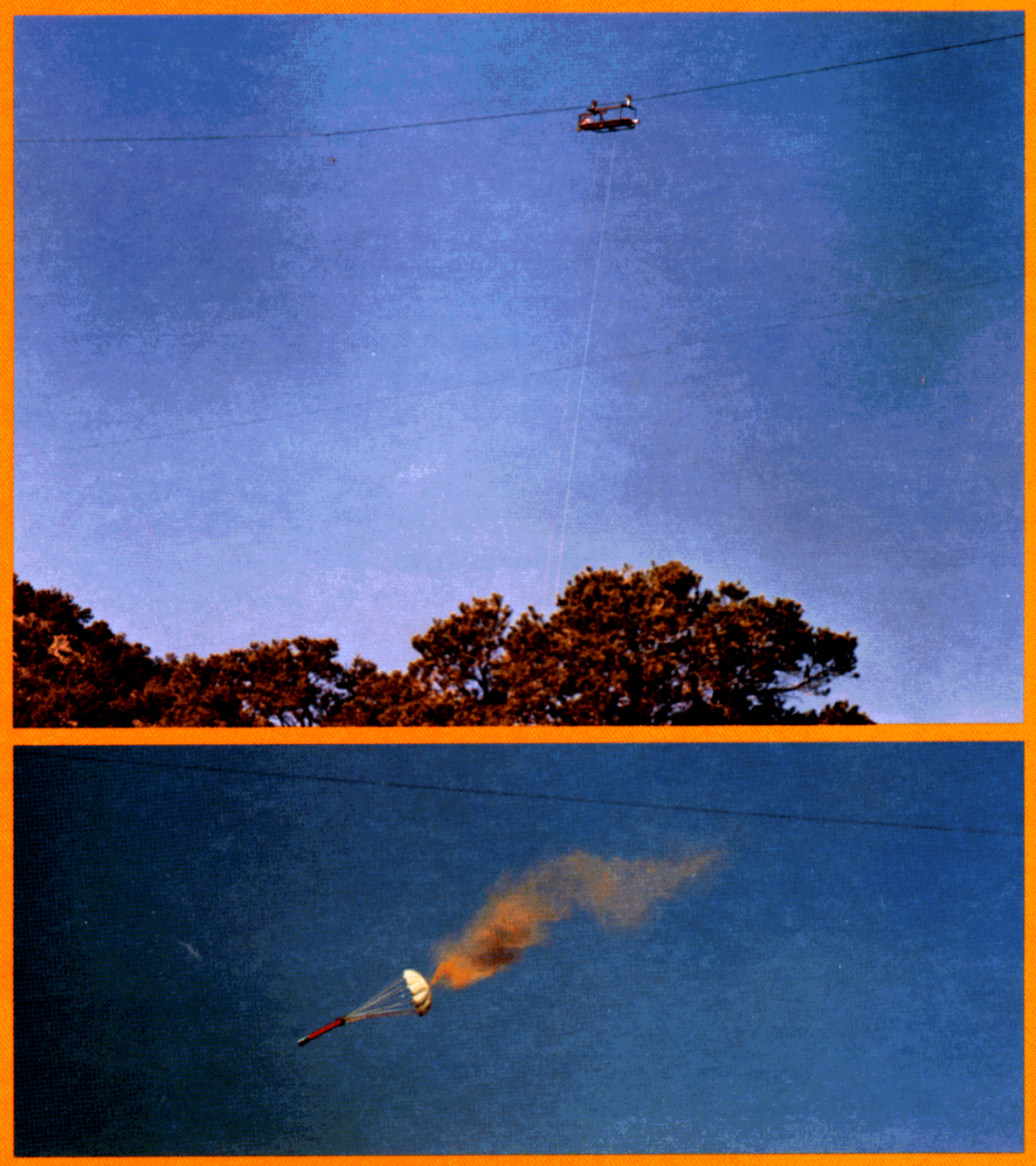

Sandia's aerial cable facility is capable of free-fall or rocket pull-down tests. Test vehicle on aerial cable trolley (top) and in controlled descent (bottom) after release. 
Among past experiments conducted at the NSTTF were simulation of aerodynamic heating of reentry shields, radomes, and antenna arrays from missiles and the National Aerospace Plane; thermal exposure of nuclear power plant instrumentation to simulated accident conditions; exposure of photovoltaic arrays to concentrated sunlight; and evaluation of the nuclear thermal hardness of defense-related components and materials, including composite material samples exposed to thermal flux under simulated flight conditions in a windowed wind tunnel. Advantages of the NSTTF include the ability to produce a Glasstone-shape pulse having an energy spectrum comparable to the thermal output of a nuclear weapon ( $6000 \mathrm{~K}$ black body) and the ability to heat active radar and antenna systems without electrical or mechanical interference with transmitted signals. The NSTTF also has experience in power conversion systems, such as Stirling engines, and alkalimetal heat pipes, and has performed tests characterizing the performance of mirror facets for the solar dynamic power system for Space Station Freedom.

\section{Impact Testing}

\section{Water Impact Facility}

The Water Impact Facility (WIF) conducts waterentry related experiments in support of Sandia R\&D. Highly controlled tests are conducted on a manmade lake measuring $36.6 \times 57.3 \times 15.2 \mathrm{~m}(120 \times 188$ x $50 \mathrm{ft})$ deep. The lake is adjacent to a $9.4-\mathrm{m}(300-\mathrm{ft})$ tower and a nearby $4.3-\mathrm{m}-(14-\mathrm{ft}$-) diameter by $6.7 \mathrm{~m}$ (22-ft) deep tank with observation ports. The WIF is fully instrumented to allow measurements by accelerometer and high-speed motion pictures. Smallscale models (ordinarily 2.5 to $5.0 \mathrm{~cm}$ ( 1 to 2 in) in diameter, weighing 4.5 to $5.5 \mathrm{~kg}$ [10 to $12 \mathrm{lb}$ ]) are accelerated by air-powered guns to impact velocities up to $213 \mathrm{~m} / \mathrm{s}(700 \mathrm{ft} / \mathrm{s})$; impact angles range from 15 to 90 degrees. Full-scale test articles up to $1360 \mathrm{~kg}$ ( $3000 \mathrm{lb})$ can be impacted into a $15-\mathrm{m}(50-\mathrm{ft})$ deep pond from a $91-\mathrm{m}(300-\mathrm{ft})$ drop tower at impact velocities up to $150 \mathrm{~m} / \mathrm{s}(500 \mathrm{ft} / \mathrm{s})$.

This facility can be used to perform water impact and submersion tests for nuclear and other safety considerations involving full-scale mock-ups of reactor systems.

\section{Rocket Sled Facility}

The rocket sled facility has two tracks, $3000 \mathrm{~m}$

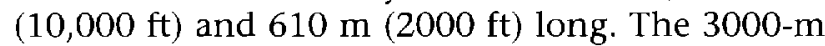
$(10,000-\mathrm{ft})$ long track is capable of accelerating 227 $\mathrm{kg}(500-\mathrm{lb})$ articles to a velocity of $1830 \mathrm{~m} / \mathrm{s}(6000 \mathrm{ft} /$ s); it can also accelerate $136,000-\mathrm{kg}(300,000-\mathrm{lb})$ articles to $30 \mathrm{~m} / \mathrm{s}(100 \mathrm{ft} / \mathrm{s})$. Test articles can be impacted on stationary targets or can be pneumatically ejected (for payloads up to $1140 \mathrm{~kg}$ ( 2500 $\mathrm{lb})$ to altitudes of $76 \mathrm{~m}(250 \mathrm{ft})$. We can also perform ejection tests of $45-\mathrm{kg}$ (100-lb) payloads to $945 \mathrm{~m} / \mathrm{s}$ $(3100 \mathrm{ft} / \mathrm{s})$ with an altitude of $30 \mathrm{~m}(100 \mathrm{ft})$ or a recoverable sled test up to $915 \mathrm{~m} / \mathrm{s}(3000 \mathrm{ft} / \mathrm{s})$. The $610-\mathrm{m}(2000-\mathrm{ft})$ sled track is used to study severe accidents for containers carrying nuclear materials, or for missile impacts.

Instrumentation includes a laser tracking system and a newly installed schlieren photography system for visualizing shockwaves.

This facility can be used to investigate crash consequences for postulated severe accidents, especially during launch pad take-off. Tests may be performed for SEI reactor mock-up impact studies to verify that a nuclear critical geometry will not occur.

\section{Aerial Cable Facility}

The aerial cable facility is comprised of steel cables $3.18 \mathrm{~cm}$ (1.25 in.) in diameter stretched between mountain peaks (maximum height of $183 \mathrm{~m}$ [ 600 $\mathrm{ft}$ )) from which free-drop payloads as heavy as 1360 $\mathrm{kg}(3000 \mathrm{lb})$ can be dropped from heights as high as $183 \mathrm{~m}(600 \mathrm{ft})$, yielding impact velocities up to 58 $\mathrm{m} / \mathrm{s}(190 \mathrm{ft} / \mathrm{s})$. Higher impact velocities, up to 305 $\mathrm{m} / \mathrm{s}(1000 \mathrm{ft} / \mathrm{s})$ can be achieved using a rocket pulldown technique. The test site is qualified for the detonation of $4550 \mathrm{~kg}(10,000 \mathrm{lb})$ of TNT equivalent.

The aerial cable facility can be used for impact testing of reactor mock-ups to identify configuration changes (due to launch pad accidents, etc.) that are of concern with respect to nuclear safety.

\section{Hyper Velocity Launch Facility}

The Hyper Velocity Launch Facility (HVLF) is a new facility. It can be used to simulate a space debris environment where test articles can be evaluated for 


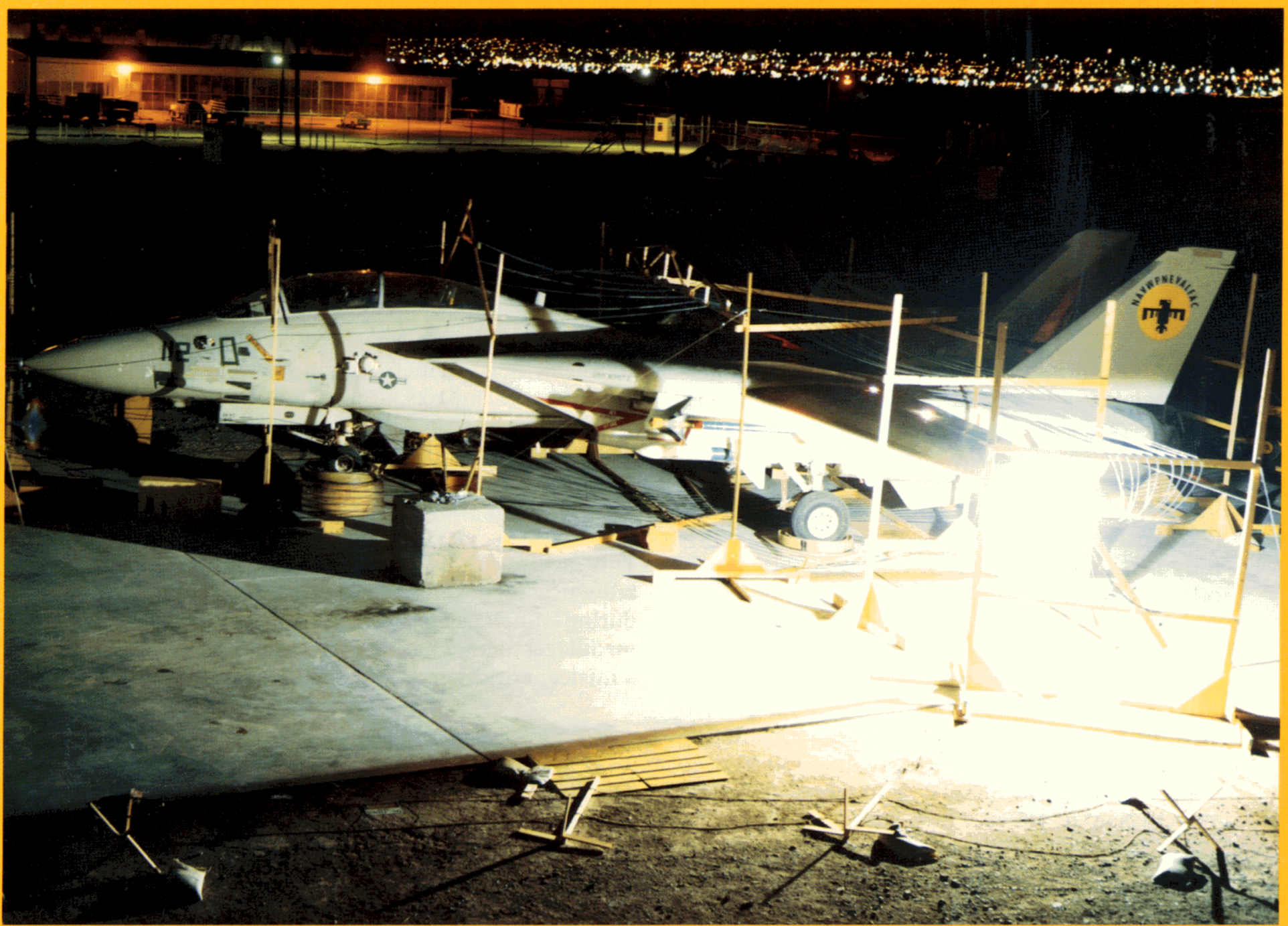

A Navy F-14A is subjected to a dramatic night test at the Sandia Lightning Simulator Facility. The test series was designed to determine how a lightning strike affects the sensitive computer electronics on this aircraft. The 80,000-amp charge entered through the nose and exited via the wing tip (the bright flash). The spark lasted for one second and was the sole light source for the picture. 
their resistance to damage resulting from space debris impact. The HVLF uses a two-stage gun (a powder first stage and a hydrogen second stage) to impact a projectile onto a target plate. The momentum transfer from the projectile to the target results in a flier plate of mass up to $1 \mathrm{~g}$ accelerated to velocities up to $10 \mathrm{~km} / \mathrm{s}$. Future modifications will increase the velocity to 12 to $14 \mathrm{~km} / \mathrm{s}$.

Development and evaluation of debris shield designs and other structures for NASA's Space Station Freedom are being assisted through the use of the HVLF. Tests have been carried out at an impact velocity of $37,000 \mathrm{~km} / \mathrm{hr}(23,000 \mathrm{mi} / \mathrm{hr})$, the highest velocity yet attained in the U.S. for gram-sized projectiles. Improved understanding of impact damage mechanisms obtained from this type of study is expected to provide guidelines for debris shield designs.

The HVLF can be used to assess survivability of critical reactor components, proposed new vehicle materials, new surface coatings and shields, etc., within a space debris environment.

\section{Horizontal Actuator - Shock Loading}

This facility consists of a 45.7-cm (18-in.) pneumatic actuator with a $28-\mathrm{m}$ - (92-ft-) long track. The actuator uses high-pressure gases under controlled application to transmit force and motion through a piston/ thrust column in contact with an external load. Maximum force capability of the actuator is 700,000 lb (3.1 MN). The test item, mounted on a sled, can be accelerated in direct contact with the thrust column or can be propelled down the track and impacted into a target. Multiple sleds can be used to obtain special pulse shapes. The $45.7-\mathrm{cm}$ (18-in.) actuator is the largest of an array of accelerated drop tables, actuators, and air guns used to create shock environments. A capability exists for qualifying spacecraft components to pyrotechnic shock environments without the use of explosives. This technique is known as resonant fixture shock testing.

\section{Measurement Standards Facilities}

The Measurement Standards Department operates a Primary Standards Laboratory (PSL) and provides a metrology program to insure accurate measurements for the DOE nuclear weapons complex as well as for other DOE programs, government agencies, industry, and universities. We develop and maintain primary standards traceable to national standards and calibrate and certify customer reference standards. We provide technical guidance, support and consultation; develop precision measurement techniques; provide oversight including technical surveys and measurements audits; and anticipate future needs. A Memorandum of Understanding (MOU) between DOE/Albuquerque and Sandia directs us to operate a PSL and a system-wide metrology program for the nuclear weapons complex.

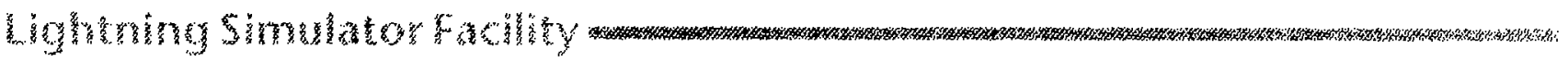

The lightning simulator duplicates the characteristics of severe natural lightning currents in a controlled laboratory environment, allowing experimental verification of lightning safety on equipment ranging from components to entire systems as well as outdoor tests (for example, on aircraft or rockets); the facility will produce up to 4 strokes per flash (peak currents of $250,000 \mathrm{amps}(\mathrm{A})$ with rise times of 1 to $5 \mu \mathrm{s}$; continuing current up to $1000 \mathrm{~A}$ ).

The lightning simulator can be used without modification to test articles to determine if positive design features have been incorporated, especially with respect to nuclear safety. 


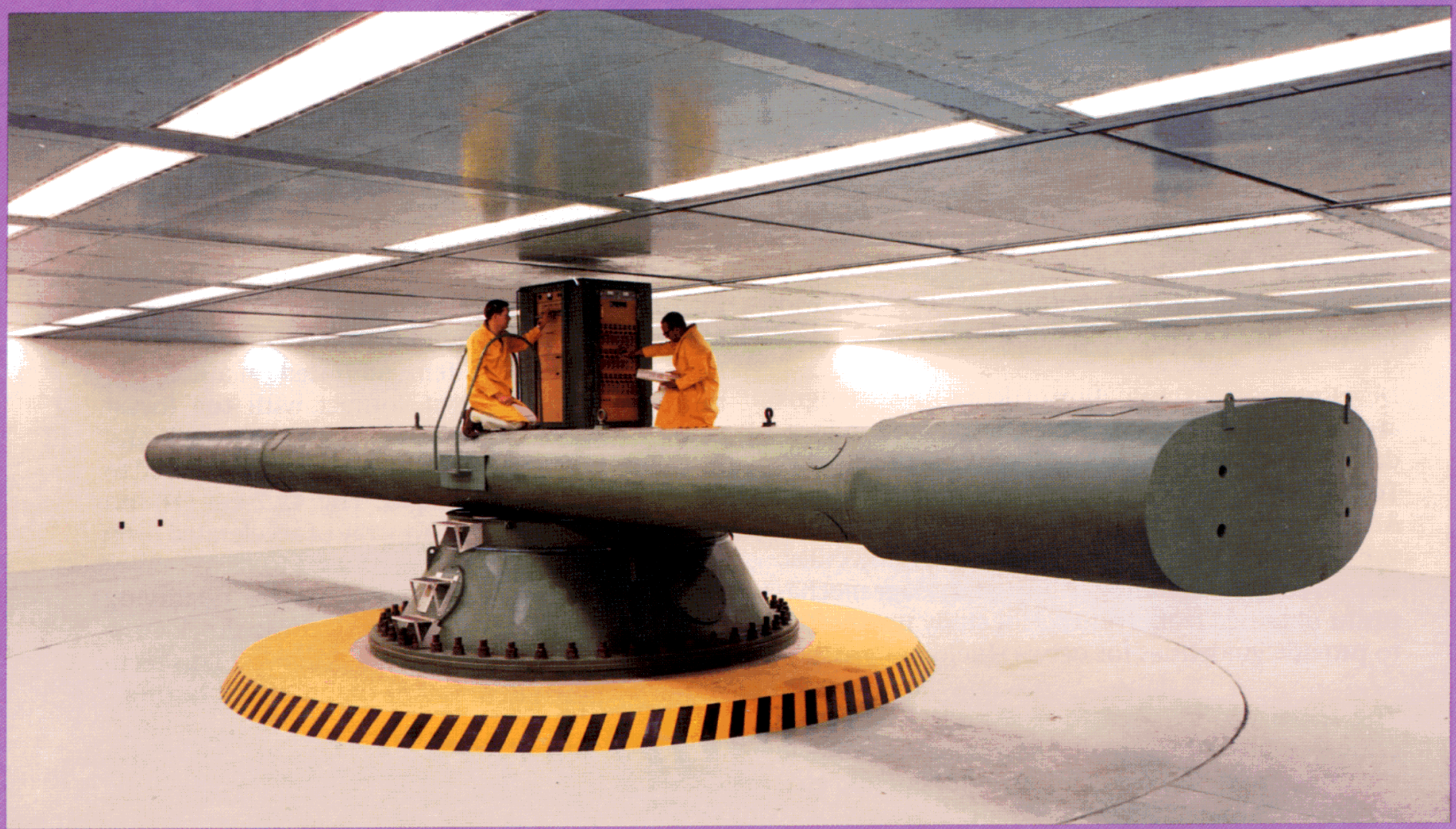

The largest centrifuge in the free world (8.8-m [29-ft] radius) is in the Sandia Centrifuge Facility in Albuquerque, NM.

Remotely sprayed high explosive is detonated by a flash of light at Sandia's Light-Initiated HighExplosive (LIHE) Facility.

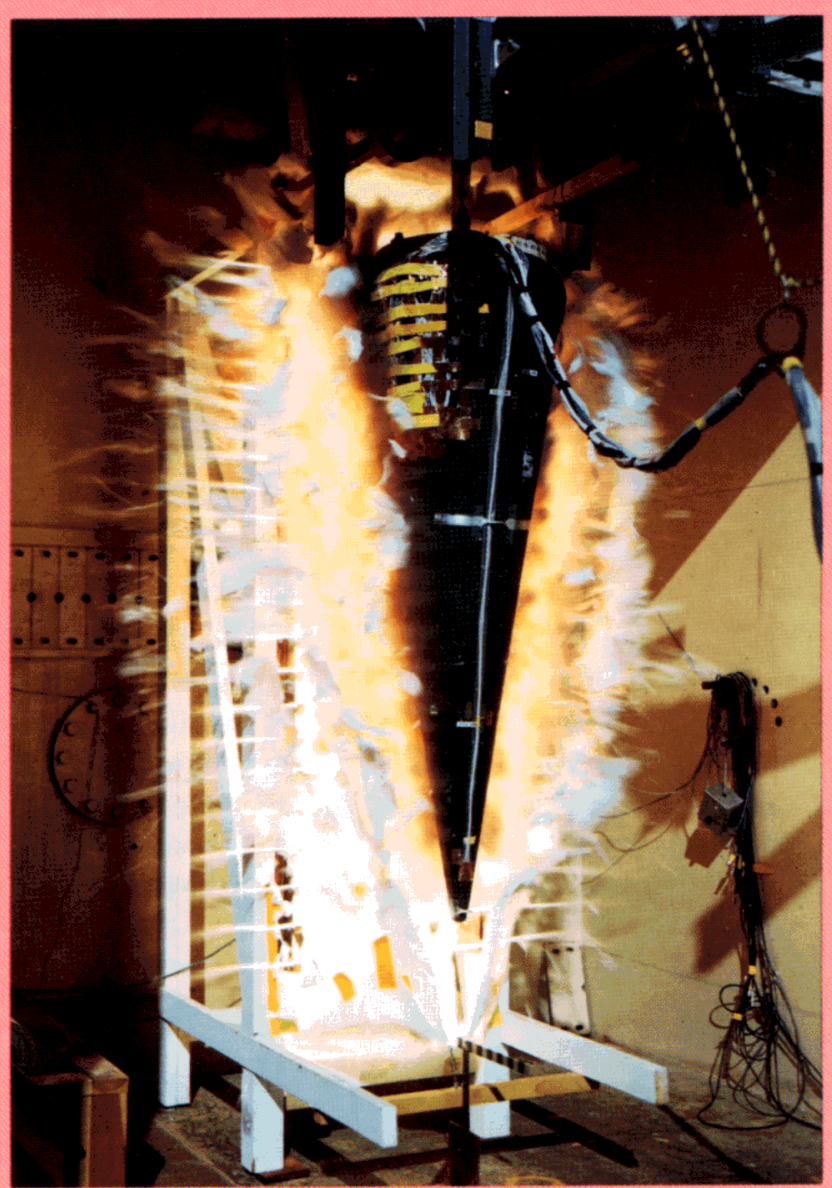




\section{Centrifuge Facilities}

The centrifuge facilities are located in Areas I and III in Albuquerque, and at Livermore. The Area I facility includes 6 centrifuges: $0.76-$ and $1.83-\mathrm{m}-(2.5-$ and 6-ft-) radius centrifuges; an inertial-grade, variable radius, reversible machine; a spinner centrifuge; and two high-onset centrifuges. The $0.76-\mathrm{m}$ (2.5-ft-) radius and inertial-grade centrifuges have temperature capabilities in the range of $-73^{\circ} \mathrm{C}$ to $93^{\circ} \mathrm{C}\left(-100^{\circ} \mathrm{F}\right.$ to $\left.200^{\circ} \mathrm{F}\right)$. The high-onset centrifuges bring small items to peak speed in a minimum of time. The Livermore facility is capable of spinning a $350-\mathrm{kg}$ test item up to $40,000 \mathrm{rpm}$.

The Area III facility has a $10.7-\mathrm{m}-$ (35-ft-) radius outdoor centrifuge and a $8.8-\mathrm{m}$ - (29-ft-) radius indoor, below-grade centrifuge. The 10.7-m (35-ft) facility can generate a $2 \mathrm{~g}-\mathrm{MN}$ dynamic load and a 4530-kg (10,000-lb) static load. It has a 29-m- (95-ft-) diameter enclosure with a $1.8-\mathrm{m}-(6-\mathrm{ft}$-) wide payload bay. The 8.8-m (29-ft) facility has a 7.3 g-MN dynamic capacity, largest of any machine in the U.S. It has the capability to accelerate $7300 \mathrm{~kg}(16,000$ lb) to $100 \mathrm{~g}$ 's, or lighter loads to nearly $300 \mathrm{~g}$ 's. It has a $24-\mathrm{m}-(80-\mathrm{ft}-)$ diameter by $3.7-\mathrm{m}-(12-\mathrm{ft}-)$ high enclosure, with a $1.8-\mathrm{m}$ - (6-ft-) wide payload bay.

The centrifuges available at Sandia include the largest centrifuge in the free world. Their capacities will enable testing of both small and large components (such as reactor central drive mechanisms) for g-loads that would be anticipated during space missions.

\section{Explosive and Blast Testing/Thunder Range}

Materials and components can be tested for resistance to blast waves, explosively propelled flier plates, and surface impulse loading. Blast testing is performed with shock tubes (overpressures from 6.9 $\mathrm{kPa}$ to $13.8 \mathrm{MPa}$ (1 to $2000 \mathrm{psi}$ ) that can direct a shock wave on structures such as buildings or reentry

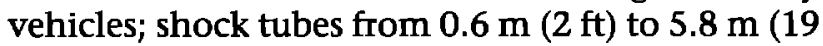
$\mathrm{ft}$ ) in diameter are available. Flier plates can be impacted on stationary targets at velocities up to
$4200 \mathrm{~m} / \mathrm{s}(13,800 \mathrm{ft} / \mathrm{s})$. Surface impulse loading is done with the use of light-sensitive explosives that are remotely spray-deposited on the test article surface.

These facilities can be used to test critical SEI components for their response to large impulsive loadings and component deformations resulting from severe accidents.

\section{high hin}

A technique developed at Sandia permits spraying of explosives onto complex surface shapes and detonating the explosives with a flash of light. The explosive is sprayed with a thickness distribution that is related to the local impulsive load to be simulated. Impulse levels may range from 100 to more than 30,000 taps ( 1 tap $=0.1$ Pa-s). Strain, acceleration, displacement, $x$-ray, high-speed photography, and impulse measurements are obtained. 


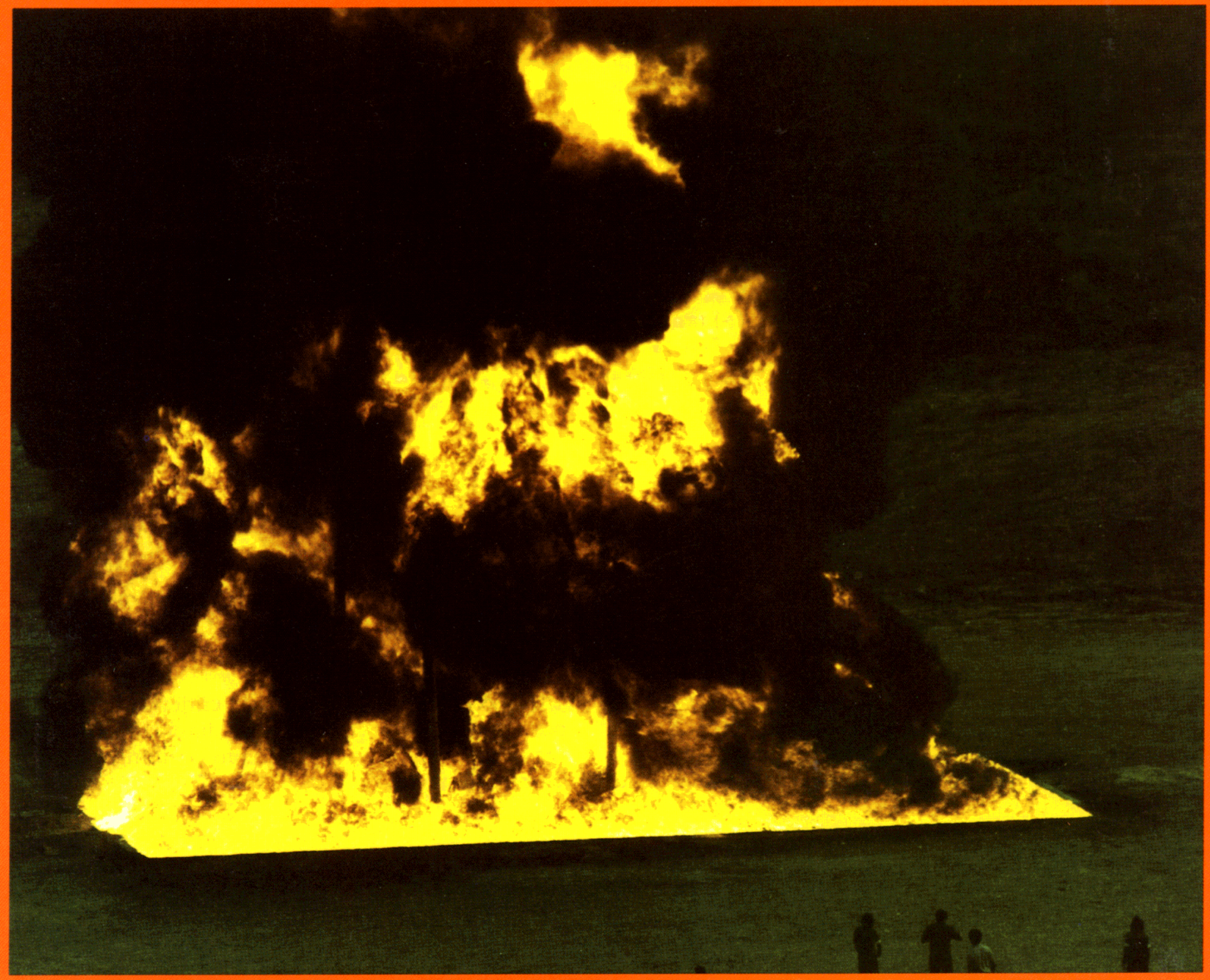

A fire test at the Lurance Canyon Burn Site. 


\section{Fire Test Facility/Lurance Canyon Burn Site}

The major components of this facility include two enclosed fire test facilities and several open pools. The two enclosed facilities shield the test setup from the wind and considerably reduce the visible emissions (soot). The smaller enclosed SWISH (Small WInd-SHielded) facility has a $1.8-\mathrm{m}-(6-\mathrm{ft}-)$ diameter pool; the larger SMERF (SMoke Emissions Reduction Facility) facility has a $3-\mathrm{m}$ (10-ft) square pool. Open pools range from $9 \times 18 \mathrm{~m}(30 \times 60 \mathrm{ft})$, $6 \mathrm{~m}(20 \mathrm{ft})$ square, $3-\mathrm{m}(10-\mathrm{ft})$ in diameter, to $1.8 \mathrm{x}$ $5.5 \mathrm{~m}(6 \times 18 \mathrm{ft})$. There are extensive data acquisition capabilities, thermal instrumentation experience, and data reduction and analysis capabilities on site.
The unique SMERF facility is a wind-shielded 3-x 3-m (10-x 10-ft) pool with a 6- x 6- x 6-m (20- x 20- x 20-ft) test chamber. It eliminates the potential for adverse wind effects on open pool tests, has water-cooled walls for proper temperature in the flame zone, close-in diagnostics with flash or real-time radiography, and access from below the pool in to the flame zone. Solid propellant fires have been used to simulate missile handling or launch abort accidents.

The burn site can be used for full-scale fire testing of SEI reactor mock-ups to determine temperature response attributable to severe accidents (e.g., launch pad accidents) and possibly operational environments.

\section{Vibration and Acoustic Testing Facilities}

These facilities are used to conduct vibration, modal, and acoustic tests on components, subsystems, and entire systems to determine how items will respond to controlled vibrations and shocks in order to define failure levels, to prove system integrity, and to develop and test theoretical models. Frequencies from near 0 to $4000 \mathrm{~Hz}$ can be supplied with a variety of machines from 4-N (1-lb) force output to $180-\mathrm{kN}(40,000-\mathrm{lb})$ force-output hydraulic shakers. Numerous environments can be simulated including: seismic transients (shock), sine, and random. Several control strategies are also available using modern digital control including: single point control, multiple input control, averaging, limit- ing, and extremal control. Acoustic tests are run in a $450-\mathrm{m}^{3}\left(16,000-\mathrm{ft}^{3}\right)$ reverberant chamber to levels of $154 \mathrm{~dB}$. Combined environments which can be produced include: vibration/temperature $\left(-54^{\circ} \mathrm{C}\right.$ to $121^{\circ} \mathrm{C}\left[-65^{\circ} \mathrm{F}\right.$ to $\left.\left.250^{\circ} \mathrm{F}\right]\right)$; vibration/steady-state-acceleration (50-g vibration, 50-g acceleration), and vibration/acoustic. Tests of units containing hazardous material (e.g., explosives) can also be run.

These facilities can be used to obtain modes of vibration of structures used for SEI missions. The dynamic loads on critical SEI components can be determined for various vibration inputs.

\section{Fuel-Air Combustion - Site 9920}

This site incorporates a number of facilities for investigating fuel-air combustion. Fuels studied to date include gaseous hydrogen, and gaseous and liquid hydrocarbons. Research and testing have been conducted in support of nuclear reactor safety programs and weapons development. Facilities include several combustion chambers of about $5 \mathrm{~m}^{3}$ $\left(178 \mathrm{ft}^{3}\right)$ in volume, the world's largest heated detonation tube (to $\sim 110^{\circ} \mathrm{C}\left[230^{\circ} \mathrm{F}\right]$ ) $13.1 \mathrm{~m}[43 \mathrm{ft}]$ long and $43 \mathrm{~cm}$ [7 in.] diameter, a reinforced concrete channel 2.4 × $1.8 \times 30.5$ m (7.9 x 5.9 x $100 \mathrm{ft})$ long (used for flame acceleration and deflagration-to- detonation transition studies as functions of gas composition, degree of venting, and obstacle configuration), and apparatus for studying hot hydrogen flame jets (from 1200 to $2000 \mathrm{~K}$ ). Unconfined combustion tests have been performed up to $45 \mathrm{~kg}$ (100 lb) TNT equivalent.

Hydrogen combustion experiments have been conducted for a variety of LWR and HWR reactor safety programs, for resolving some Space Shuttle launch safety questions, and for fuel-air explosive weapons development and testing. 

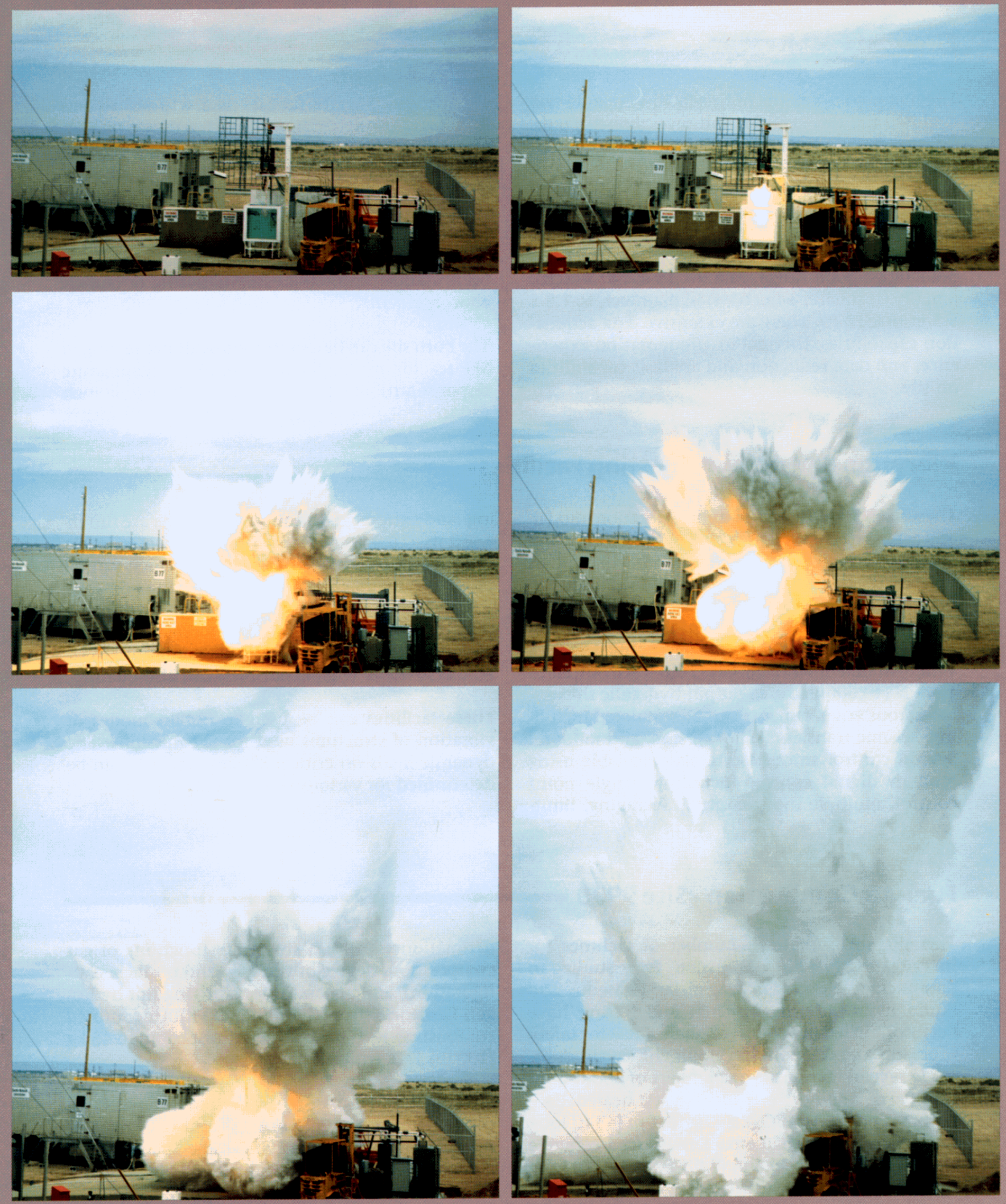

Large-scale steam explosion created by molten fuel-coolant interaction at Sandia's Albuquerque location (Site 9940$).$ 


\section{Large Melt Facility - Site 9939}

This site incorporates two induction furnace power supplies, data acquisition capabilities, and aerosol measurement facilities (supported by the Sandia Aerosol Research Laboratory in building 6600). This site is currently used for the generation of large 100to $1000-\mathrm{kg}$ melts for melt-interaction studies in support of the NRC and Savannah River Lab reactor safety programs. The capabilities of this site include high-temperature materials compatibility studies, studies of magnetic fields for radiation and charged particle shielding, temperature behavior of reactor fuel simulants, and measurement and characterization of aerosols arising from tests.

The LMF has an extensive diagnostics capability including unique embedded sheathed thermocouples (for measuring temperatures to $2300^{\circ} \mathrm{C}$ $\left[4170^{\circ} \mathrm{F}\right]$ ), pyrotubes (temperatures to $3600^{\circ} \mathrm{C}$ $\left.\left[6510^{\circ} \mathrm{F}\right]\right)$, and impactors, filters, and cyclone samplers for measuring aerosol particle size distributions, densities, and chemical composition (post test).

\section{Sandia Aerosol Research Laboratory/Building 6600}

Aerosols may be produced from the operation of pumping or compressing machinery, vibration of reactor components, or thermal or mechanical releases from the fuel. These aerosols may interfere with the operation of the reactor or produce substantial radiological hazards in the event of a nuclear accident. A program to identify aerosol sources in the various reactor configurations under consideration and to assess their effects on the performance of the reactor would be helpful in the development of effective and reliable space nuclear reactors, both in normal operation and during accidents. Sandia has the capability and experience in aerosol sourceterm measurement and characterization from processes such as melt interaction and ejection.

This facility has provided aerosol measurement and characterization support for melt-concrete interactions and pressurized melt ejection programs. The facility has calibration capabilities for aerosol and flow measuring equipment for high-temperature and high-concentration environments.

\section{Molten Fuel-Coolant Interaction - Site 9940}

This site has been primarily devoted to investigating the safety implications of mixing high-temperature molten metals or oxides with water (called molten fuel-coolant interactions or steam explosions). A 5$\mathrm{m}^{3}\left(178-\mathrm{ft}^{3}\right)$ chamber can be heated to $100^{\circ} \mathrm{C}\left(212^{\circ} \mathrm{F}\right)$ and can withstand internal pressures up to 30 bars. The probability and strength of these explosive interactions can be measured, along with the gases generated and the residue debris. An external test pad is also available for studying large-scale explo-

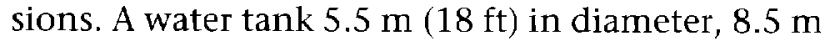
( $28 \mathrm{ft}$ ) deep can be used to study underwater explosions and related phenomena.

The site facilities have been used to investigate steam explosions with the intent of preventing their occurrence during accidents in nuclear reactors, metal foundries, and paper mills. The site has been used to investigate explosions up to $45 \mathrm{~kg}$ ( 100 lb) TNT equivalent. 


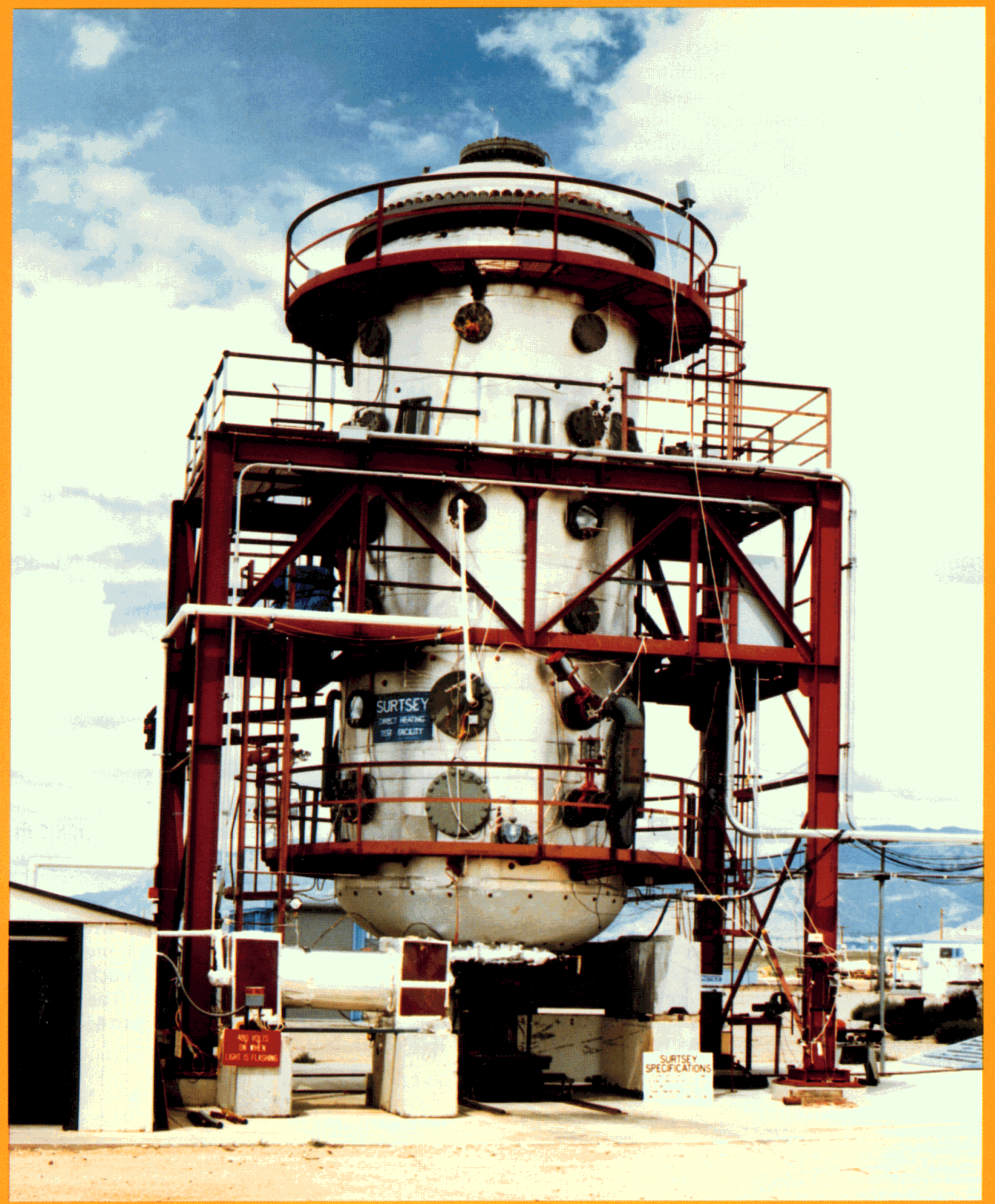

Surtsey direct containment heating facility. 


\section{Surtsey Facility}

The Surtsey facility has a large $103-\mathrm{m}^{3}\left(3680-\mathrm{ft}^{3}\right)$ chamber with a controlled atmosphere (pressures up to $10 \mathrm{~atm}$ ) and temperature (temperatures from ambient to $267^{\circ} \mathrm{C}\left[513^{\circ} \mathrm{F}\right]$ ) environment. It is instrumented for pressure, gas composition, temperature, and aerosols. Data acquisition capabilities of 200 channels are available. The chamber has been used to study aerosol-atmosphere reactions for reactor safety studies of high-pressure melt ejection and direct containment heating. It could be used for environmental exposures of devices or monitoring aerosol production.

\section{Space Satellite/Sensors Facilities}

As part of Sandia's programs on satellites, space systems, and sensors, several facilities have been built and staffed: a Space Simulation Laboratory, containing one 2.4- x 3.7-m (8- x 12-ft) thermal/ vacuum chamber, one $2.1-\mathrm{x} 3-\mathrm{m}$ (7- $\mathrm{x}$ 10-ft) chamber, and a number of smaller chambers, all capable of maintaining a pressure of $10^{-6} \mathrm{~mm} \mathrm{Hg}$, while cycling over temperatures from below $-100^{\circ} \mathrm{C}\left(-148^{\circ} \mathrm{F}\right)$ to above $100^{\circ} \mathrm{C}\left(212^{\circ} \mathrm{F}\right)$; Thermal Simulation Facilities, consisting of two large walk-in chambers and numerous smaller chambers, which are used for temperature cycling and long-term constant temperature testing (bake-out) of space instruments at ambient pressure; Payload Integration Facilities, consisting of one large (15.8 $\times 13.7 \mathrm{~m}$ [52 $\times 45 \mathrm{ft}]$ ) and numerous smaller labs, with raised, computer floors for final assembly and testing of instrumentation payloads for space applications by computercontrolled testing equipment; an Optical Alignment Laboratory, for aligning and calibrating optical sensors to within \pm 25 microradians; Power Supply Development Complex for developing, designing, assembling, and testing of power-conditioning subsystems required to generate and regulate power for satellite sensors and data processors; SpaceFlight Quality Repair and Cleaning Complex, for the repair, cleaning, and inspection of flight electronic and mechanical sub-assemblies by spacequality certified technicians; and a variety of other facilities related to testing, and data acquisition and reduction.

\section{Aerodynamic Test Facilities}

\section{Wind Tunnels}

Sandia operates two state-of-the-art wind tunnels, the Trisonic Wind Tunnel (TWT) and the Hypersonic Wind Tunnel (HWT). The tunnels are used for nuclear and conventional weapons system development, stockpile maintenance and redevelopment, experimental aerodynamics and fluid mechanics research, and for validation of computational fluid dynamics and aeropredictive computer codes. The TWT is a $0.3-\mathrm{x} 0.3-\mathrm{m}$ (1- $\mathrm{x}$ 10-ft) blowdown-toatmosphere tunnel that operates over the Mach number range 0.5 to 2.5 , and unit Reynolds number range 2 to 18 million/ft. For both tunnels, test time is 30 to $60 \mathrm{~s}$, and angle of attack is variable over a range of approximately 30 degrees.

Precision force, moment, and pressure data are obtained routinely, and other specialized diagnostics are available. These include still/video schlieren and shadowgraph, surface flow characterization using oil flow and liquid crystals, boundary layer transition detection, heat-transfer instrumentation, and 3-D laser holographic interferometry (LHI) for flow density measurement. Sandia has pioneered the use of liquid crystals in hypersonic flow and is the first to develop and use LHI as a 3-D density diagnostic.

\section{High Altitude Chamber}

Sandia operates a High Altitude Chamber (HAC) in which pressure altitudes of up to $67 \mathrm{~km}(220,000 \mathrm{ft})$ can be attained at programmed ascent and descent rates. This facility complements the Space Satellite/ Sensors facilities described above. The HAC is a 8.2$\mathrm{m}$ - (27-ft-) diameter sphere (one of three vacuum vessels for the HWT) provided with a floor, a 1.5-m(5-ft-) diameter access door, low- and high-speed centrifuges, and video recording. The low-speed 


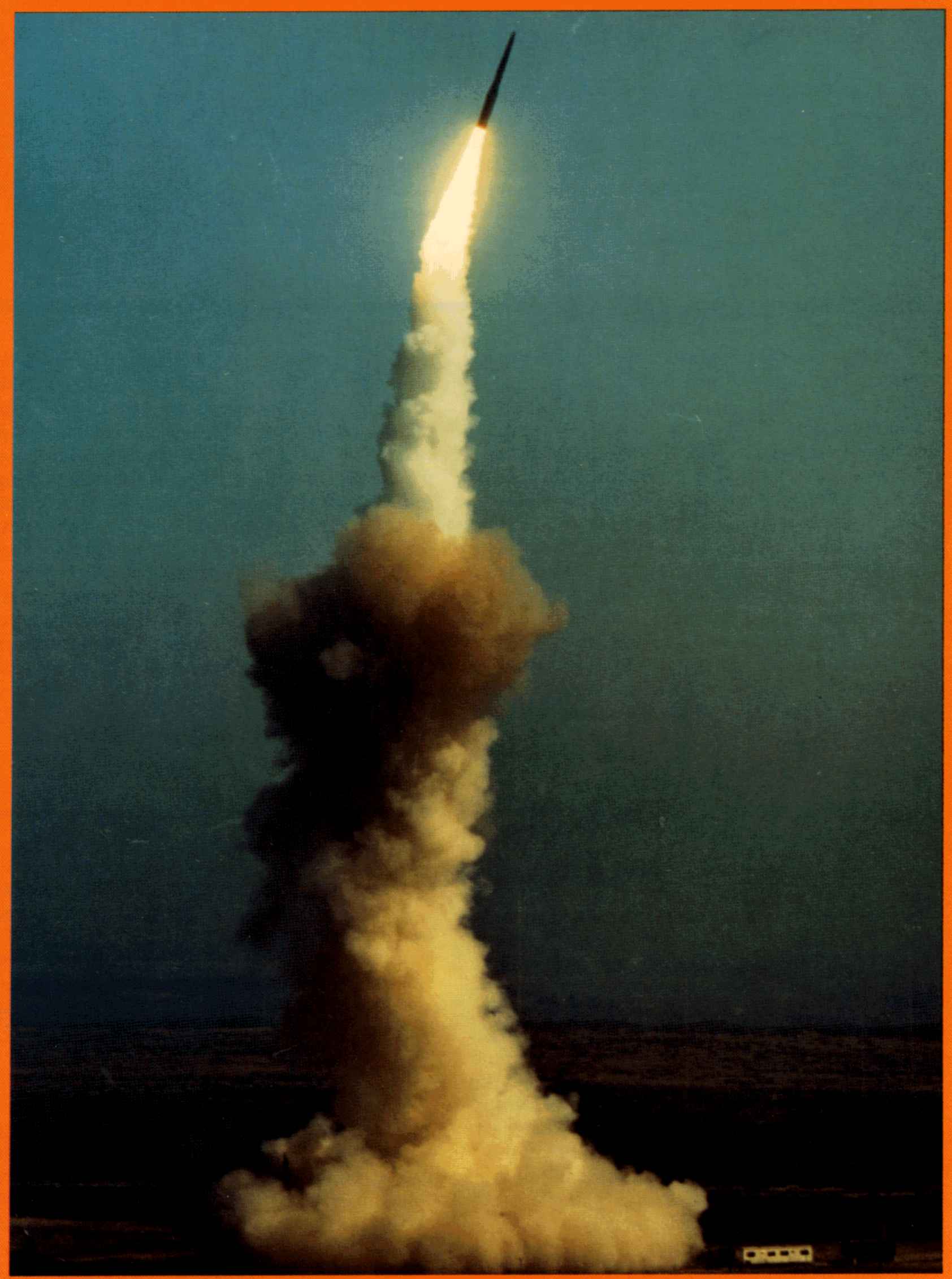

Sandia was involved in the Pershing III missile testing program. 
centrifuge allows spin testing of components weighing up to $454 \mathrm{~kg}(1000 \mathrm{lb})$ at up to $600 \mathrm{rpm}$. The high-speed centrifuge is used to test components weighing up to $4.5 \mathrm{~kg}(10 \mathrm{lb})$ at speeds up to 30,000 rpm. The HAC is equipped with over 100 data channels, of which approximately half are through slip rings and provide data rates of up to $1 \mathrm{MHz}$ each on spinning systems. A remotely controlled lighting and video system allows visual recording of test components during tests.

\section{Remote Field Test Facilities and Ranges}

\section{Tonopah Test Range}

The Tonopah Test Range (TTR) is a permanent outdoor testing laboratory with unique capabilities for gathering data from a variety of test vehicles. This $1360-\mathrm{km}^{2}\left(525-\mathrm{mi}^{2}\right)$ area is located on the north end of the Nellis Bombing and Gunnery Range and about $52 \mathrm{~km}$ ( $32 \mathrm{mi}$ ) southeast of Tonopah, Nevada. The TTR is used for flight and trajectory studies, rocket static tests, and high-altitude rocket and reentry body studies. The range provides state-ofthe-art integrated instrumentation systems for test vehicle tracking and data acquisition. Over 200 tests are conducted each year. Multiple radars, optical trackers, telemetry stations, a central computer complex, and communications systems provide full coverage for tests involving cruise missiles, artilleryfired projectiles, rocket-launched payloads, Davis Gun fired penetrators, and high-performance aircraft-delivered test units. In addition to the airborne vehicular tests, various areas of the range have been used for explosives studies involving blast effects, case ruptures, shock wave phenomena, and cratering; experiments have also been performed to simulate tornado-propelled objects impinging on nuclear reactor containment walls.

\section{Kauai Test Facility}

The Kauai Test Facility (KTF) in Hawaii, residing on the Pacific Missile Range Facility, has a rocketpreparation and launching capability for both raillaunched and vertical-launched rockets. Launches primarily support high-altitude scientific research and reentry vehicle systems development. Small rockets typically fly ballistic trajectories with payload attitude control systems available as an option, while the larger systems contain navigation systems. The largest system (STARS) has a total vehicle/ payload weight of $16,400 \mathrm{~kg}(36,000 \mathrm{lb})$ and will be used to deliver payloads to the Kwajalein Missile Range area for test and evaluation of Strategic Defense Initiative (SDI) systems.

\section{Nevada Test Site}

Sandia has been involved in underground nuclear testing at the Nevada Test Site for the past 25 years. We have provided project leadership, technical assistance, pretest calculations, experiment hardware, data acquisition and recording, data reduction and analysis, and logistic support for our own underground weapons effects tests and in support of the tests by other laboratories. Two years of planning may go into acquiring up to a thousand pieces of data on a onetime-only opportunity with a reliability in the high $90 \%$ range. The test conditions are so severe that we must often develop our own instruments and gauges to measure radiation environments, earth motions and radiation effects on materials and components. We have also developed our own remotely operated digital data acquisition systems utilizing fiber-optic techniques for frequencies from dc to $1 \mathrm{GHz}$.

In addition, Sandia has extended its capability to field complex measurement systems into such diverse areas as monitoring conditions in oil shale retorts (in Colorado, Utah, and Wyoming) and underground nuclear waste repositories (NTS and New Mexico [Waste Isolation Pilot Plant]). In all of these situations, Sandia brings an end-to-end systems approach to bear on the problem.

\section{Mobile and Remote Ranges}

Sandia Mobile and Remote Ranges provide engineering field support and data acquisition, including advanced telemetry receiving, optical measurements, recording, and analysis for research and development testing in Albuquerque, throughout the U.S., and often at world wide locations. A fleet of mobile instrumentation stations is available for deployment to Sandia facilities, DOE and DoD ranges, test-unit integration sites, and designated remote locations. Examples of test support include: environmental and qualification tests; strategic and tactical missile launches; earth and water penetration; and bomb drops. 


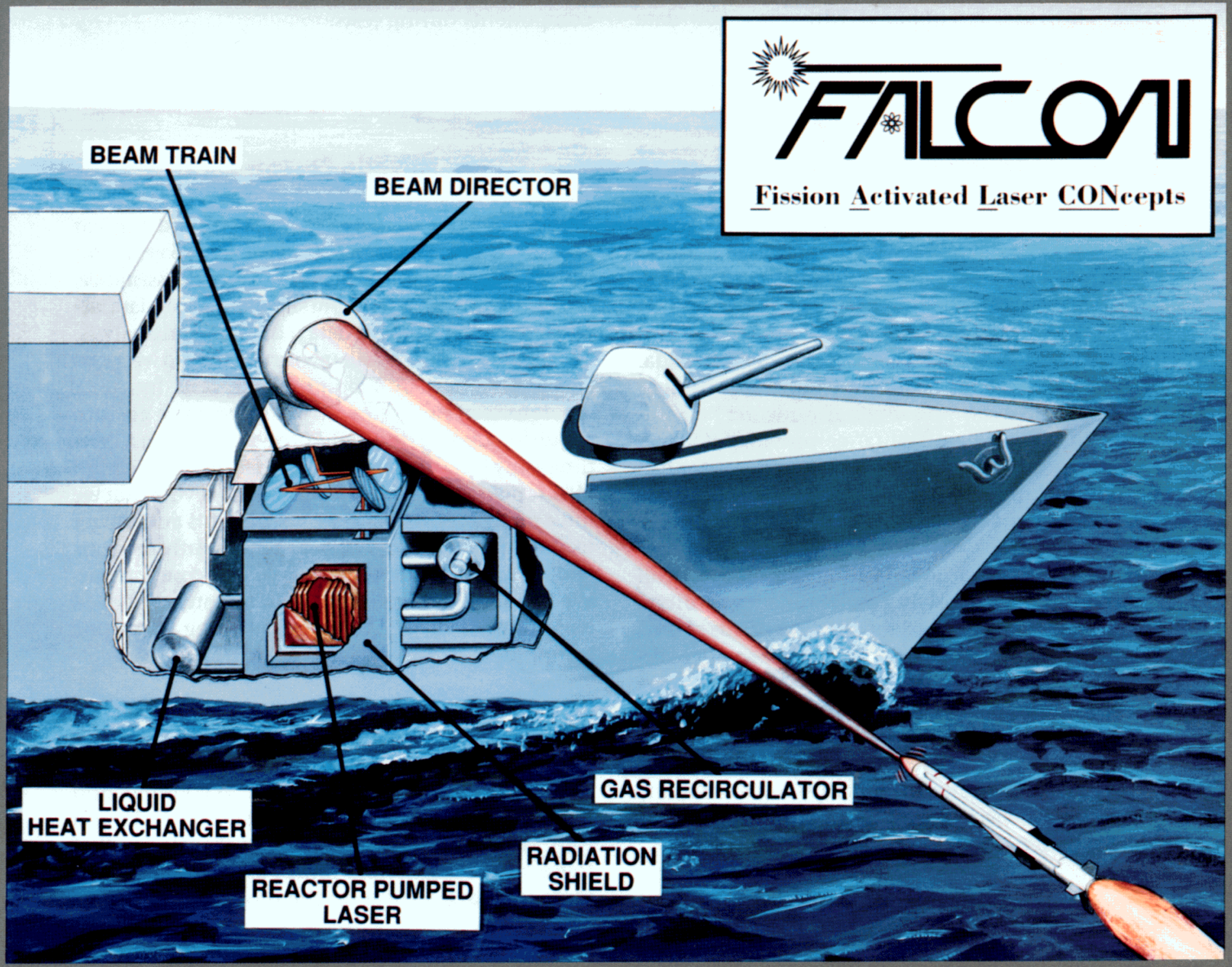

The FALCON system will use a fission reactor to power a laser. Possible applications include defense, imaging of objects in space, and laser propulsion. 


\section{Sandia Programs}

Because of the synergism of multiple governmental and industrial sponsors of many programs, Sandia is frequently able to provide complex technical solutions in a relatively short time, and often at lower cost to a particular customer. We have listed a few ongoing programs at Sandia related to space nuclear technology as examples of the possible synergisms that could result from forming teams and partnerships with related technologies and objectives.

\section{FALCON}

The DOE Fission Activated Laser CONcept (FALCON) program is developing the technology for large laser systems pumped directly by a nuclear reactor. This advanced nuclear technology is being developed for defense applications, but may also have potential NASA implications in the areas of laser power beaming and laser propulsion. Substantial progress has been made in establishing and demonstrating the feasibility of this technology, based on analysis and reactor experiments over the past few years.
FALCON is expected to scale up to $100 \mathrm{MW}$, is selfpowered, is relatively compact, uses near-term technology, can have extended run times, and employs wavelengths that have near optimum transmission characteristics. FALCON has many possible applications in both military and civilian missions. These include space object identification (imaging), antisatellite, anti-missile ship defense, laser propulsion, and power beaming earth to satellite and space to space.

\section{Thermionic Space Power Systems}

The New Mexico Alliance (see New Mexico Alliance) has developed a program to test and evaluate the Soviet Union's Topaz II reactor, a thermionic nuclear space power system. The 6-kW, 3.6-m (12$\mathrm{ft}$ ) tall, $900-\mathrm{kg}$ (2000-lb), unfueled test assembly will be tested in a building now under construction at the University of New Mexico's (UNM) Industrial Park in Albuquerque. The goal of the program is to step up U.S. research into the potential use of reactors using thermionic energy conversion to improve space power technology. Beginning next year, after the Topaz II reactor is delivered and readied for operation, the efficiency and performance of the reactor assembly will be tested. An electrical power source will be used to generate the heat that drives the reactor; no nuclear power source will be used. Private industry will also reap the benefits of the research effort. Several companies involved in nuclear power, such as Westinghouse, General Electric, General Atomic, Rockwell, Space Power Inc., and others will participate in the research effort.

\section{Space Exploration Initiative}

Sandia's objective is to form a full-time team of scientists and engineers to assist NASA and DOE in assessing and developing safe and reliable nuclear power systems for use in future SEI missions. Sandia has established the following primary roles of support:

\section{- Concept and Technology Evaluation}

This involves evaluating the applicability of the many potential nuclear concepts and technologies to NASA missions. Systems studies are being performed to determine how the various concepts and technologies compare with one another, and the development status of the technologies will be evaluated and compared with respect to availability in a given time frame, cost, and reliability.

\section{- Safety}

Sandia will develop a set of safety criteria that need to be met for each mission and will then develop methods to meet these criteria. All aspects of safety will be addressed including ground transportation, safeguards, launch, operation, etc. 


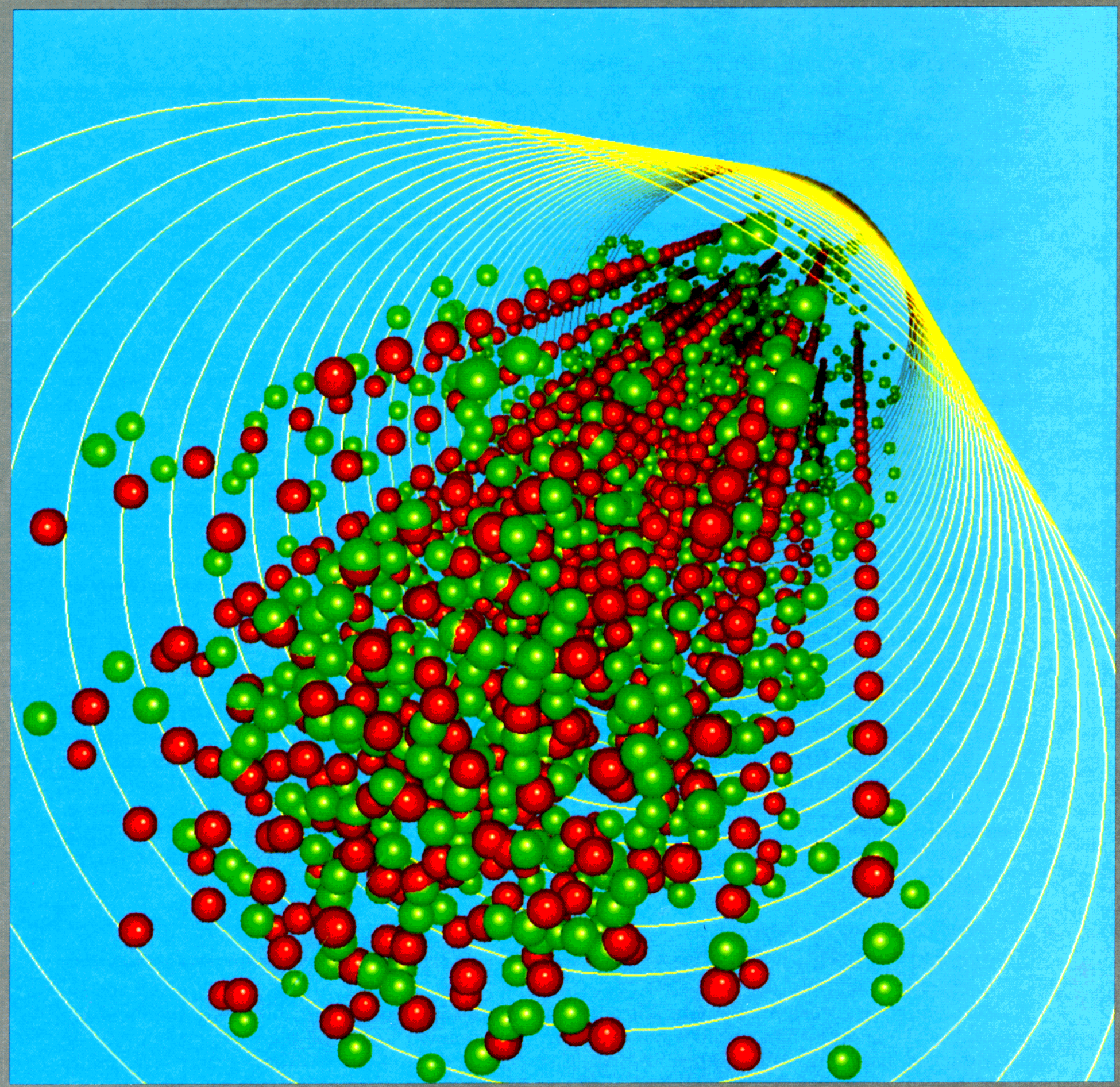

Simulation of electron beam propagation in which the green particles represent relativistic electrons propagating through a cloud of positive channel ions (red). 


\section{- Reliability, Availability, Maintainability}

Sandia will help NASA develop an approach to power system design that will ensure the necessary reliability to meet the mission lifetime. This work will address both system and component reliability, availability, and maintainability.

These roles support the Nuclear Power Project Office at NASA's Lewis Research Center. Work that has been completed includes:

\section{- Assessment of Lunar Power Sources}

NASA has proposed using liquid metal cooled reactors with Thermionic Fuel Element (TFE) energy conversion and particle bed reactors with gas turbine energy conversion to provide power to a lunar base. In this work the technology status of TFE and Brayton energy conversion systems was evaluated and summarized; design features of the two 550$\mathrm{kW}$. power systems buried in the lunar soil were established; the mass, area, and volume of the systems were determined; and various techniques for using lunar materials for radiation shielding were evaluated.

- Study of the Potential for Using the SP-100 Nuclear Power System at Power Levels Above $100 \mathrm{~kW}_{\mathrm{e}}$

This study proposed and evaluated design and technology advances, mainly in the area of fuel and cladding, that would enable the SP-100 to operate at higher temperatures and therefore higher power levels without increasing the mass of the system per unit of electricity produced.

\section{- Study of the Travel Time to Mars}

This study investigated all possible transfer orbits between Earth and Mars and compared transit times, mass, etc., for nuclear and chemical rockets. It showed that the time can be significantly reduced by using a nuclear rocket.

\section{- Study of Human Radiation Exposure During a Trip to Mars}

This study evaluated the radiation dose an astronaut would receive using the various options for travel to Mars and suggested methods for reducing this dose. Of all the natural and reactor produced radiation sources considered, solar flares were the most troublesome in that it is impossible to protect against them in a lightweight spacecraft.

Sandia is currently providing the consultation required to transfer one of its reactor design codes to NASA's Lewis Research Center, performing radiation calculations to determine shielding requirements and operational constraints required to limit the dose an astronaut will receive if the Dynamic Isotope System is used to power lunar surface vehicles, and participating in NASA's "Lunar SP-100 Brayton Conceptual Design Study."

Sandians also serve on all six of NASA's Nuclear Propulsion (NP) Technical Panels: Mission Analysis, Nuclear Safety Policy, NTP Technology, NEP Technology, NP Facilities, and Nuclear Fuels and Materials Technology. These Working Groups provide (1) design studies for nuclear sources including the instrumentation and control and power conditioning subsystems for both nuclear electric and nuclear thermal propulsion, (2) mission analyses, (3) guidance on nuclear safety policy, (4) information on existing and proposed nuclear propulsion developmental facilities, and (5) information on nuclear fuels and materials technology.

\section{BOLT}

The Beams On Laser Technology (BOLT) project is a proposed experiment to demonstrate guided electron- (e-) beam propagation in space. This project brings together established Sandia technologies in e-beam accelerators, lasers, pulsed power, rocket boosters, payload integration, diagnostics, telemetry, and flight testing.
BOLT flight objectives are to propagate an e-beam across the earth's magnetic field in space, overcome space charging, bound the effects of space plasmas on propagation, and achieve record propagation lengths. The project will also benchmark laboratory experiments and models with space data. 


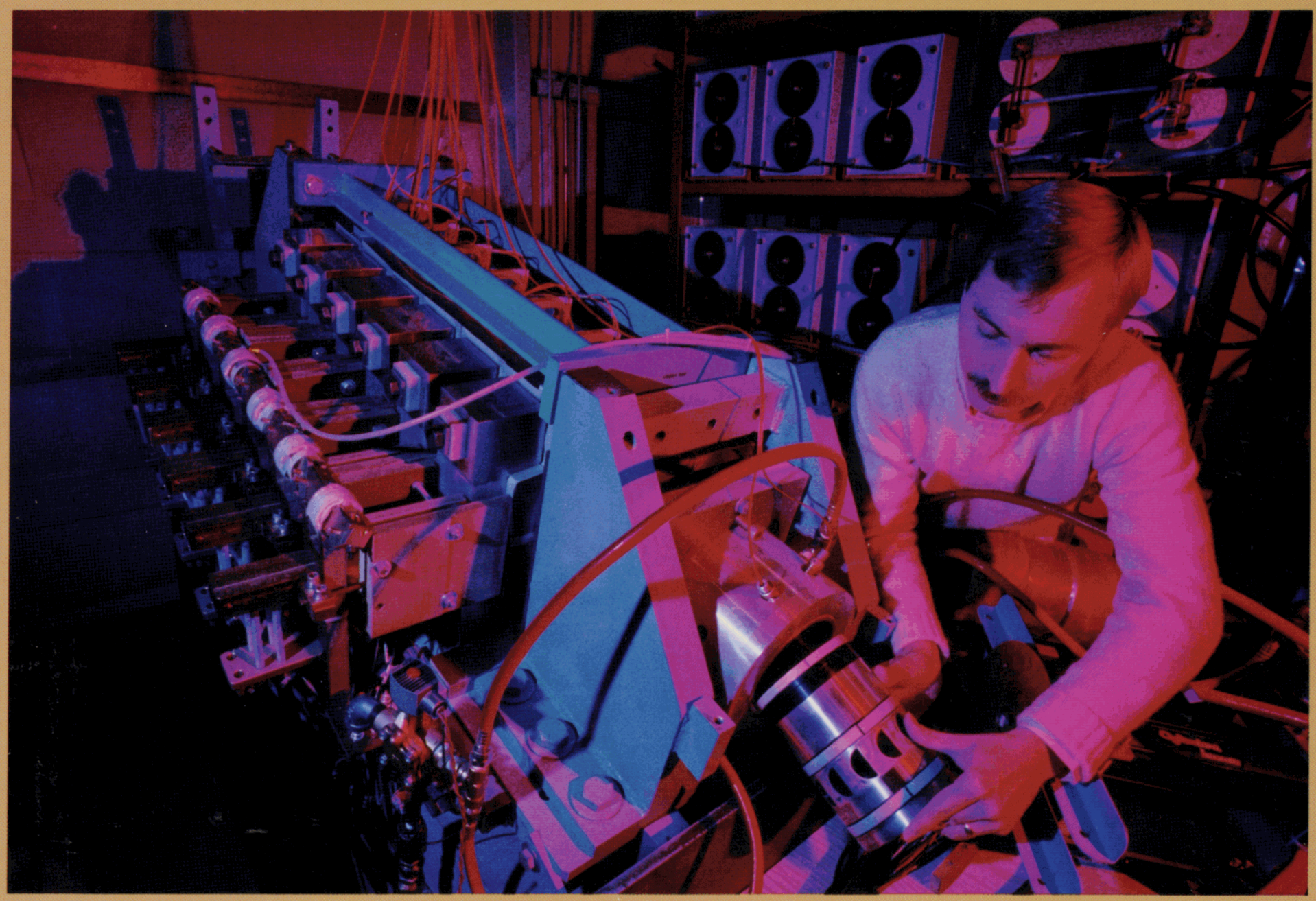

Ronald Kaye of Sandia's Electromagnetic Launcher Division inserts a projectile into breech of six-stage electromagnetic launcher. Sandia is developing electromagnetic launcher technology as a potential alternative to rockets for launching small satellites to earth orbit. 
EDNA (Externally Driven Nuclear Assembly) is an advanced radiation simulator which will be capable of delivering intense gamma and neutron radiation over a large test volume. EDNA will be able to deliver both multi-pulse and multi-radiation synergistic environments at threat levels for testing of highpriority tactical and strategic military systems. EDNA is designed to deliver a neutron fluence of $10^{15}$ neutrons $/ \mathrm{cm}^{2}$ with a pulse width of 1 to $10 \mu \mathrm{s}$, and a gamma fluence of $5 \times 10^{13} \mathrm{rad}(\mathrm{Si}) / \mathrm{s}$ with a pulse width of 18 to $25 \mathrm{~ns}$.
Technically, EDNA consists of a high-energy pulsedpower accelerator which generates an intense electron beam that strikes a high-Z target. Gamma rays are produced in the target by bremsstrahlung production. These gamma rays can directly irradiate a system or be focused to produce primary neutrons through photonuclear reaction in a fissile target. The neutrons are multiplied in a subprompt critical assembly of fissile materials from which the test item is irradiated. These two effects can be combined to produce a multiradiation, synergistic environment.

\section{STARS (Strategic Target System)}

The STARS missile is a fully guided, three-stage solid rocket system that Sandia is developing to launch payloads from the Kauai Test Facility. STARS is a vertically-launched rocket system which employs active guidance and control throughout its flight. This system can deliver payloads of up to $340 \mathrm{~kg}$ $(748 \mathrm{lb})$ to the Kwajalein Atoll at ICBM reentry velocities. It can also be used to loft payloads to altitudes of $2000 \mathrm{~km}(1250 \mathrm{mi})$ in the vicinity of the
Hawaiian Islands. A four-stage version of STARS can place a $165-\mathrm{kg}$ (363-lb) satellite in a 485-km (303$\mathrm{mi}$ ) polar orbit. STARS uses a ring-laser gyro inertial measurement unit and thrust vector control on all three stages, operating under the control of a multiprocessor guidance and navigation computer. First flight of the STARS is expected in the fall of 1991. Approximately four launches per year for various customers are anticipated to begin in 1993.

\section{Electromagnetic Earth-to-Orbit Launcher}

An electromagnetic launch technology, with one possible application being earth-to-orbit launch of small satellites, is being developed at Sandia. This novel coilgun technology may be able to serve as an alternative to rockets for launch of satellites (up to $400 \mathrm{~kg}$ [182 lb]), especially where quick response times are needed. The technology may also offer lower launch costs per payload mass. The technology uses electromagnetic induction and involves no sliding electrical contact between projectile and barrel. So far the basic principles of the technology have been demonstrated in a series of experiments and tests at a field-test site at Sandia. An operational launcher can propel a $3.5-\mathrm{kg}(1.6-1 \mathrm{~b})$ cylinder up to $330 \mathrm{~m} / \mathrm{s}$ at an acceleration of $10,000 \mathrm{~g}$. By October 1992 , we expect to achieve $1 \mathrm{~km} / \mathrm{s}$ for a $0.4-\mathrm{kg}$ (0.9-lb) projectile to be accelerated at $50,000 \mathrm{~g}$. 


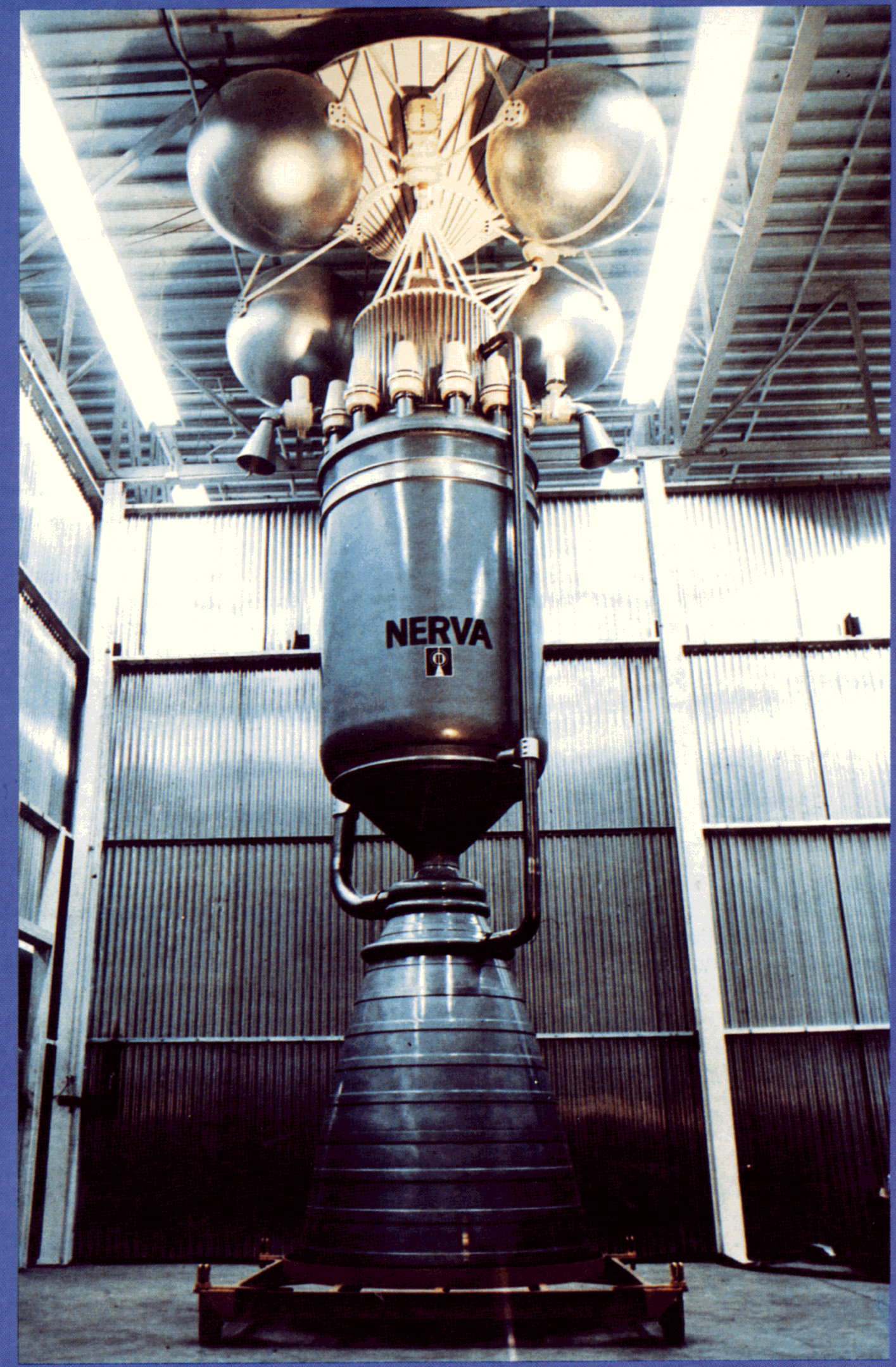

Sandia performed critical safety tests for the NERVA engine program and continues to contribute to the nation's space nuclear thermal propulsion programs. 
We have proposed to build an AFGL (Air Force Geophysics Laboratory) funded state-of-the-art LIDAR (Light Detection and Ranging) facility in the auroral zone at the Poker Flats Rocket Ramp in Alaska, and this proposal was recently adopted by the University of Alaska in Fairbanks. This unique LIDAR facility will allow us to measure in real time the auroral zone upper atmospheric/ionospheric winds and temperatures at altitudes of 80 to $100 \mathrm{~km}$. The LIDAR will consist of an all solid-state laser system. Single mode Nd:YAG lasers operating at 1064 and $1319 \mathrm{~nm}$ will be used to generate 589.1 $\mathrm{nm}$ for a sodium resonance LIDAR source to make measurements on the upper atmospheric sodium layer. Combining the $589-\mathrm{nm}$ system with an additional $1064 \mathrm{~nm}$ Nd:YAG will produce 20 to $24 \mathrm{~W}$ of single-mode 532-nm light for Rayleigh and Mie backscatter measurements of upper atmospheric aerosols. These measurements could play a crucial role in understanding the dynamics of the upper atmospheric, transport and gravity waves, auroral driven winds, and their effects on global climate and environmental change.

\section{Space Nuclear Thermal Propulsion}

Sandia has a long-held belief that nuclear propulsion for space is important to the national interest. This belief has been translated into action through our significant contributions to all major space nuclear thermal propulsion programs conducted in the United States. These contributions have ranged from safety tests in the 1960s on the orginal ROVER/ NERVA engine designs to development work today on advanced solid core and innovative nuclear propulsion concepts. Some current roles include incore testing of nuclear fuels, development of unique facilities, assurance of nuclear safety, evalu- ation of innovative concepts, research on automated reactor control methods, and development of specialized instrumentation, electronics, and components. Sandia is uniquely qualified to support nuclear propulsion development since we are the only organization in the country that currently operates both nuclear reactors and rocket launch sites. We have both aerospace and nuclear departments to deliver on our commitments. One-of-akind testing facilities and personnel experience allow Sandia to be a partner that adds value to industry/national laboratory teams.

\section{Other Programs}

On behalf of the DOE and DoD, Sandia conducts several major classified programs relevant to nuclear space technology which involve design, development, evaluation, and testing of systems hardware.
These programs support a sophisticated technology base that can be used to support Sandia/industry/ government laboratory partnerships and alliances. 


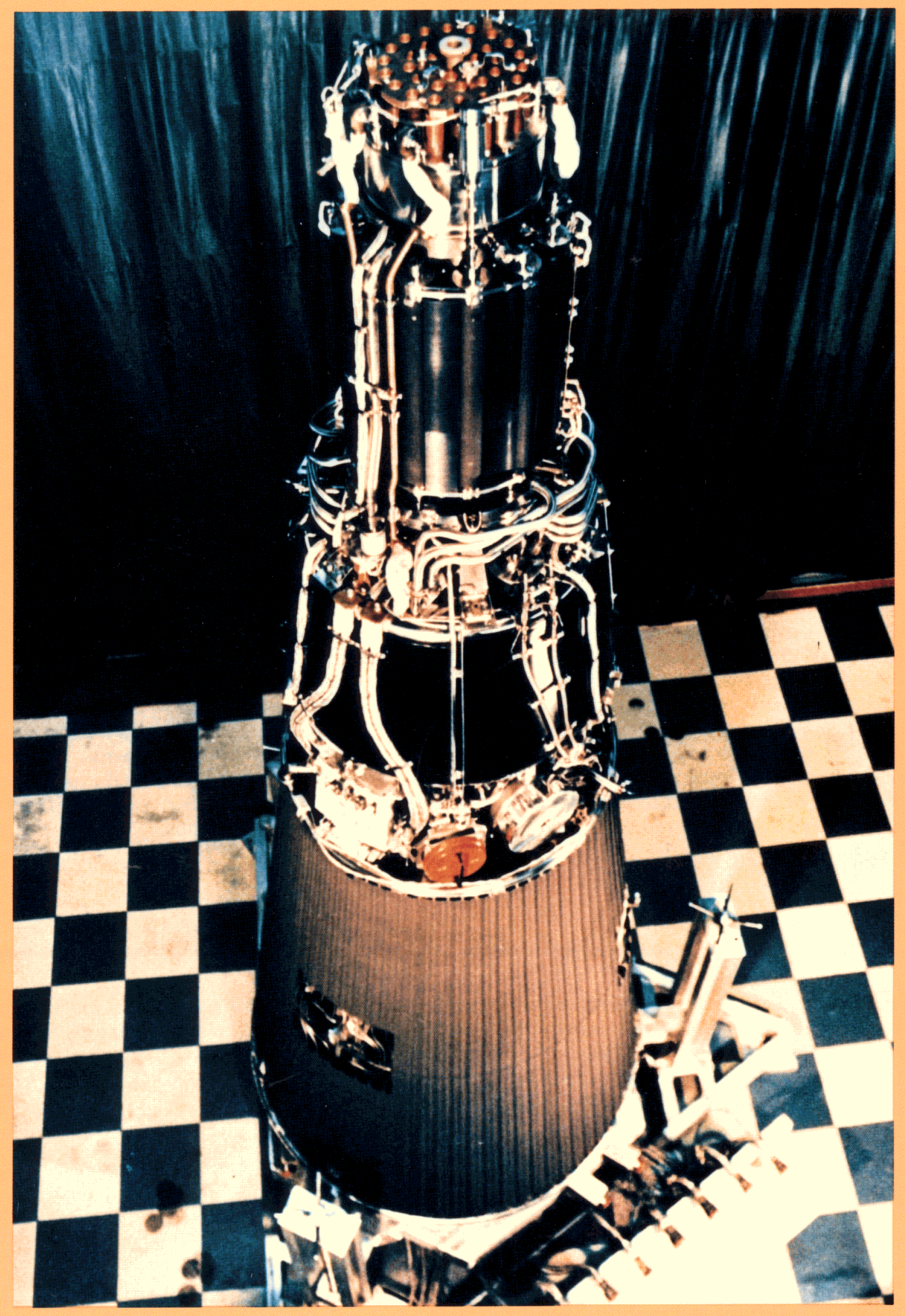

Unfueled Soviet TOPAZ thermionic reactor system. 


\section{SNL Partnerships, MOUs, and Agreements}

A few recent examples of Sandia partnerships and agreements are listed below.

\section{Sandia/Phillips/LANL}

During the next decade, the ability to maintain our technical capabilities to support national security missions and to provide leadership in technology innovations will be challenged by declining $R \& D$ resources. Meeting this challenge will require a greater reliance on cooperation between organizations.

To help meet this challenge, USAF Phillips Laboratory, LANL, and Sandia have established a strategic alliance. Its intent is to demonstrate our resolve to collaborate for the betterment of the nation. The strategic alliance will facilitate the exchange of information developed within each organization to support their respective missions. This alliance will enable our staff to broaden their knowledge base, will provide mechanisms for technology transfer through direct interactions with each other, will determine areas of mutual interest, and will identify unique and complementary facilities and activities that could support programmatic requirements in the most effective manner. A steering committee has been established to guide coordination, cooperation, and interreliance among the three labs.

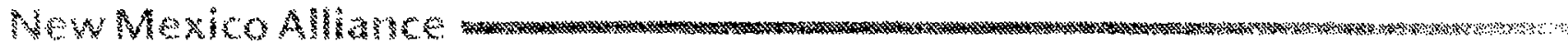

Sandia, LANL, the USAF Phillips Laboratory, and UNM recently formed an alliance to pursue space nuclear technology. Initially, the Alliance will concentrate on testing of the Soviet thermionic-reactor power system called TOPAZ. This is a joint DoD, DOE, SDI Office program. In the future, the Alliance will develop and pursue broader objectives in thermionics and other $\mathrm{R} \& \mathrm{D}$ opportunities in space nuclear systems. The objectives of this alliance, stated in the Memorandum of Agreement, include assuring the safety, environmental protection, and safeguards of thermionic space nuclear-power sys- tems; assuring compatibility of those systems with USAF and DOE mission requirements; continuing the current TFE verification program; and developing technologies for improving these systems' performance. Other plans include assuring the survivability, reliability, and testability of thermionic space nuclear-power systems while identifying a reference mission for flight demonstration; completing preliminary design of a reference thermionic system; and transitioning a thermionic space nuclear-power system to a flight demonstration if appropriate.

\section{Specialty Metals Processing Consortium, Inc.}

Scientists from 11 companies have teamed with Sandia in a pioneering DOE effort to increase U.S. competitiveness in the world specialty metals market. These specialty metals are used in aircraft, satellites, nuclear power reactors, and other products.

Sandia's role will be to provide technical consultation with a number of experienced materials re- searchers, to offer access to the Labs' state-of-the-art metals processing equipment, and to undertake associated research. Unique, specially instrumented equipment at Sandia's metallurgy laboratories includes a 310-kW e-beam furnace, a vacuum-arc remelting furnace, and an electroslag furnace. Experts in these processes as well as in computer modelling, analysis, and testing will contribute to the research. 


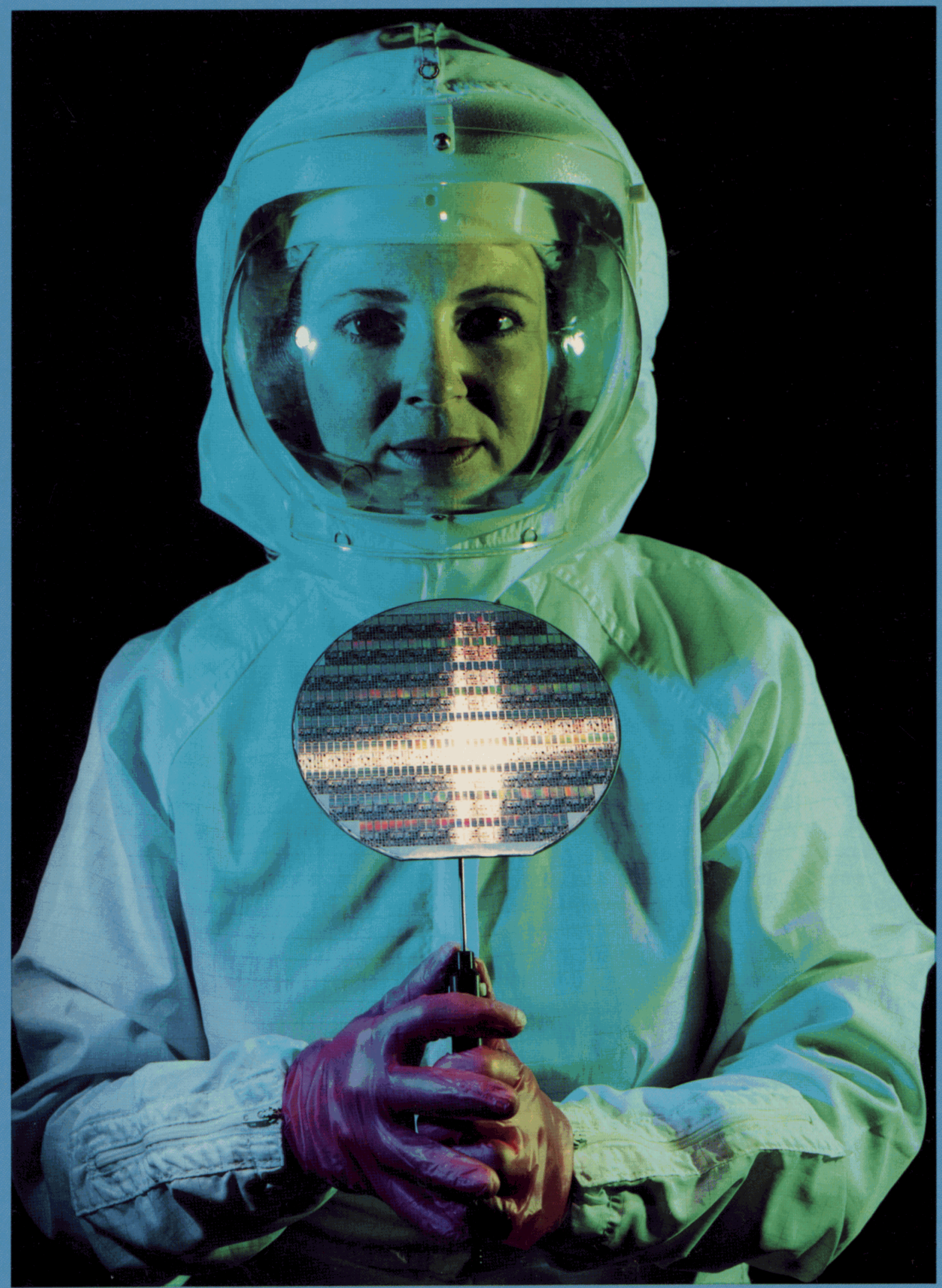

Sandia researcher April Howard displays a wafer of semiconductor chips manufactured in Sandia's Microelectronics Development Laboratory. The lab incorporates a 13,000- $\mathrm{ft}^{2} \mathrm{clean}$ room that uses the laminar air flow clean room principle invented at Sandia to make prototype semiconductor chips for weapons, satellites, and spacecraft. 


\section{UNM/Sandia Materials Research and Development Laboratory}

Sandia has joined with UNM to build and operate a Materials Research and Development Laboratory (MRDL) to be housed in UNM's new south-campus University Research Park. The Laboratory will promote education in science and engineering and foster technology transfer to industry. The MRDL will provide premises where Sandia and UNM researchers can work together with their industrial counterparts on long-term projects that are of mutual interest. Facilities are available for about 30 personnel. Initial projects involving the advanced processing of polymer, metal, and ceramic materials include high-temperature crystal growth of refractory borides, structural analysis of colloids, and aerosol generation of ultrafine particle ceramics.

\section{SETEC}

SEMATECH is a consortium of U.S. semiconductor industries and the U.S. Government that was formed in 1987. SETEC (Semiconductor Equipment Technology Center) is a joint collaboration of SEMATECH and Sandia. Its mission is to provide leading research and precompetitive technology bases in materials and processing technology, and to work interactively with equipment manufacturers in their development of reliable new processing equipment. Specific technologies include chemical vapor deposition, plasma processing, reliability engineering, ergonomics, and process control.

\section{Alliance for Photonic Technology}

The Alliance for Photonic Technology is a cooperative venture set up by the University of New Mexico's Center for High Technology Materials (CHTM), the Air Force Phillips Laboratory, LANL, and Sandia. Its mission is to enhance U.S. industrial competitiveness in selected areas of photonics-lasers, optoelectronics, and fiber optics. Five areas of technology development have been targeted by the Alliance: semiconductor diode-based laser sources; highpower diode laser sources; multidimensional optical interconnects; high-speed optoelectronics, and optical sensors. The Alliance will focus on marketdriven, product-specific developments in response to the competitive needs of individual customers.

\section{Signetics/Sandia CRADA}

Sandia's Microelectronics Quality/Reliability Center (MQRC) will work with the Phillips Components/Signetics plant in Albuquerque in the first cooperative research and development agreement (CRADA) that Sandia has signed with an individual company. The MQRC was established to provide
U.S. industry access to microelectronics reliability testing and failure analysis capabilities that are not availableelsewhere. The CRADA will combine Sandia's unique capabilities with Signetics' expertise in highvolume integrated circuit manufacturing.

\section{UTC/Sandia Cooperative Agreement}

United Technologies Corporation (UTC) has developed a concept for a nuclear rocket that uses a plasma-core engine. This nuclear thermal propulsion system is called the Nuclear Light Bulb (NLB). The NLB is theoretically capable of delivering five times the performance of chemical propulsion systems and twice the performance of most solid-core nuclear engines. UTC and Sandia are currently negotiating a long-term cooperative agreement to develop the NLB. UTC will have primary responsibility for non-nuclear component development, analysis, design, and testing. Sandia will have primary responsibility for nuclear analysis, design, testing, safety, and environmental issues. A CRADA may also be developed as part of this cooperative effort. 


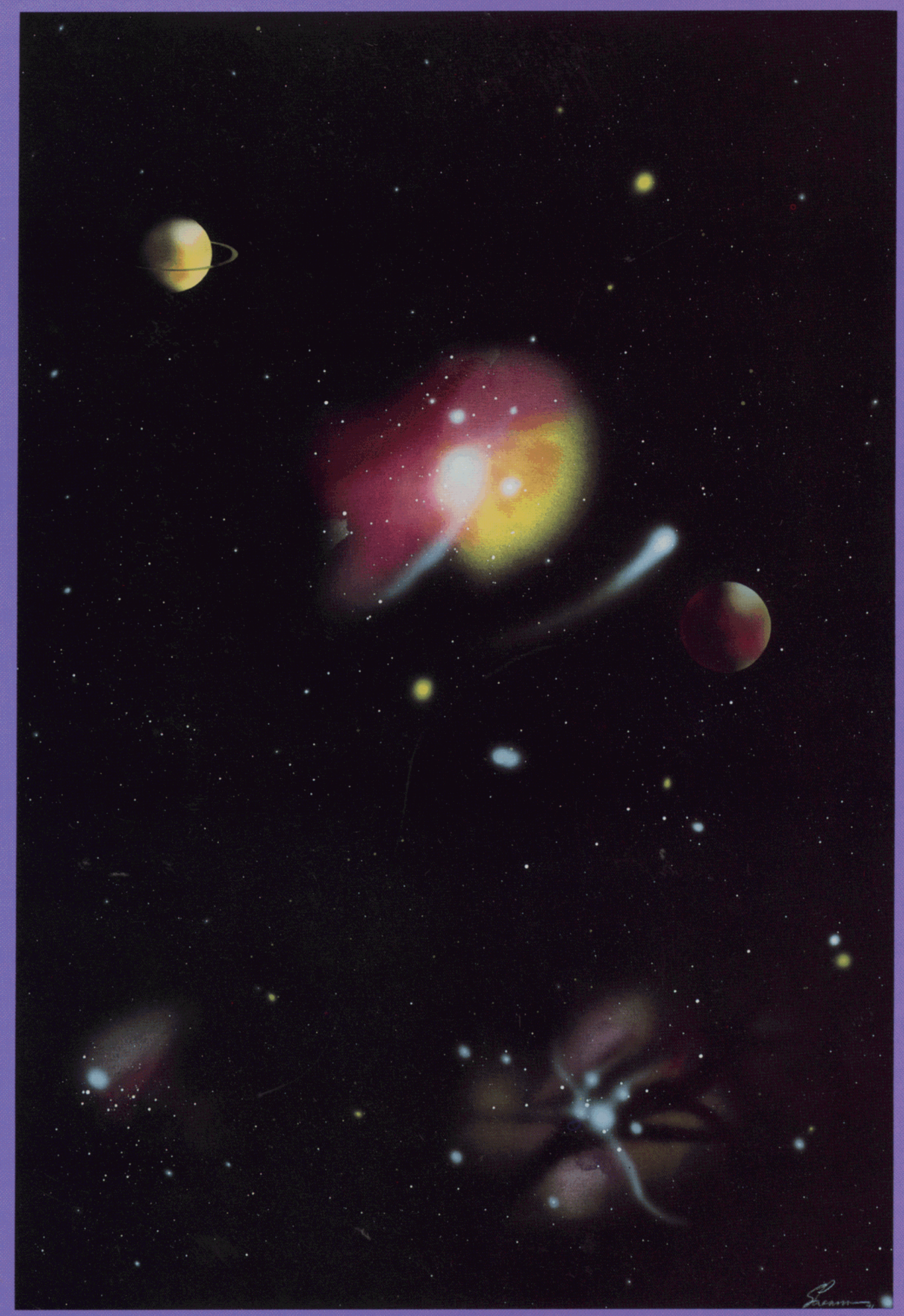

Whether serving our country's needs at home or in deep space, Sandia remains dedicated to its mission ". . to enhance the security, prosperity, and well-being of the nation." 


\section{SNL Corporate Objectives to Participate with Industry}

\section{Objective}

Sandia's mission as a laboratory includes a dedication "to enhancing the security, prosperity, and well-being of the nation.... As a DOE multiprogram laboratory, we are devoted to leadership in anticipating national priorities and in applying the best integration of scientific and engineering creativity to achieve comprehensive, timely, and cost-effective solutions to our nation's most pressing problems."

We currently view the SEI and the DoD/DOE/NASA missions in space as a high-priority national need. We have targeted nuclear technology in space as an area where Sandia will play an ever-increasing role in the future. Both civilian and military applications will be included. We are currently working with DOE, DoD, and NASA to develop this role. In pursuit of this strategy, Sandia will participate, as part of national laboratory-industry teams, in the development and testing of new nuclear systems for propulsion and space power applications. Sandia, as DOE's primary nuclear weapons engineering laboratory, has many capabilities that will allow us to make significant contributions in these areas.

\section{CRADA Relationships with Sandia}

AT\&T, Sandia, and DOE have signed an agreement that will allow Sandia to sign Cooperative Research and Development Agreements (CRADAs) with private companies.

CRADAs are expected to be key vehicles for technology transfer from Sandia to private industry. The agreements are provided for under the National Competitiveness Technology Transfer Act of 1989, sponsored by U.S. Senators Pete Domenici and Jeff Bingaman of New Mexico. The legislation is designed to help domestic companies compete in the international marketplace by allowing them to take advantage of technology developed at the national laboratories. The act gives technology transfer full status as a DOE mission and establishes a legal framework for signing of CRADAs. Under these provisions, the laboratories can negotiate directly with industry, dispose of intellectual property developed in a CRADA, and withhold publication of commercially valuable information developed under a CRADA for up to five years.

Sandia would like to develop CRADAs with private companies to pursue common technologies in space nuclear power and propulsion.

\section{Conclusion}

Sandia has a broad spectrum of talented scientists and engineers and state-of-the-art facilities. Many of these capabilities are already being applied to solving civilian and military problems related to space including rockets, satellites, lasers, launchers, and radiation-hardened components. Teams are being formed with industrial, government, university, and national lab partners. Innovative space nuclear technologies for propulsion and electric power is an area consonant with Sandia's mission to serve the national interest. Sandia invites prospective partners and customers to come and visit us. 


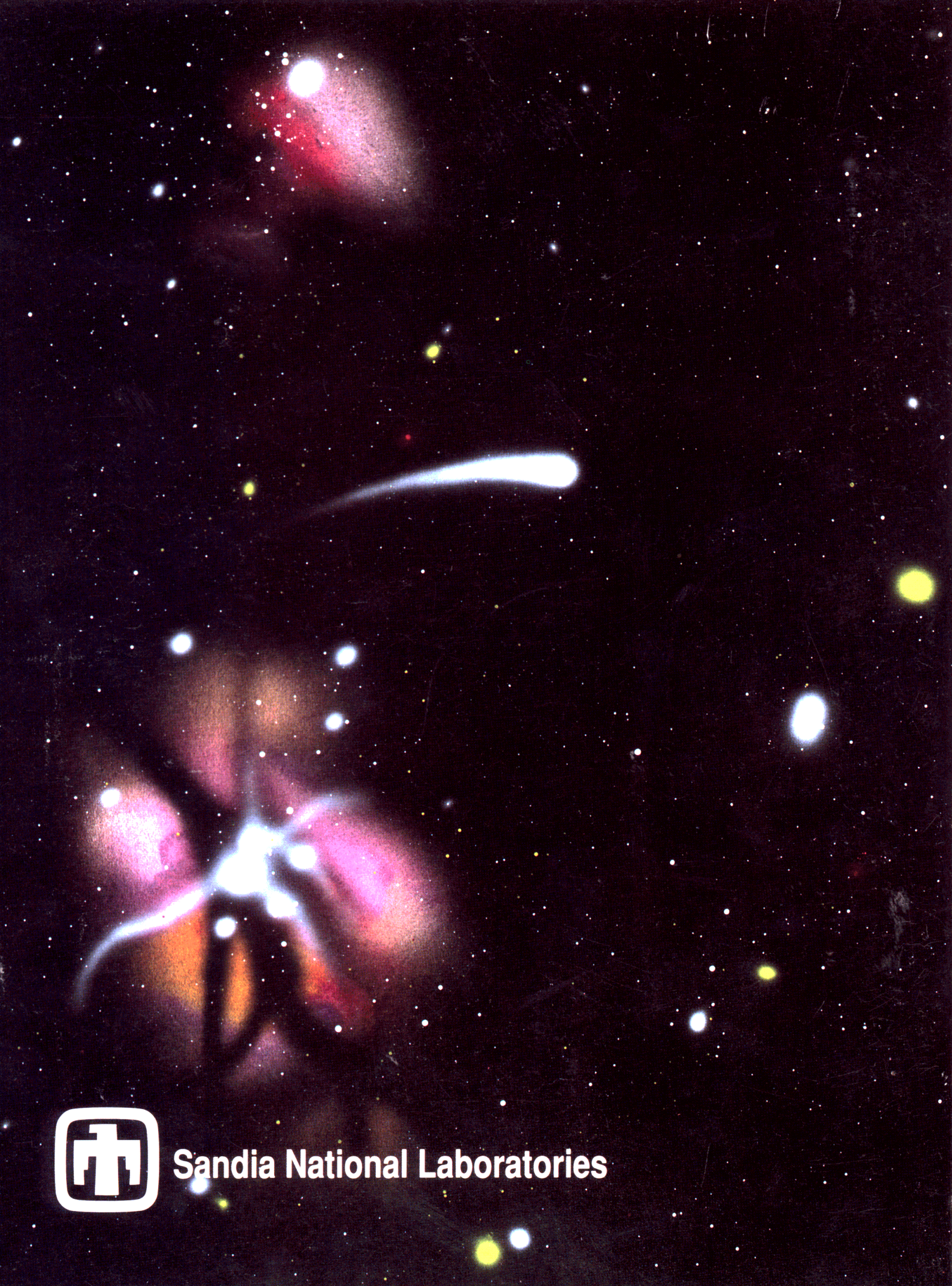

